\title{
An Exploratory Case Study of Citizenship Education in the Social Studies Curriculum of the Solomon Islands
}

By

\section{BILLY FITO'O}

A thesis submitted in partial fulfilment of the requirements of the Master of Education degree at the Faculty of Education of the Victoria University of Wellington.

Victoria University of Wellington

2009 


\section{The Abstract}

This exploratory case study stems from the belief that teaching appropriate values to develop good and active citizens will improve the chaotic situation of the Solomon Islands. However, while this intention seems commendable, little thought has been given to the nature of Citizenship Education needed in a Solomon Islands context. A concern therefore, is that the curriculum reform agenda will ignore or marginalise the conceptualisation and contextual understanding of Citizenship Education to the extent that the Social Studies curriculum might not end up reflecting a contextually balanced approach to citizenship.

In substantiating the concern, this case study research explores the perspectives of education stakeholders in the Solomon Islands on Citizenship Education in the Social Studies curriculum. The study examines the knowledge, values, and skills of Citizenship Education that are relevant and contextual to Solomon Islands. It investigates more fully the linkages between the Social Studies curriculum and Citizenship Education. The study scrutinises the conceptualisations of Citizenship Education in a Solomon Islands context and their implications on the curriculum.

The research also explores the extent to which the Social Studies curriculum educates students about themselves, their diverse neighbours, and how to live as good and active citizens in a complex and dynamic national social environment.

Using a case study involving 21 Solomon Islands participants (education officials, teachers and students), the study recommends the inclusion of contextually relevant values of rights and responsibilities, moral and social values, national identity and social cohesion in the Social Studies curriculum. Recommendations for further research are also offered. 


\section{Acknowledgement}

The appreciative terminologies used to acknowledge sincere gratitude to individuals and groups that have contributed to the success of this project may not reflect the volume of support I received. The contribution many people made towards the study was exceptional. Unfortunately, it is impossible to name every person that has contributed to the completion of this project - in particular, the education stakeholders in the Solomon Islands, University colleagues and staff, friends, Church members, and the Solomons community in Wellington. I will however, mention a few individuals and organisations.

Firstly, I would like to thank God for the opportunity to attend Victoria University of Wellington (VUW), facilitated by New Zealand Development Aid Scholarship (NZAID). Similarly, I wish to acknowledge the VUW, College of Education staff for the useful knowledge and insights I acquired from lectures and academic guidance to fulfil my course-work component. My sincere acknowledgement goes to the Te Kura Maori School with which I was affiliated as a student and where I have been mentored, guided and encouraged to go the extra mile.

Secondly, I sincerely acknowledge my supervisor, Associate Professor Kabini Sanga, for his agreement to guide me through this research project. I want to thank Dr. Sanga for his patience and perseverance in helping me to move on in my academic work. It was wonderful to be guided by someone who has very great interest and experience in studies involving Peoples of Pacific Islands nations. Significantly, his supervision covered not only academic research study, but also mentoring, counselling, and guidance during times when I thought I could not proceed any further; particularly at the point when life for me seemed meaningless due to unforeseen challenges experienced by my family and me in mid-2008. Without his counselling and guidance, I could not have finished this project. I also extend my sincere appreciation to Dr. Sanga's family for the support rendered to my family while we were in Wellington, New Zealand.

Thirdly, my sincere appreciation goes to Ruth Davidson-Toumu'a from the Student Support Learning Centre and also to Cherie Chu and Benny Prince for proofreading 
my drafts. A special thank you goes to my final proof reader, Laura van Peer, for her wonderful professional work in putting together my final draft. I will never forget my colleagues at 31 Campbell Street and the times when we shared important thoughts and delicious food. My sincere appreciation goes to the Pacific Leadership Cluster group led by Dr. Sanga and Cherie Chu for the inspirational discussions we had together as a group. My personal commitment to leadership has been rekindled and sharpened by the group. Thank you Pacific Leadership Cluster members for inspiring me. On this same note, I wish to thank Dr. Mark Sheehan, Bronwyn and the Social Science cluster group where I was a part of, for the monthly important discussions on issues in social studies.

Fourthly, I wish to sincerely thank the Kwaimani family, the Prince family, the Minchington family, and Penelope and family for the kind support rendered to my family and of course the Christian fellowship sharing on weekends, not forgetting the Solomon Islands community for the fun we had together through celebration of important occasions and sports activities. Similarly, I wish to sincerely thank the Lower Hutt Baptist Church and the Anchor Baptist Church for spiritual blessings during our two years in Wellington.

Lastly, but foremost, I wish to sincerely acknowledge my family: Lois my wife, daughter Lisa, and son Liam Lambert who have stood by me during the course of my studies in New Zealand. Their presence with me during our time here has been appreciated. And on behalf of my family, once again thank you all. 


\section{TABLE OF CONTENTS}

Title Page................................................................

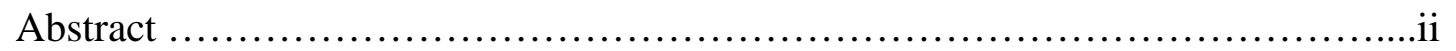

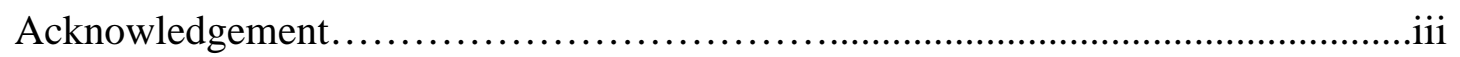

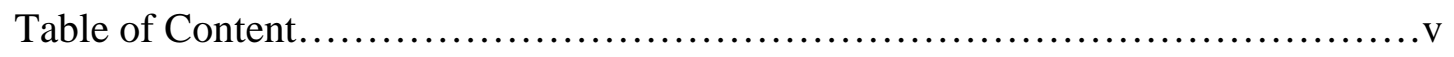

List of Tables......................................................... viii

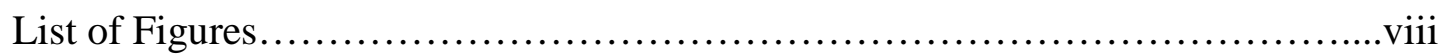

\section{Chapter 1: introduction}

1.1 Introduction and Overview..................................................

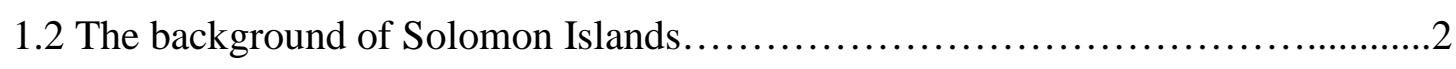

1.3 The Education System................................................ 5

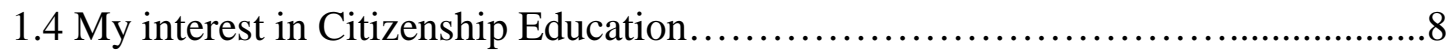

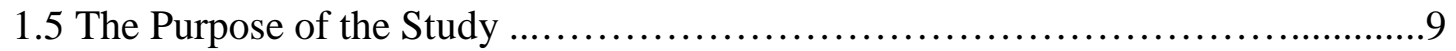

1.6 The Statement of the Problem ............................................. 9

1.7 Research Questions................................................ 10

1.8 Significance of the Study............................................ 10

1.9 Limitations of the Study........................................... 11

1.10 Operational Definitions............................................ 11

1.11 Structure of the Thesis...................................................

\section{Chapter 2: Literature Review part 1}

2.1 Introduction and Overview............................................ 15

2.2 Origin of Citizenship and Conceptualisation of Key Concepts....................16

2.3 Historical perspective of Citizenship......................................... 17

2.4 Citizenship Debates...................................................21

2.5 Citizenship Education Theories.......................................23

2.6 The Rationale for Citizenship Education................................28

2.7 Citizenship and Citizenship Education for indigenous people of Pacific

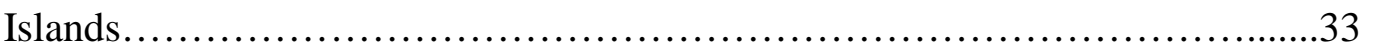

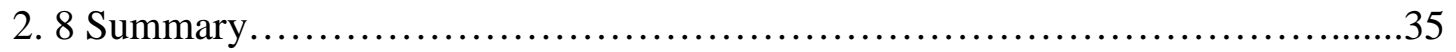


Part 2: Citizenship Education Curriculum and the Social Studies Curriculum

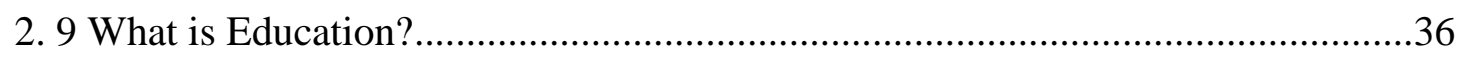

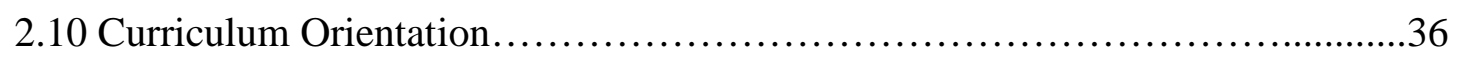

2.11 Citizenship Education Curriculum......................................40

2.12 Social Studies Curriculum and Approach...................................42

2.13 The purpose of Education in the Solomon Islands..............................46

2.14 Social Studies Curriculum of Solomon Islands...............................47

2.15 Barriers to Social Studies Teaching in the Solomon Islands.........................48

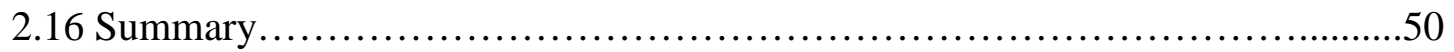

\section{Chapter 3: The Methodology}

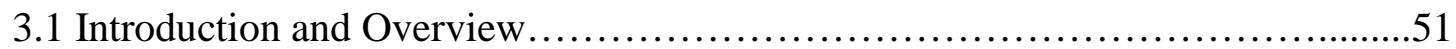

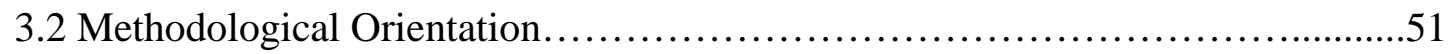

3.3 Interpretative/ constructivist paradigm....................................56

3.4 Ethnographic approach..................................................57

3.5 Case Study - a strategic tool use for this study................................58

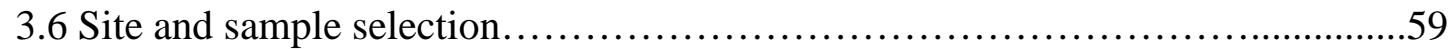

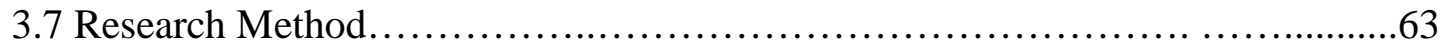

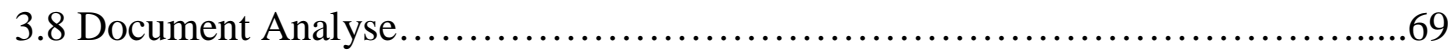

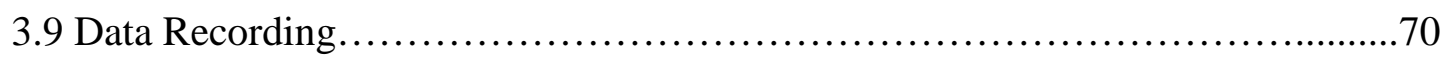

3.10 Data Analysis Techniques........................................... 70

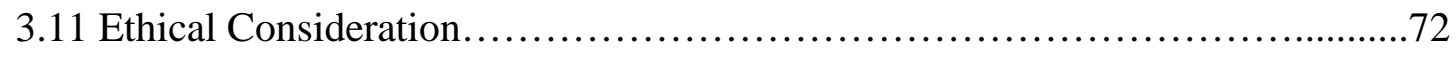

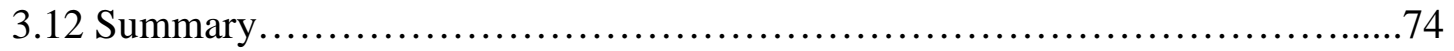

\section{Chapter 4: Interview - Description and Findings}

4.1 Introduction and Overview............................................. 75

4.2 Defining Citizenship and Citizenship Education Concepts and

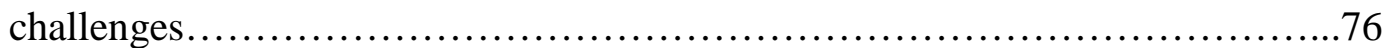

4.3 The extent to which values are successfully taught in the social study

Curriculum 
4.4 The extend to which Social Studies Curriculum is successful in teaching citizenship education. .90

4.5 Barriers and recommendation for Citizenship Education in the Social Studies Curriculum 96

4.6 Summary 102

\section{Chapter 5: Analyses and Discussion}

\section{Part 1: Citizenship and Citizenship education}

5.1 Introduction and Overview 104

5.2 Conceptualising Citizenship based as status. 105

5.3 Citizenship as moral imperative. 119

\section{Part 2: Citizenship Education Curriculum Approach, Model and Pedagogies}

5. 4 Citizenship model of active learning/community participation................126

5.5 Citizenship Education Curriculum Policy...................................129

5. 6 Citizenship Education Curriculum Pedagogies..............................133

5. 7 Summary ..................................................... 138

Chapter 6: Research conclusion; contribution, Implication, Future Direction

6.1 Introduction and Overview................................................. 140

6.2 Summary of Findings.................................................. 140

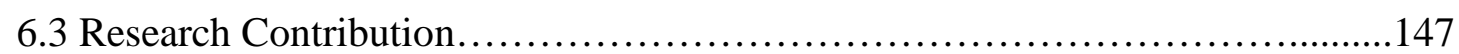

6.4 Research Implications and Recommendations.................................149

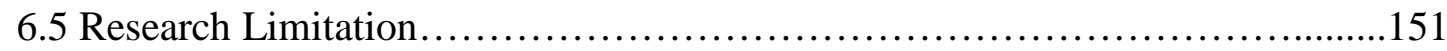

6.6 Future Studies...................................................... 152

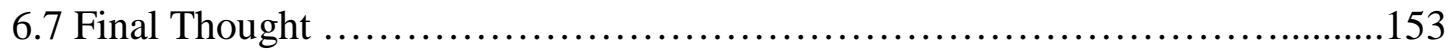

Reference.................................................................. 155

Appendices........................................................ 165 


\section{CHAPTER ONE}

\section{INTRODUCTION - THE RESEARCH OVERVIEW}

\subsection{Introduction and Overview}

This introductory chapter sets the context for the study by providing background information about the Solomon Islands. Firstly, it presents brief background information about the people, geographical location, political system, education system, and curriculum system. Secondly, it highlights issues currently experienced in the education and the curriculum system along with its structures. Thirdly, it provides the reasons why the study is undertaken - particularly my interest in pursuing it, the purpose, significance, and relevance of the study, along with limitations and the main questions that directed it. The chapter ends with a brief outline of what will be covered in the proceeding chapters of the study.

There is, generally, a concern for the social environment of any society when social behaviours and actions of some members undermine the social norms, rules, cultures, beliefs, traditions, and the rule of law. Such was the case of Solomon Islands. As observed by Sanga and Walker (2005), during the period from 1999 to 2003 Solomon Islands was a country in chaos. "There was ethnic intimidation, forced eviction, murder, rape, arson and open warfare among certain ethnic groups" (p. 7). Among such conditions, Sanga and Walker noted that there were deep social inequalities; corruption; crises in the justice, legislative, and bureaucratic systems; and a general lack of respect for diversity.

Moreover, the state's capacity to unite people of different ethnic groups remained a huge challenge. This occurred because people usually identify themselves along ethnic and cultural affiliations. Rueda, (1999), notes that when this happens, the contesting multiple identities challenge the meaning of unity thereby resulting in a shaky national identity and a reduced capacity of social acceptance. This, in turn, results in disunity and a lack of tolerance by citizens for one another and their social environment. In the Solomon Islands such long-standing perceptions have became the subject of much debate in the country among education reformers, politicians, civil society, women's' movement, youth, and the general population. 
In view of such interest, this study explores the linkages between the social study curriculum currently being taught in schools and Citizenship Education. It explores the conceptualisations of Citizenship Education in a Solomon Islands context and the relationship with the Social Studies curriculum. The data generated from the study may be used to formulate a new Citizenship Education framework relevant to the modern Solomon Islands context. The framework also seeks to provide new direction for policy and the formal education Curriculum Statements of the government.

\subsection{The background of Solomon Islands}

In order that readers may have a fair idea of Solomon Islands as a country socially, politically and geographically, in this section I set the context for the study by introducing background knowledge of Solomon Islands.

\subsubsection{History}

The Solomon Islands was first inhabited by Papuan speaking settlers who arrived on the chain of islands around 30,000BC. They were followed by Austronesian speakers who arrived circa 4,000BC. It was between 1,200 and 800BC that the ancestors of the Polynesians arrived from the Bismarck Archipelago (Solomon Islands Times Online Archives retrieved $26^{\text {th }}$ June 2008). The chain of islands was first "discovered" by Spanish navigator Alvaro de Mendana de Neira in 1568. Because gold was found on some of the islands, he named them after the rich Biblical King Solomon. Christian missionaries arrived in the Solomon Islands in the mid-19th century. Their arrival made little impact at first because of the ongoing "black birding" (brutal forced recruitment of labourers for the sugar plantations of Queensland and Fiji) (Solomon Times Online, 2008). The experiences of the labour trade prompted the United Kingdom to declare a protectorate over the Islands in 1893 and later in 1896 the islands were officially named the British Solomon Islands Protectorate (BSIP).

In 1960, a legislative council was created as the protectorate's policymaking body. In 1974, a new constitution was adopted, establishing a parliamentary democracy and ministerial system of government. In mid-1975, the name Solomon Islands British Protectorate was officially replaced by the name Solomon Islands. On January 2, 
1976, the Solomon Islands became self-governing. On July 7, 1978 Solomon Islands gained its political independence (Solomon Times Online Archives, 2008).

\subsubsection{Political system}

The Solomon Islands is a constitutional monarchy and has a parliamentary system of government. The monarch is represented in the Solomon Islands by the GovernorGeneral who is elected by the parliament for a five year term. There is a unicameral parliament of 50 members, elected for a four year term. Parliament may be dissolved at any time before the completion of its term by majority vote of its members. Parliamentary representation is based on single-member constituencies. Suffrage is universal but voluntary for citizens over age 18 . The head of government is the Prime Minister, who is elected by a simple parliamentary majority and who chooses the other members of the executive cabinet. Each ministry is headed by a cabinet member, who is assisted by a permanent secretary, a career public servant who directs the staff of the ministry (Solomon Times Online Archives, 2008). 


\subsubsection{Geographical locations}

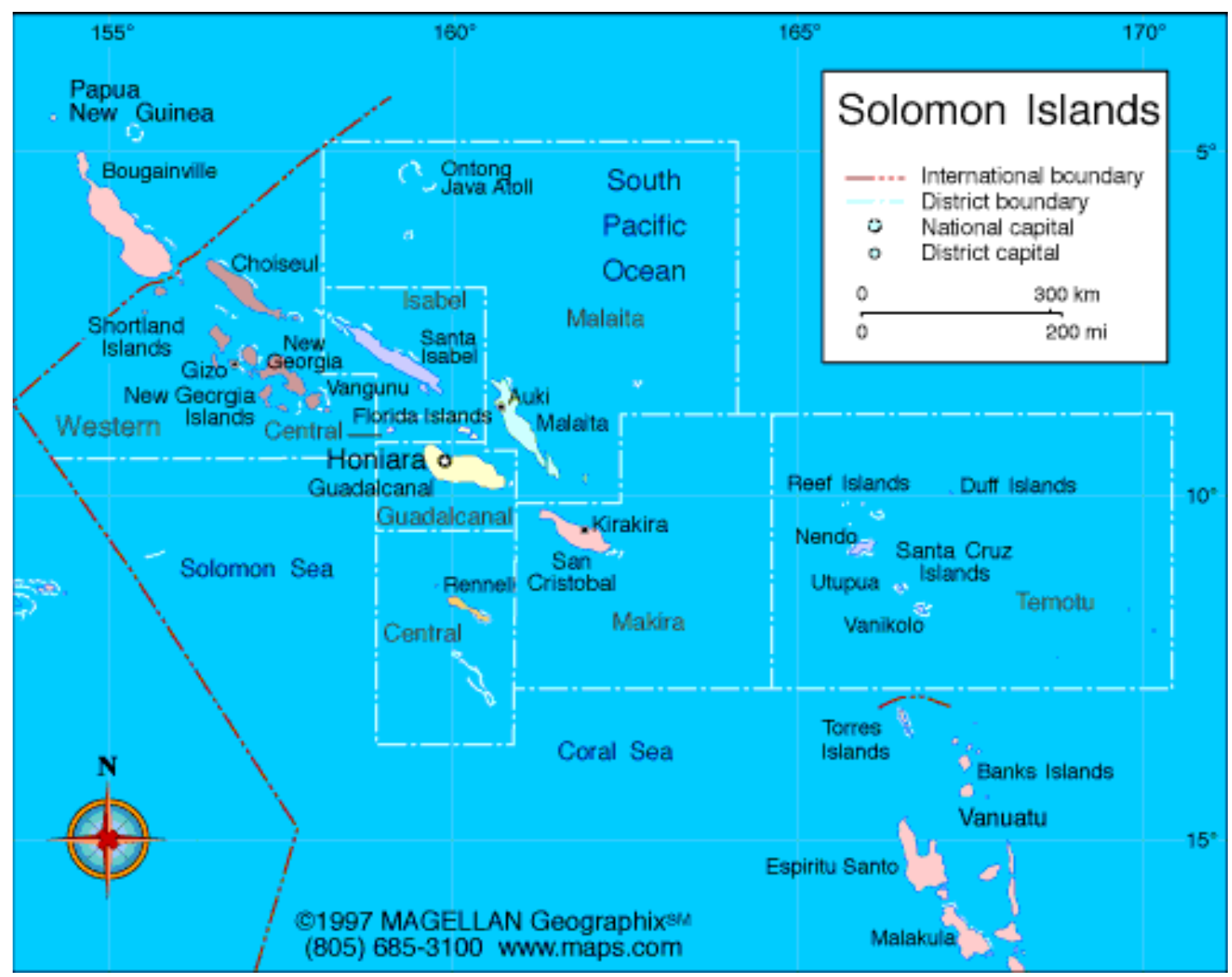

Solomon Island map retrieved online, $26^{\text {th }}$ June (2008).

Figure 1. A map of Solomon Islands by province

The Solomon Islands is a chain of Islands located in the south west Pacific ocean, spreading over 1.6 million square kilometres of ocean territory. It comprises over 900 islands and has over 29,000 square kilometres of land area (Pollard, 2005). It is an Island nation that lies east of Papua New Guinea and north of Vanuatu. The islands are politically demarcated into nine provinces and one municipal authority, which is Honiara city.

\subsubsection{Demography}

In 2005 , the population was estimated to be 538,000 with a growth rate of $2.7 \%$ per annum and a relatively young population with a median age just under 19 for both males and females (Solomon Islands- country information paper-New Zealand Ministry of Foreign Affairs and Trade, 2008). The population is predominantly Melanesian (95\%) but also includes Polynesians (4\%) and others such as 
Micronesians (1\%). There are more than 80 different cultural groups, each with a distinct language and territory.

Only $16 \%$ of the population is urbanised while $84 \%$ live in rural areas and still adopt a subsistence livelihood (Pollard, 2005). The majority of the population still relies on gardening, fishing, and hunting for survival. People live in clusters of tribal rural villages and they hold the majority of land under a communal customary land arrangement. In terms of English literacy development, only $30 \%$ of the adult population is literate.

\subsection{The Education system}

The education system of Solomon Islands was established according to the provisions of the National Education Act 1978. Under the provisions of the Act, schools are established to meet the goals of education for the country. The types of schools that are conferred under the Act are primary schools, secondary schools, tertiary institutions and, more recently, early childhood education, and vocational training centres were added.

The education system is centralised whereby all functions of the education system are determined only by the state. This includes the establishment and approval of new schools as well as recruitment, training, assessment, promotion, and payment of teachers. The state is also responsible for designing, developing, and financing of the curriculum and is responsible for dissemination of resource materials to schools.

The establishment of schools in the Solomon Islands is aimed at achieving several purposes. In the pre- and post-colonial period, the primary goal of education for Solomon Islands was to develop students to be competent in taking up the official responsibilities that were left by the colonial government. This could be observed from the desire to maintain the academic tradition gained from the legacy of the colonial past by the government and people. Such a desire for Solomon Islands is to train students in skills for paid employment, to fill the jobs that were left by the departing administrators of the colonial government (Solomon Islands Education 
Strategic Plan, 2005). The whole system of education therefore, becomes acknowledged as the route to paid employment.

The acknowledged conceptualisation of education by the people of the Solomon Islands has caused considerable confusion which might not be easily solved by the government. Firstly, is the demand for more schools to accommodate the high population growth rate, which is currently estimated to be around 2.7\% (Dorovolomo, 2005). To meet these demands, the secondary education system was expanded rapidly. In the 1990s from the initial national secondary schools (NSS) and the provincial secondary schools (PSS) there was a rapid growth of community high schools (CHS). The table below summarises the number of secondary schools and the rapid increase in the numbers of community high schools.

\subsubsection{Table 1. Number of secondary schools by type from 2003 to 2005}

\begin{tabular}{|l|c|c|c|}
\hline School type & $\mathbf{2 0 0 3}$ & $\mathbf{2 0 0 4}$ & $\mathbf{2 0 0 5}$ \\
\hline NSS & 9 & 9 & 9 \\
\hline PSS & 16 & 16 & 16 \\
\hline CHS & 105 & 109 & 115 \\
\hline Total & $\mathbf{1 3 0}$ & $\mathbf{1 3 4}$ & $\mathbf{1 4 0}$ \\
\hline
\end{tabular}

(Solomon Islands Education Strategic Plan, 2005)

The population of students in secondary schools and the number of secondary schools spaces have increased significantly in the $21^{\text {st }}$ century because of the newly introduced Community High Schools policy. However, the highly competitive examoriented education system has prevented many students from reaching the final stages of the secondary system. Table 2 shows the number of students who entered primary schools and the number of students who remained to complete the final class of secondary school. 
1.3.2 Table 2. Enrolment by class level in 2005

\begin{tabular}{|l|r|}
\hline School level & Total enrolled \\
\hline Kindergarten & $\mathbf{1 1 , 2 5 1}$ \\
\hline Preparatory & $\mathbf{2 1 , 0 8 2}$ \\
\hline Standard 1 & $\mathbf{1 7 , 3 8 9}$ \\
\hline Standard 2 & $\mathbf{1 5 , 2 2 0}$ \\
\hline Standard 3 & $\mathbf{1 3 , 9 4 1}$ \\
\hline Standard 4 & $\mathbf{1 2 , 3 5 2}$ \\
\hline Standard 5 & $\mathbf{1 1 , 0 5 3}$ \\
\hline Standard 6 & $\mathbf{9 , 3 1 9}$ \\
\hline Form 1 & $\mathbf{6 , 5 2 2}$ \\
\hline Form 2 & $\mathbf{5 , 8 3 9}$ \\
\hline Form 3 & $\mathbf{4 , 8 5 4}$ \\
\hline Form 4 & $\mathbf{3 , 7 0 3}$ \\
\hline Form 5 & $\mathbf{3 , 0 2 9}$ \\
\hline Form 6 & $\mathbf{8 8 1}$ \\
\hline Form 7 & $\mathbf{1 8 9}$ \\
\hline Total & 136,624 \\
\hline
\end{tabular}

(Solomon Islands Education Strategic Plan, 2005)

Such statistics raise disturbing questions such as "Where do the rest of the students go?"; "What do they do next?"; "Are they prepared for life after school?" and "How do they respond to the needs of the society?" Rather than answering these I merely raise them to illustrate an important issue for the educational situation in the Solomon Islands.

\subsubsection{Curriculum System}

The curriculum of Solomon Islands is centrally managed and its design is intended to convey knowledge of academic subjects like Maths, English, Science, and Social Studies. Other subjects that are also included but are taught optionally are Business Studies, Agriculture, Industrial Arts, Home Economics, and New Testament Studies. At the time of political independence, the purpose of the curriculum was initially to provide staff for the public service which self-government and later, independence required. A second purpose was the provision of a workforce with appropriate skills to take on the new development paradigms created by the newly created state (Coxon $\&$ Tolley, 2005). The goals of the curriculum are purposely to prepare students for formal employment. The curriculum is employment driven, and highly academically and exam orientated. 
All students who go through the education system have been selected through a process of periodic assessment at various stages through the sitting of national examinations. Consequently, only a few able students can manage to get to the final stages of secondary school. Such a system overtly displaces a huge proportion of school "drop-outs". In a country where more than $80 \%$ of the people are still living in rural areas, this system is extremely concerning, particularly when people aspire to education only for formal employment.

The population growth rate of $2.7 \%$ for the Solomon Islands is among the highest in the Pacific. The educational facilities and resources cannot keep up with the population pressure (Dorovolomo, 2005). The overly academic- centric curriculum, geared towards the requirements of formal employment, causes problems such as urban drift of "drop-outs". People move to the city (Honiara) to find formal employment for which they are mostly unqualified and uncompetitive. Most end up hanging around town. Those who end up back in the villages do not have the skills and confidence to help themselves or to contribute meaningfully to their communities (Solomon Islands Education Strategic Plan, 2005).

The curriculum of the Solomon Islands does not seem to equip pupils with appropriate skills, values, and attitudes to enable them to contribute effectively to the nation or to the productivity and stability of their communities as required. It only gives rise to false hopes in pupils. Clearly, what is needed is for students to be exposed to knowledge that simulates meaningful learning and provides them with appropriate skills and values so that they do not emerge de-conceptualised or handicapped when they leave schools.

\subsection{My interest in Citizenship Education}

At a personal level, my experience as a secondary school Social Studies teacher has made me question the linkage between the school curriculum and Citizenship Education. When I later became a secondary school principal, with additional oversight for students' discipline, my interest in Citizenship Education was further 
fuelled. My 15 years in these roles allowed me to witness first-hand the progressive decline of students' moral behaviour and social attitudes over time.

As a community member and Solomon Islands citizen, it is also painfully obvious to witness a general rise of social problems and ethnic strife along with political instability, official corruption in government, and a breakdown of law and order.

Upon undertaking post-graduate studies at Victoria University of Wellington, particularly in the course work component of the Maori-Pacific education course, it became clear to me that for Solomon Islands, and possibly other Pacific Islands people, the curriculum offered in their school systems requires close scrutiny. In particular, consideration of the irrelevance and non-alignment with national-local social realities needs careful analysis. My interest in Citizenship Education was further fuelled.

\subsection{The purpose of the study}

First, the study explores the extent to which the existing Solomon Islands Social Studies curriculum is offering Citizenship Education. Second, the study proposes to obtain needed insight based on the perspectives of education stakeholders regarding the introduction of Citizenship Education concepts into the Social Studies curriculum. Third, it is hoped that the study might offer a framework of key learning outcomes on Citizenship Education, appropriate for the Solomon Islands context, challenges, and the changing future.

\subsection{The statement of the problem}

This study wishes to explore the education stakeholders' perspectives on Citizenship Education in the Social Studies curriculum of the Solomon Islands. The intention is to explore the usefulness and validity of knowledge, values, and skills of Citizenship Education that can be incorporated in the formal secondary school social studies curriculum of the Solomon Islands. 
This perspective is based on the belief that teaching appropriate, relevant, and contextual citizenship values in the social studies curriculum will improve the chaotic situation in the Solomon Islands. Such an urging prompted the government to initiate major reforms in the education sector whereby a need to change the Social Studies curriculum is highlighted. According to the Solomon Islands National Curriculum Statement (2007), Citizenship Education is one area of teaching discipline that should be added to the formal curriculum system as either a component of the Social Studies curriculum or be developed as cross-curricula approach.

\subsection{Research Questions}

This study will be directed by the following questions:

1. How do Solomon Islanders conceptualise citizenship?

2. To what extent does the Solomon Islands Social Studies curriculum teach values that promote appropriate qualities that enhance good and active citizenship as conceptualised?

3. To what extent is the Social Studies curriculum successful in teaching values for good and active citizenship?

4. How might changes or improvements to the Social Studies curriculum be made to include values that better enhance good and active citizenship?

\subsection{Significance of the study}

The research has potential to positively contribute to the Solomon Islands and other similar nations in a number of ways. First, according to the Solomon Islands Ministry of Education's Curriculum Statement (2007), Civic and Citizenship Education are recommended for inclusion in the school curriculum. This study is therefore timely, with the potential to inform appropriate policy formulation and curriculum development. Second, the study is likely to foster community awareness and engagement on the subject of citizenship. As different societal stakeholders participate in the study and as its findings are reported, community and civil society 
groups will be encouraged to address Citizenship Education in their own jurisdictions. Third, as the first research study on this topic in the country, the documentation of the findings will be pivotal for future policy, curriculum, teaching, and research development.

\subsection{Limitations of the study}

In qualitative research, the primary aim is to enhance the validity of the study while reducing perceived weaknesses (Weirsma, 1995). Importantly, validity in qualitative research is influenced by the context in which the study is undertaken. In this case, as an insider researcher, the methodology used, the research tools employed, site, participants, and related natural activities that may be happening at the time of the research can create or enhance invalidity to the research. Therefore, the following were limitations to the study. Firstly, a tropical sickness such as malaria has been a threat to the researcher. When it attacked the researcher it distorted the flow of the study. Secondly, community events such as cyclones, death, or weddings had negated the participation of respondents, thereby hindering or distracting students and teachers from interviews. Thirdly, in societies like Solomon Islands where the perception people have towards education as primarily for the purpose of formal employment, the responses of participants seemed superficial at times. Particularly when questions relate to community values, people interpreted this as something backward, uncivilised, or something belonging to the village and not relevant to schooling. Fourthly, another concern in an interpretative study relates to what Copper (1998) labelled as a "self-fulfilling prophecy" (p.9). This phrase refers to the genuineness or otherwise of the response of study participants.

\subsection{Operational Definitions}

The definitions provided below explain the meanings of words or concepts as used in this study. The definition of Citizen, Citizenship and Citizenship Education is adopted from the definition provided by (Grossman, 2008).

\section{Citizen}

A person recognised within a community of people or constituent member of society

\section{Citizenship}


The recognition conferred on people as citizens based on sets of characteristics of being a citizen and by derivation.

\section{Citizenship Education}

The contribution of education to the development of characteristics of being a citizen

\section{Good citizenship}

Citizens that have the ability to solve social problems and improve society; show good character; display honesty, respect, and responsibility; be a law-abiding member of a society

\section{Active citizenship}

Citizens who actively participate in the affairs of the society to improve and develop the people's quality of life.

\section{Democratic citizenship}

Citizens who understand their rights and freedom and another's rights and freedom.

\section{Moral values}

Code of conduct that is acceptable to the society. This includes cultural and church virtues - values such as honesty, faithfulness, care, responsibility.

\subsection{Structure of the thesis}

Chapter 1 introduces the thesis and links the study by setting the context through a brief introduction of the background of Solomon Islands. This includes the history, geographical location, population, political system, and the education and curriculum systems. The chapter also provides the purpose and significance of the research, the statement of the problem with research questions, and briefly describes the methodology and limitations of the study.

Chapter 2, part one provides a review of relevant literature on citizen, citizenship and Citizenship Education. It begins with the conceptualisation of key terms including, citizen, citizenship, good citizenship, active citizenship and democratic citizenship. 
This is followed by reviews of literature on the origins of the concept of citizenship, theories of citizenship, Citizenship Education and their conceptual debates and challenges.

Chapter 2, part two provides a literature review on Citizenship Education curriculum; in particular, Social Studies curriculum and the concept of citizenship. This chapter includes the review of literature on the curriculum domains, approaches, models, and frameworks that are commonly used in Citizenship Education. This is followed by a discussion of citizenship curriculum, Social Studies as an approach to the teaching of citizenship, and overview of the existing Social Studies curriculum of the Solomon Islands, and ends with a chapter summary.

Chapter 3 discusses the methodology used in the study. It starts with a brief introduction of what is covered in the chapter, and then it proceeds with the methodological orientation by discussing the definitions of the concepts and methods of gathering data. This covers the selection of participants, a discussion on interview questions, data gathering, and analysis techniques used. It ends with discussion of ethical procedures and considerations, and ends with a brief chapter summary.

Chapter 4 provides the descriptions of the findings from the methodology and research tools used to collect data. This includes interviews from two interview techniques, namely focus group and one-on-one interviews. The information and data highlighted in this chapter are from the selected respondents of both techniques who answered the questions. The data collected describes and exposes interviewees' reasons and views on the questions being asked.

Chapter 5 provides discussions and explanations of the methodological underpinnings of the analysis and the adopted framework and process of analysis used. This is followed by discussions outlining the findings that later form the theory for the study. The chapter ends with a brief summary.

Chapter 6 provides the conclusion of the thesis including the summary of the findings, and the contributions and implications of the research. It covers limitations 
encountered during the course of the study, identifies areas which are recommended for future study, and closes with a brief final thought to end the research project. 


\section{CHAPTER TWO \\ LITERATURE REVIEW}

PART 1: CITIZENSHIP AND CITIZENSHIP EDUCATION

\subsection{Introduction and Overview}

In the previous chapter I introduced the study by setting the scene for the project. This literature review chapter is in two parts. The first part covers the origin and conceptualisation of "citizenship" and "Citizenship Education". As well, literature discussions are undertaken on citizenship theories, the concepts of good citizenship, and active citizenship. The overview of Citizenship Education theories includes the historical perspective, the significance of the Citizenship Education theories, and various debates on the concepts of citizenship and Citizenship Education. This is followed by a review of versions of Citizenship Education concerning concepts such as maximal and minimal approaches. The chapter ends with a discussion on conceptualisation of Citizenship Education by certain Pacific academics and educationists, and it concludes with a brief summary.

Part two of this literature review focuses on Citizenship Education and the curriculum. This part of the chapter provides reviews of the area of citizenship curriculum, the curriculum domains, approaches, and models of designing and teaching Citizenship Education. This part also provides a review of literature on the Social Studies curriculum of Solomon Islands, including the challenges, and barriers to teaching and learning. The chapter concludes with a brief summary of what has been covered.

Citizenship Education (CE) has attracted numerous studies from researchers and is greatly supported by both developed and developing democratic countries. Purta, Schwille and Amadeo, (1999) have compiled case study reports on Citizenship Education research projects carried out by the International Association for the Evaluation of Educational Achievement (IEA) in twenty four developed and developing countries; Grossman, Lee, and Kennedy, (2008) have compiled case study reports on Citizenship Curriculum in Asia and the Pacific. This reflects the importance placed on the teaching of Citizenship Education within the school system, 
implying a correlation between teaching Citizenship Education and good and active citizenship. Despite these numerous studies, much is yet to be explored in relation to Citizenship Education in the school curriculum of Pacific Island countries. Because little literature from Solomon Islands is available, the literature reviewed here focuses on definitions of concepts, theories, and debates from outside the context of the study.

\subsection{The Origin and Conceptualisation of Citizenship}

This section firstly presents the origin of the term citizenship. Secondly, it provides the conceptual definition of the term citizenship.

\subsubsection{Origin}

The concept of "citizenship" has its origin specifically in ancient Greece (Heater, 1999). In the period of the Greek and the Roman civilisations, according to Heater, citizenship was adopted as a legal term and a term of social status. It is closely related to the creation and rebuilding of a nation state (Heater, 1999; Kymlicka and Norman, 2000; Crick, 2000; Stevick and Levinson, 2007). Further, citizenship is also a key part of modern and contemporary civilisation (Crick, 2000). The citizens in this regard are people who have legal rights and who have a say in the affairs of the city (Hargreaves citied in Cricks, 2000). The polis (city) represents a community of people who share common ideologies and have followed one common structure. People who live in a city or community of people have certain status which is conferred on them by the city (Heater, 1999). According to Heater, this status is conferred by the state in order to politically shape the society to fit the kind of citizens the state wants its citizens to be.

\subsubsection{Conceptualisation of Citizenship}

What it means to be a citizen is defined by Engle and Ochoa (1988) as a recognition that is conferred on individuals by the state for legal identification. According to Engle and Ochoa, citizens are identified in recognition of their affiliation to or membership of social, political, and religious institutions; their work places, their schools, and the world. 
According to Heater, (1999), citizens are people who are furnished with knowledge of public affairs, instilled with attitudes of civic virtue, and equipped with skills to participate in the public arena. Having these attributes is through a lifelong undertaking which formal and non-formal institutions are believed to have provided through some systematic learning. Wesley (1978) citied in Engle and Ochoa (1988) defined a citizen as someone who conforms to the norms of certain values, participates in certain activities, and conforms to norms which are often local in character.

The term "citizenship" has a multiplicity of meanings. For Herbert and Sears (n.d) and Engle and Ochoa (1988) citizenship refers to the relationship or set of relationships existing between the individual and the state and among individuals within the state. Engle and Ochoa further explained that in a broader sense citizenship refers to the whole of life. It involves relationships, membership, decisions making, participation, or action that in any way affects others. For instance, someone's actions may be noted directly or indirectly, knowingly or unknowingly when they are acting as citizens.

According to Lynch (1992) and Heater (1999), citizenship has both a legal meaning and a social meaning. In a legal sense, citizenship refers to the rights or set of rights and responsibilities that are granted to the people by the state in recognition of their attachment or affiliation to a particularly country. Socially, citizenship refers to the participation of people in their communities, engaging in activities that demonstrate their rights and responsibilities. Similarly, Engle and Ochoa (1988) citing the work of Wesley (1978) views citizenship as inextricably related to the characteristics of the society. He further explained citizenship as a process of making rational, considerate, well thought-out decisions by citizens. The rationale for this belief is that those who live in a society are continually caught in complex situations, thus requiring them to make decisions in morally ambiguous circumstances.

\subsection{Historical perspective of citizenship}

Historically, two political camps - the liberal tradition and the republican tradition have influenced the conceptualising and practising of citizenship. However, the 
underlying factor that perpetuates the concept is, generally, to unify people and establish cohesion to build a national identity. Thus, this section also presents historical perspectives of the National Identity and social cohesion model.

\subsubsection{Liberal traditional model}

According to Heater (1999), the notion of rights was emphasised and enforced by the liberals through a liaison between revolutionary upheavals and natural rights theory. It was the British and Americans that laid the foundation for the evolution of liberal citizenship and citizen's rights dating back from the aftermath of the political theory of John Locke and the seizing of independence by the American colonies (Heater, 1999). Locke's Natural Theory holds that "every man have the free and equal right to preserve his/her life liberty and estate" (Heater.1999, p.1) The Americans, during the aftermath of the revolution, adapted this formula to life, liberty, and the pursuit of happiness. The British on the other hand had adopted a model that included the right to vote, the right to just treatment by the law, and the treaties of the civil government (ibid). The French introduced a model that included liberty, property, security, and resistance to oppression (Heater, 1999). Such a liberal conceptualisation of citizenship has later become the foundation of many democratic governments and their Citizenship Education programmes.

The liberal styles of interpreting citizenship, as Heater (1999) explained, have characterised citizenship through the emphasis of rights. According to Crick (2000), citizens have three types of rights. These include "personal rights (freedom of thought and conscience and privacy and personal autonomy), political rights (freedom of speech, press and assembly) and economic rights (the right to acquire, use, transfer, and dispose of property" (p.62). Such rights were extended to the theories of the natural rights theorised by Locke. In Lock's conceptualisation, every person has free and equal right to preserve his or her own life, liberty, and estate (Heater, 1999). Mcgregor, (1999) explained the liberal tradition of citizenship as "individualism and the central idea that all individuals are equal and have inalienable rights (e.g human rights) that cannot be revoked by the state or any social institution" (p.208). A further explanation provided by Crick (2000) is that, for liberals, civil liberties are frame-works of the law to protect individuals against the state. 
The aims and purpose of citizenship according to a liberal description are founded on the principles of freedom of individual citizens to participate in shaping the future destiny of their own states (Heater, 1999). Freedom as conceptualised rests entirely on the doctrine of sovereignty (the state's supreme authority over the citizens or subjects) of the people and is affirmed by the principles of equality (social cohesion) (ibid). To build a nation according to the principles of rights and freedom requires certain mutual obligations. One example is for political institutions to weaken the privileges that individuals usually have by taking advantage of and enhancing cohesion. A simple explanation of cohesion among people is the ability to initiate people into a common culture and identity (Wylie, 2004). The principal basis of this belief, as Heater (1999) noted, focuses on the construction of coherence in nation building through civic and national equality and standardisation.

\subsubsection{Republican traditional model}

Republicans on the other hand have emphasised duty and responsibility. This model stems from the theories of Aristotle in the ancient Greece period. In his theory, Aristotle points out that citizens' character have to be considered in relation to one another since the intimacy between the citizens would make a common bond. Such a bond would pave the way for citizens to share in the civic life of ruling and being ruled in turn. There is no room for apathy as citizens are expected to be publicly active (Heater, 1999).

Further, the republican model's ultimate focus as Heater explained was to develop citizens to possess and display arête, goodness or virtue to fit in the society socially and politically. Virtue in this sense is related to quality. Aristotle claimed that qualities are moral calibre that has to be demonstrated by citizens before they can display maturity, so that benefit can emerge for themselves and for the state (Heater, 1999). In general the above perception could be summarised as the classic exposition of the civic republican form of citizenship.

According to McGregor (1999), the republican traditional model for citizenship stresses three main principles: "the sense of belonging to a political community, 
loyalty towards one's home land and the predominance civic duties over individual interest" (p.208). In order to create a stable and just society, it is necessary for individuals to "engage in a symbolic relationship with the state. Only, then will the individuals enjoy freedom and the state can be created and sustained" (Heater, 1999, p.45). Such a republican conceptualisation denotes that harmony and stability among citizens can only emerge through mutual agreement by the state and the citizens to work together. That agreement is believed to influence the affairs of the nation state (Millers, cited in Pearce and Hallgarten, 1988).

Aristotle once said, the nature of CE has often been disputed (Heater 1999. p.45). This is evident in how educationists, academics, and historians try to define the concept. Kerr cited in Kerr and Cleaver (2004) used the term "contest concept" to represent this common dispute on Citizenship Education. According to Lynch, (1992); Deuchar, (2003); Engle and Ochoa (1988), the contentions are sparked by the definition of the term citizenship and Citizenship Education, the adequate model, the preferred approaches, and the models and domains that are used for the discipline.

\subsubsection{National identity model}

According to Stoessinger (1990), national identity in citizenship is attributed to sovereignty (man's relationship with the state) and nationality (peoples' collective destiny). The theories of citizenship in its early inception have considerable recognition on national identity as central to creating a nation-state. Such perspective has remain since then. In Western countries - for instance, European countries, North America, Canada, and Australia - national identity is increasingly vital to unify people of different ethnicities and cultures, particularly the new migrants who come from very diverse social and cultural backgrounds and educational levels, into the tenets of citizenship within democratic societies (Lynch, 1992). In New Zealand, the development of citizenship is tied to identity as New Zealanders and what it means to be a New Zealander (White and Openshaw, 2005).

To define identity, Taylor (citied in Kymlick and Norman, 2000) attributed identity as the politics of recognition that relate to the idea of difference and the principle of equal dignity. Recognition is the idea that others should be sensitive to the 
individual's quest for authenticity (ibid). "No one can do without official recognition - the recognition of a nation state" (Stoessinger, 1990, p.6). An individual cannot escape from a nation-state as it is the highest secular authority (ibid). However, the argument of national identity has become a phenomenon of much debate. For instance, "the conceptualisation of Citizenship Education was hidebound... it does not redefine to permeate some of the characteristics that describe citizenship" (Lynch, 1992, p.9). However, citizenship has continued to equate only with nationality (Lynch, 1999). In fact, historically, that equation was neither the first definition of the term nor its predominant use until the age of nationalism. What is nationality or nationalism? Nationality or nationalism, according to Stoessinger (1990), is “peoples' sense of collective destiny through a common past and the vision of a common future" (p.9). The author further explained the terms as the "nation's personality" which is the nation's common past. "A nation is a group of people occupying geographical space" (Stoessinger, 1990, p.9).

The common underpinnings of national identity are to produce cohesion and standardisation among citizens. In Western countries, the ability to unify people is possible because most societies are monolingual and mono-cultural in nature (Lynch, 1992). However, in non-Western countries, such attempts might be very complicated. For instance, a great majority of nation-states in the developing world are in reality multi-ethnic, multi-cultural, multi-lingual and multi-religious states. To produce cohesion and standardisation in such diverse national spaces would be a complex process. However, as Lynch (1992) points out, Western nations now have similar diverse complexities. Therefore, they should not be complacent and take for granted the force of tradition, ethnicity, and language in order to shape a nation. Many Western countries are now multi-lingual and multi-cultural. They face problems of their own, based on a mix of new demographics, growing prosperity and voter apathy (Print and Smith, 2002). This indicates that all countries have some reason to promote national identity.

\subsection{Citizenship Debates}

The theories of citizenship are highly contested (Purta, Schewille and Amadeo (comp.) (1999); Print, Brown and Baginda,(comp.) (1999); different groups define 
citizenship in different ways for different purposes. They are what some philosophers called "essentially contested concepts" (Crick, 2000, p.2). The fact is that the concept "citizenship" carries significantly different meanings. What Crick meant here was that, the concept does not have an essentially or universally true meaning. It can be defined into reasonable meaning only when people who use the term in societies have accepted and acknowledged what has been morally transferred down to modern societies from history including peoples culture and customs.

However, although there are contrasting views, the important factor to note here is the understanding of what it is to be a human being and how human beings relate to themselves and to the state (Kiwan, 2005). According to Kiwan, there are three common factors underpinning the debate about the relationship of the state and the individual in building a nation state. They are: the national identity which relates to forming a nation state; the legal and political status of relationship which includes the rights and freedoms of individuals; and moral virtues and a sense of belonging and rendered duties. However, although the factors mentioned are often debated, they are important instruments used in Citizenship Education programs to stabilise society.

Lynch (1992), in his debate on the theories of citizenship, has considered the term on three typical levels of local, national, and international membership. At the local level, the concept of education for citizenship is defined according to the domain of the knowledge of individual membership, family base, and cultural and ethnic affiliation. At the national and international levels the definition encompasses the ideologies of fundamentally universal recognition of basic rights and freedom. This has now been used as the goals of international instruments such as the United Nations Declaration of Human Rights and the Council of Europe for the Education of Human Rights. Yet still, as noted above, generally such conceptualisation falls short of what is considered by Crick, (2002) to be a citizen or citizenship.

Miller, as citied in Pearce and Allgarten (1998), explained citizenship according to three types of citizens: the liberal, the consumer, and the collective civic engagement. For the liberals, rights and responsibilities are balanced to give all citizens equal status. The consumer in this regard has consumer rights, is entitled to a certain standard of service provided by the state, and is empowered to seek compensation if 
the service is not satisfactory. Civic engagement refers to active citizenship. Active in this sense requires citizens to be prepared to see beyond their own interest and commitments and take a wider, more impartial view Miller (cited in Pearce and Hallgarten, 1988).

\subsection{Citizenship Education theories}

Citizenship Education is an instrument used by Democratic states to prepare their citizens for the challenges that their state will meet in this new century (Print, 2008). That is the reason why the study of Citizenship Education has become of considerable importance to researchers, academics, state curriculum, national curriculum, national governments, and the general public. As Cogan (cited in Mutch 2005) asserted, what constitutes education for citizenship that is appropriate to the demands and needs of a rapid changing global community is critical in both national and international contexts.

\subsubsection{Conceptualisation of Citizenship Education (CE)}

Citizenship Education according to Ross (2006), "represents the historically dominant justification of Social Studies and that it includes knowledge or information, skills, values and the socio-economic participation" (p.60). Ross further related CE to programmes formally proposed or enacted and sanctioned by certain recognised governmental or professional organisations aimed towards the expressed purpose of “good", "active" "effective", or "democratic" citizenship (Ross 2006).

CE as defined by the Civic Expert (1994) encompasses a whole range of educational processes, formal and informal, that encourage and inform participation by citizens in community activities and public affairs (citied in Jenning, 2003). According to Hebert and Sears (n.d)), "Citizenship Education is the preparation of individuals to participate as active and responsible citizens in a democracy" (p.1). In a report on Citizenship Education, Mutch, citing the work of Kerr, (2000) in White and Openshaw (2005) defines the field of study of Citizenship Education as "encompassing the preparation of young people for their roles and responsible 
citizenship and in particular, the role of education (through schooling, teaching and learning) in the preparatory process" (p.198).

\subsubsection{Historical Perspective of Citizenship Education}

Citizenship Education has always been intended to help integrate diverse populations into a single national culture based on Republicanism (the principles of liberty, equality, fraternity, and human rights). According to Osley \& Stakey, cited in Wylie (2004), from the early 1890s to the 1920s, during the early introduction of formal education, Citizenship Education was considered a vehicle for indoctrinating children on values of nationalism to build a nation state (Herbert and Sears, n.d).

\subsubsection{Citizenship Education Debate and implication}

The debate on Citizenship Education has no end. As noted earlier by Kerr and Cleaver (2006); Gilbert (citied in Mutch, 2005) the concept is a "contested" one. According to Lee (2008), the "tension and contention are related to what is to be taught, how it is to be taught... or whether the curriculum to be remain unchanged" (p.215).

Similar perspectives are also shared by Herbert and Sears (n.d)) on what should constitute an effective and adequate model and the approaches of Citizenship Education. In a related note, Micheal, Adeyemi \& Moffat, (2003), use the terms, "problematic and ambiguous" (p.3) to refer to the complexities educationists, academics, and scholars endure when trying to agree on a common definitive explanation that might give a more acceptable meaning to the concept of Citizenship Education. Such controversies are long held by Nation States when trying to develop a suitable and appropriate domain that would reflect the needs of their immediate society and what they aspire to achieve in the future.

Some writers see Citizenship as a topic with many facets, Anderson, Avery, Pederson, Smith and Sullivan, 1997; Davis and Fernlund, 1995; Drisko, 1993; Field, 1997; Parker and Jarolimek, 1984; Patrick and Hoge, 1991; Quiley and Bahmueller, 1991 Cited in Zarrillo, 2004). These authors view the subject as having little consensus about what good and active citizenship mean. Some of the writers argue in favour of 
rights (entitlement) and responsibility (duties and obligations) as basic components of CE. Others see CE as an enabling factor for participation in political arenas and/or active involvement in politics (Lawton 2001, cited in Adeyami., Boikhuso., and Moffat 2003). Consequently, CE from the outset is far from static (Ross, 2006; Heater, 1999). The concept has been the subject of numerous ongoing disputes among educationists and philosophers since the early periods of its origin, because the term is defined contextually.

\subsubsection{Citizenship Education version}

The term citizenship is "conceptualised and contested along a continuum" (McLaughlin, citied in Kerr, 2002). The implication of this continuum has caused the concept to be defined and interpreted into two Citizenship Education version. The minimal and the maximal version of Citizenship Education (Kerr, 2002). Both versions of citizenship are now currently dominant and have represented the Citizenship Education curriculum across the globe

\subsubsection{Citizenship Education - Minimal version}

The minimal version of Citizenship Education is interpreted as a narrow definition of citizenship which only focus on particular exclusive interest (Kerr, 2002). These interest as Kerr further explained includes the narrow formal approach to citizenship which is label "Civic Education". This includes the teaching of geography and history of the society. This approach is "largely content and knowledge led" (Kerr, 2002 p.215)

Secondly, the "minimal approach" to Citizenship Education is the teaching of values that consider citizenship knowledge based on governance, rights and responsibilities (Deuchar, 2007). This relates to the promotion of a good citizen who is law-abiding, works hard, and possesses a good character. The advocates of the approach argue that the teaching of those values should be the fundamental principle of schooling if the state or individuals want to see a harmonious life among citizens (Lynch (1992). The implication is for people to recognise and acknowledge basic rights and freedom among citizens as ideal unifying themes. 
Deuchar (2007) points out that such an approach to teaching Citizenship Education will provide for knowledge about rights, personal identities, and the values of lawabiding citizens. However, according to the early history of citizenship, such a perspective is linked to the original definition of citizenship which concerns individuals giving up their allegiance to the church or the state through certain religious convictions and education. Philip (1999) citing the work of Rousseau interpreted the concept of citizenship as, having ramification in later years (citied in Ireland, Kerr, Lopez Nelson, and Cleaver (2006). Rousseau argued that educating children to appreciate the values and procedures that are beneficial to society had a vital role to play in fostering a sense of nationality and national pride.

The changes of behaviours and values, subjected to the rapidly global-changing communities have caused the direction of the focus to change. Many people now desire to shift from an understanding of education for citizenship based on the promotion of the rights of the learners towards the one based on the idea of mutual obligation and active citizenship (Kymlicka and Norman, 2000). The argument here is that, learners can claim their rights only if they carry out their duties more diligently in society. Kerr, cited in Kerr and Cleaver (2006) interprets the mutual obligation as, "something for something". A mutual responsibility by all stakeholders" (p.36). He argues that skills/values should be internalised and have to constitute the inner character of the learners and must be re-enforced across the school. Such an argument can be perceived as a reinforcement of the old conservative, republican tradition which defines Citizenship Education in terms of duty.

In England, such a notion has been taken into consideration following the Douglas Hurts discussion of the need to promote "active citizens." Active citizens are viewed only as a function of social control. The description and interpretation is limited to those who pay taxes, obey the law, and take care of their neighbours (Cunningham and Lavette, citied in Deuchar, 2007). However, converse arguments on this subject pointed out that the changing nature of the world needs to consider an approach that encompasses a commitment to participate in public life (Logan and Derricah cited in Deuchar, 2007). Such a view does not support a citizenship approach that promotes decent, law abiding citizens. 
In addition, the minimal version of Citizenship Education produces passive/functional citizenship. This passive learning is produce through the Citizenship Education which stresses knowledge of the legal system, state, elections, function of central and state government, and state welfare matters (Mamat \& Singh, 2008 p.89).

\subsubsection{Citizenship Education - Maximal Version}

The maximal version of Citizenship Education also "includes the contents and knowledge components of minimal interpretation, but actively encourages investigation and interpretation of the many ways in which these components are determined and carried out" (Kerr, 2002 p.215).

Commitment and participation are highlighted in a "maximal approach" to Citizenship Education (Davis, 2001; Osley and Starley, 2002 citied in Deuchar 2007). Such an approach does not allot recognition only to good citizenship but encourages more of the sense of obligation which involves the responsibility entrusted on the individual and the duties expected by society concerning the willingness to undertake change on a local, national, or even a global scale (Osley and Starley 2002 citied in Deuchar). In other words, the maximal approach encourages pupils to become agents for social change, developing enquiring minds and skills for participation (Wilkinson cited in Deuchar, 2007).

Lynch, (1992) argues that Citizenship Education is just a mode of "ideological domination" (p.31). Students were indoctrinated by Citizenship Education to accept the inequalities in wealth and power among the dominant groups nationally and internationally while ignoring the core societal and environmental needs. Lynch (2002) advocates that the concern of Citizenship Education should be to enhance the capacity of "learners to reconstruct their communities and societies according to the principles of human sensitivity and reciprocity, social justice, wise environmental stewardship and greater economic equity" (p.31).

The turbulence, change, and uncertainties of the times is evident as countries prepare to meet the challenges facing them. The question of "what constitutes education for citizenships in various nations that is appropriate to the demands and needs of a rapid changing global community is critical in both national and international context" 
(Cogan cited in Mutch, 2005 p.189). The planet and the human family are facing an unprecedented set of challenges, issues, and problems including globalisation of the economy, deterioration of the quality of the global environment, and ethical and social issues. How does one respond to those problems as a member of the nation?" Asked Cogan (cited in Mutch, 2005 p.187).

In this discussion, the maximal approach to Citizenship Education which requires "development of critical, reflective and independent thinking among individuals regarding social issues is important... This version is believed to produce citizens who play active roles in matters concerning social, economic and political issues. This version of citizenship is believed to produce a citizen that is active" (Mamat \& Singh,2008 p.89).

\subsection{The Rationale for Citizenship Education}

Citizenship Education is considered to be the finest vehicle the state can resort to in order to conform children to values that stabilise the society (Heater 1999). A nation needs the loyalty of its citizens in all circumstances and situations. However, loyalty has to be nurtured in the face of challenges and dangers of discrimination to provide equal recognition to all citizens. Loyalty requires its citizens to demonstrate values and disposition of character that are acceptable and proper under the jurisdiction of the state. All individuals are obliged to act and behave in a manner that shows tolerance to one another for the good of "human-human and human-environment harmony" (Lynch, 1992, p.27). Such tolerance and loyalty is believed to be beneficial to sustain stability in the society. Those are characteristics that Citizenship Education programs wish to develop among citizens.

\subsubsection{Citizenship Education for Democratic citizenship}

One fundamental goal of Citizenship Education is for societies to have democratic citizenship. Considering the meaning of democracy, it is a "system of governing which is based on the version of popular representation and governance" (DeLeon, 1997, p.1). It is a system of community government in which, "by and large, the members of the community participate or may participate, directly and indirectly in making decisions which affect them all" (Cohen, cited in DeLeon, 1997, p.14). In 
democracy, the emphases are expected to be central to the individual in a society. In this explanation the citizen acting in a democratic society is the focus of attention. This includes activities the citizens have performed which reflect the elements of a democratic mode of participation (DeLeon, 1997). One popular reiteration was provided by Abraham Lincoln for American Democracy: Democracy is the Government "of the people", "by the people", "for the people" (cited in Deleon, 1997).

In Citizenship Education for democratic citizenship, what is significant is to develop programmes that focus particularly, on knowledge, values and skills that develop citizens to understand and practise the principles of freedom and equality in their immediate setting. To be a citizen is to recognise the principles and rules of democracy. This includes individual liberty and rights and civic activity and political participation. (Polydorides, 2002). In brief, teaching and learning for democratic citizenship aims to develop citizens to apply the principles of democracy in their society.

\subsubsection{Citizenship Education for an ideal state and good citizenship}

Earlier prospects and purposes of education are twofold: "to develop individuals for their own sakes and to fit them for life in the society into which they were born" (Heater 1999). Forming a citizen, Rousseau argued, requires the acquisition of knowledge and the development of skills. Such knowledge and skills have to be bolstered by techniques devised and created by the society. Aristotle has said, "the citizens of the state must be educated to suit the constitution of their state" and Plato once wrote, "what we have in mind is education from childhood in virtue, a training which produces a keen desire to become a perfect citizen who knows how to rule and be ruled as the justice demands" (Heater 1999. p.66). Montesquieu (1949), an eighteenth century writer, once asserted that in a republic, inspiring love of the laws and of our country ought to be the principle business of education (Heater 1999). Most early writers, (Rousseau, Aristotle, Plato) envisaged that for an ideal state, it is only through the transmitting of required knowledge that pupils can become accustomed to the rules, equality, fraternity, and to live in sight and harmony with one another. 
Good citizenship is the end product of the practice of Citizenship Education for an ideal state. Good citizenship concept is referred to as an achievable value. Kelly (1989) defines values as entities that have some kind of existence of their own even in some metaphysical sense. Similarly, theories provided by Clark (1997) propose that "value has its origin in our genetic structure. We are born with an affective capacity to like and to dislike aspects of our experience" (p.92). According to Kelly (1989), value is an activity, something people do. Zarrillo (2004), conceptualised values as "constituting the standard or criteria against which individual behaviour and group behaviour are judged, beliefs represent commitments to those values" (p.29). For example, rights, responsibilities, duties, and dispositions are sometimes characterised as honesty, respect, and goodness. "The disposition itself is neuropsychological, acquired socially and displayed behaviourally" (Brower, cited in Clark, 1997, p.92).

Good citizenship is defined by the right knowledge proper behaviours and respect for authority (Wesley 1978). He sees a good citizen in relation to the following characteristics: a citizen who carries out all of the duties and responsibilities of the nation's citizenship; a good member of the nation state; a citizen who obeys the law, pays taxes and attends school; and good citizens are willing to defend their country. The emphases in this definition are on participation, knowing what is expected of oneself, and fulfilling these expectations. Such conceptions when promoted put pressure on citizens to conform to national patterns. These national patterns are constructed to enforce patriotic virtues and bring individuals, groups, and communities to see the benefit of allegiance (Kerr cited in Mutch, 2005). Such virtue, as claimed by Heater (1999), provides a mark of a good citizen.

\subsubsection{Citizenship Education for active citizenship}

The term "active citizenship" is a relatively new concept in policy and practice. There is a broad range of opinion as to what it entails (National Foundational of Educational Research (NFER, 2006). However, in its simplest definition, active citizenship refers to the active participation and involvement in activities that help young people to take an active role in their school communities and beyond. The active dimension in citizenship, as opposed to the knowledge component of education for citizenship, is 
driven by political, legal, and social spheres (NFER, p.35). The main drive for the political sphere is the democratic deficit (Jowell and Park, 1998; Patman, 2000 cited in NFER). The values of democracy are embedded in the drive of the legal and social spheres to promote human and participation rights at local, national, and global levels (NFER, p.35).

Active citizenship is premised on the desire to educate students not as passive or good citizens who are decent and law abiding citizens, but as those who play an active part in the affairs of the state. From the literature (Davise, et.al. 2001; Osker \& Starkey, 2002 cited in Deuchar 2007) "active" refers to a sense of obligation to one another and willingness to undertake changes in local, national, and global scales. It is what people can do for each other, working with each other and with the communities (Crick, 2000). However, in general, active citizenship is literally equated with active participation in political and social activities such as voting, joining political parties, involvement in junior parliamentary activities, and involvement in voluntary work.

Crick (2000) argued that, "active citizenship is an active moral value. It is not just the provision by the state but also what people can do for each other, working with each other and their communities" (p.97). The dispositions of character such as respect, honour, and active participation are central to active citizenship. Pearce et. al. (1988) claim that active citizenship refers to someone who is actively shaping the way that his community functions, and not only a right-holder or claimant. Lynch (1992) sees such a revival of interest in the development of character, attitudes, and values as the reorientation of greater emphases on reflexive and active thinking and citizens' decision making and political participation. Some educators refer to this as teaching social actioning while others see it as education for active citizenship.

Citizenship Education according to Heater (1999), is the "the finest way to encourage the development of the individual being's personality and potential (p.165)." Certain citizenship theories have argued that "students who learn CE in school are more likely to become active citizens in tomorrow's democracy" (Print, 1999, p.83). Therefore, the decision made now for CE to be taught in school will have a profound impact on how citizenship is understood in the future (ibid). 
The concept of citizenship has to be learned in order for the public to be aware of what the families, communities, and state expect from them. Gore, (1999) asserted that the "future of all countries lies partly in the education of their youths. If that education ignores CE then the country's future will be less influenced by its political heritages and values that mould the society" (p.75). In that sense, it is important for the general population to gain access to the knowledge and understanding of the social, legal, and political systems in which they live and operate. Not only that but, they need to be endowed with the values and dispositions that would put their knowledge and skills to beneficial use (Heater, 1999). Civic and Citizenship Education as Gore (1999) further explains, is all about values and about the programmes that make a difference in schools and in the wider community.

\subsubsection{Citizenship Education for social cohesion}

The existence and promotion of education for citizenship have been influenced by and coincide with several factors. The most common ones are: the tensions for recognition among minority groupings, wars, social and environmental chaos, the break down of law and order, and the demise of moral values in societies (Heater, 1999). For example, in the late $19^{\text {th }}$ and early $20^{\text {th }}$ century, Citizenship Education was highly promoted to unify people of different ethnicities (Hebert and Sear, n.d). In the mid $20^{\text {th }}$ century, after the end of the Second World War, it re-emerged because of new trends of migration due to the surging demand for urban labour (ibid). From the 1960s to 1980 s, because of issues caused by multiculturalism, CE was promoted again to acknowledge the contribution of migrants as well as dealing with the reoccurrence of hatred and racism (Hebert, and Sears n.d).

According to Lynch (1999), the work of Dewey and the birth of the new paradigm of Social Studies in the United States based on the concept of education for citizenship has marked the ebb and flow of the concept's broader acceptance in American society. During the period from the 1960s to 1980, such an acceptance from the state distinguished the era from the time when the education system tried to homogenise people of ethnic diversity to create a durable civic culture from a mixture of different identities and interest (Lynch 1999). 


\subsubsection{Citizenship Education for entrepreneurship}

During the 1990s, there was a step back or abandonment of citizenship as an educational goal. The education and curriculum goals were redesigned to promote economic agendas (Hebert, and Sears, n.d)). The agenda was for competition and entrepreneurship as means for survival in a globalised economy (ibid). The problem with this was that, "schools did not succeed in preparing youths for an economic future" (Hebert, and Sears, n.d).

The resurfacing of $\mathrm{CE}$ in the $21^{\text {st }}$ century is significant for a number of reasons. Foremost is the intention to promote Citizenship Education in educational, political, and public interest to compact the new emerging global, economic, social, and political constraints? Cogan (citied in Mutch, 2005) warned that "the planet and the human family are facing an unprecedented set of challenges, issues and problems including globalization of the economy... deterioration of the quality of global environment and the ethical and social issues (p.187). Consequently, the educational response to such situations became a matter of national interest.

\subsection{Citizenship and Citizenship Education by indigenous people of the Pacific}

Citizenship and Citizenship Education for indigenous people of the Pacific Islands need careful consideration. The fact is, indigenous people of the Pacific consider a citizen, or what it means to be a citizen, differently from the Western interpretation. According to one Pacific Island writer (Gegeo, 2001), in the context of Solomon Islands, a citizen is interpreted as people and citizenship is referred to as "people of place". Gegeo uses the term "people of place" strictly to explore the way in which people conceptualise and discuss their identity in the rapidly globalising world" (p.3). Gegeo (2001) explained citizenship (people of place) in terms of the following factors. First, one's existential foundation, which refers to geographical and physical location. Second, genealogy - that is, one's location in a kin group both in the present and reaching backward and forward in time. Third, having land through genealogy and marriage. Fourth, the unquestioned position, based on genealogy and marriage, from which one may speak on important issues without being challenged about identity. Fifth, that one is knowledgeable about culture, history, ontology, and 
cosmology. Sixth, is citizenship accompanied by certain kin obligations and responsibilities that cannot go unfulfilled and from which one is freed only by death. Such responsibility includes contributing to bride price or bride wealth payments in marriage.

In the case of Fiji, Nabobo - Baba (2009), interpret citizenship to mean "those who have the record of speaking the truth, are hard working and attended all customary obligations. More importantly, those people are known for their wisdom; they live well and work really hard" (p.140). In order to acquire such important knowledge, values, and skills, children are given special education.

Education for citizenship for the indigenous people of Pacific Island countries may also vary from content, pedagogies, and strategies of Western education philosophies. In the Solomon Islands, children gain worthwhile knowledge through the parents and family interactions and peer socialisation. As such, the rights and freedom of the child are determined by the parents, family, or even the extended family. It is a shared responsibility. These are contextual based influences as defined by Sanga (2004). Learning is influenced by the immediate social setting and knowledge is acquired through the child's generalisation of what is seen, touched, heard, felt, and smelt from the family unit and the community (Gegeo, 2001). Learning is a matter of obligation, not of the child's right, or free choice. This learning is acquired through listening, watching, imitating, and doing things. Again, this is an obligatory act accompanied by the narration of fairytales, stories about battles and important characters, singing of songs, chants and dances about the environment, love, relationships - all carefully guided by the parents. These are avenues for teaching of values, power, secrets or taboos, and the important teaching about nature and people's relationship with the environment. Children watch while the activities are performed. They can imitate the activity at the same time or at a later date. The knowledge acquired in this process is the truth and reality to the children. This is what is referred to as important knowledge. People believe to live in harmony with each other because people demonstrate and apply the values they have nurtured from birth and their socialisation with the social and physical environments. The values that uphold social norms and the respect for people's way of life are central to stability and harmonious living. Children show their allegiance through respect and obedience, and duty and 
responsibility to their immediate family, community, and societal institutions. In Solomon Islands this is what is meant by teaching and learning for good and active citizenship.

\subsection{Summary: Part 1}

It is obvious then that citizenship and Citizenship Education are contested terms. According to the literature, from the origination of the concept until the present day, the meaning of the term has been debated. The implication is that citizenship approaches and education systems differ between countries. Therefore, to apply the concept of one country to a different context and situation may not work as effectively as assumed. However, since the goal and purpose of education is to educate pupils to become good and active citizens, blended with the goals of Citizenship Education which is to prepare children to become active members of a democratic state, it is imperative to construct Citizenship Education that is based on the national expectation of individual states. According to the literature, what is contextual and relevant to the lives of people is valuable to citizenship. Citizenship Education helps to determine who people are in relation to their local communities and nation state. Citizenship Education is an essence which states use as catalyst for economic, social, and political development and stability. The main attribute of Citizenship Education is its ability to purposely promote values, knowledge, and skills in the school system, to alleviate social complexities that distance people from the state. A second important attribute is to build relationships among people of different ethnicities and varying social behaviours commonly found among the underprivileged, minorities, or people of differing ethnicity. There is no "one size fits all" in citizenship and Citizenship Education concepts. In that sense, each individual state has to develop a framework of Citizenship Education that include values, knowledge, and skills relevant enough to solve the social, political, economic and development aspirations of societies. 


\title{
LITERATURE REVIEW \\ PART 2: CITIZENSHIP EDUCATION CURRICULUM AND THE SOCIAL STUDIES CURRICULUM
}

\begin{abstract}
2.9 What is Education?
Education, according to Dewey, is "the art of giving shape to human powers" (Ryan, 1998. p. 397). It is the development of the child in preparation for his/her future (Gilbert, 2005). Such a preparation needs children to be put in complete possession of all their powers, requiring teaching and learning to be considered carefully. However, how to empower children through education is a complex process because such an undertaking involves the interaction of teachers and significant others. In other words, systematic interactive teaching and learning between teachers and significant others causes education to be seen as a complex process. Education therefore, is a process which will make students change their behaviours in preparation to change their own world for the betterment of their own life in the future. In addition, the education system is a social system which is expected to change along with the changes found in societies (Ross, 2006). It also has to respond appropriately to the increasing understanding of education processes and that should be the central concern, especially with the curriculum.
\end{abstract}

\subsection{Curriculum Orientation}

Any curriculum is a "selection from our cultures and the values of our cultures are central to understanding and participating in it" (Gilbert \& Hoepper, 2004. p. 93). According to Lawton, cited by Winch and Gingell (1999)“ a curriculum is everything that goes on in the school, planned, sustained and regular learning which is taken seriously, which has distinct and structured content and which proceeds via some kind of stage of learning" (p.52). It is a document that contains planned activities for implementation of the educational aims. "Activities which are designed to implement a particular educational aim - or set of such aims of what is to be taught and the knowledge, skills and attitudes which are to be deliberately fostered" (Winch and Gingell, 1999, p.52). The goals of curriculum are those that are purposefully arranged to transfer the stock of knowledge, whether academically or behaviourally to the next 
generation. It is a text, usually a document, which "outlines the aims, goals and objectives of the school, presents a summary of the subject areas to be covered and the content of the teaching and points out ways in which teachers and pupils can work with the various subjects and themes to be covered" (OCDE, 1991. p. 43). It is also recognised as a framework and constituted guidelines or direction for school actions (ibid).

Winch and Gingell (1999) sees curriculum in three ways. First, "as it is now (the determined curriculum). Second, as it ought to be to meet the contemporary social needs as generally defined (the adaptive curriculum). Third, as it ought to be to bring about some desired changes in the existing social structure (the determining curriculum)" (p.1). Considering the above conceptualisation, converse arguments see curriculum not as a uniform trend towards a comprehensive guideline, but rather as a document for advancing state priorities according to the frameworks that are believed important to met the economic and social goals of each particular country (OCDE, 1991).

\subsubsection{Curriculum planning}

In terms of planning the curriculum, as Lawton (cited in Kelly, 1989) points out, selection of objectives has to be related to the nature of the child, the nature of the society in which he lives and the nature of the knowledge itself and thus effectively, it advertently makes decisions about the content prior to those concerning purpose. The content of the model has to acknowledge the set of values which will direct the choices and underpin the planning and these will need not only to be stated clearly but also justified (Kelly, 1989, p.28). The issue of content then must remain central to the curriculum even if it must not be permitted to dominate it. The primary issue is often about what knowledge must be included in the curriculum (ibid).

Conversely, Kelly (1989), looks beyond a consideration of content alone and recognises that questions or reasons for the decisions are logically made prior to those about the substance or what knowledge, skills, and values are deemed necessary to be promoted. He advocates that curriculum planning begins with a statement about the purpose that is hoped to be attained or the principles upon which the practice is to be 
based. He argues for decisions about the content of the curriculum to be subsidiary to that prior choice. Ralph Tyler said such decisions will answer the question "what educational experience can be provided that is likely to attain those purposes?" (Kelly 1989, p. 26). This question requires planning of curriculum to focus on the experience and real life situation that needs to be address.

\subsubsection{Curriculum debates}

The debates about curriculum have shown that the model, framework, approach, and domain developed and used by any one country is likely to differ from the purpose, aims and objectives of curriculum planning and development of another. Therefore, it is important to understand curriculum, not as a static entity but as a document that is dynamic and able to change according to changes in content of education and in teaching and learning processes following the needs of the social environment and government decree (OCDE, 1991). Some debates for curriculum change have focused on social differences. Demaine (2004) argues that any curriculum construction should first consider the factors that marginalise groups and individuals from the society, and other forms of differences. However, such arguments indicate a very narrow conceptualisation. There needs to be teaching that provides the understanding to see clearly the impacts of these differences if not addressed properly. Moreover, if Citizenship Education is to be effectively practiced, the approach, domains, and models that provide effective learning to students need careful scrutiny.

Some debates argue that curriculum is the foundation of any education system. Therefore, to meet the demands of the society, any change to the education system has to be based on a corresponding modification to the curriculum. (Adeyemi, et. al., p. 2). Without curriculum change, modifications to the structure of the system make no sense and have little point. However, if educational change is to keep pace with and match changes in society, and at the same time maintain the standards and values in the particular society, it must be deliberately managed rather than merely left to chance (Adeyemi et. al., p.2).

In other arguments, the knowledge source and curriculum construction is important in planning and constructing the curriculum. However, if the development of the 
curriculum is just a matter of general listing of details of information content to be taught, or just about the order and method or, "the teaching for facts" then this is inadequate (Gilbert \& Vick, 2004). Three important reasons are provided. First, "knowing how to use the knowledge and knowing how to test and justify knowledge claims. ...knowledge without such dimension is not knowledge at all" (ibid p.81). Second, "knowledge changes and what is seen to be important changes and different perspectives give different priorities to knowledge" (Gilbert \& Vick, 2004, p. 81). This is reaffirmed by Gilbert that there is no one way of specifying what must be taught as a detailed list of information. Third “...identifying content is always a process of construction and interpretation that must constantly be scrutinized and reflected upon. Such arguments hold that curriculum content cannot be determined once and for all" (Gilbert \& Vick, 2004, p.81).

\subsubsection{Curriculum debate from Pacific Islanders}

Thaman, citing the work of Lawton has described curriculum as the "selection of the best of culture" (Manu, 2009, p.49). In this debate Manu describes Pacific curricula as being explicitly geared towards university study and not so much on the best of culture which reflects the interest of Pacific societies.

Further, debates by Pacific Islands academics and educationists claim that the formal education system is alien and foreign to Pacific Islanders (Thaman, 2009; Sanga 2004; Taufe'ulungaki (2009). Thaman, (2000) defines education as an "introduction to worthwhile learning" (p.1). What she referred to as worthwhile in this regard is the culture of Pacific peoples. Culture, in her definition, is a way of life of a group of people which includes their store of important knowledge, skills, and values. For Thaman, "education and culture are interwoven" (Thaman 2001 p.1). In an epistemological and ontological debate, Sanga (2004) has argued that peoples of the Pacific have their own world that they influence and control. He explains reality as subjective to the context of people, which includes the social, cultural, and spiritual world. Sanga assumes knowledge as relativist and inseparable from the context and the social realities of Pacific people.

In another debate Taufe'ulungaki (2009) states her belief that curriculum is the heart of any education system. She expressed that the policies of the curriculum direct the 
country's initiative for its formal education system. The curriculum policies therefore should include the values, knowledge, and skills that each country wishes to transmit to its future generations. As Taufe'ulungaki (2009) has stated,

\footnotetext{
The policies identify the goals, key principles and priorities of the system. Moreover, curriculum policies emphasise the content areas, levels, delivery mechanisms and expected outcomes. As well, the policies determine the frameworks through which curriculum is processed, delivered and measured. The values underpinning official policy documents, where these exist in the Pacific region, are more often than not covert, rather than explicitly stated. (p.127)
}

As noted by Taufe'ulungaki, such an omission is a flaw in Pacific Education systems. Therefore, curriculum reviews or changes have to ensure that the ways of life of indigenous peoples of the Pacific Islands are considered seriously.

\subsection{Citizenship Education curriculum}

Citizenship as defined in the literature refers to the status and identity of individuals within their societies. This citizenship curriculum discussion, covers the curriculum domains, models, approaches, and curriculum pedagogies. Many people equate the curriculum with the syllabus. Kelly (1989) citing the work of John Kerr (1968) has defined curriculum as "all the learning which is planned and guided by the school whether it is carried on in groups or individually inside or outside of the school" (p. 26).

\subsubsection{Citizenship Curriculum Domain}

The literature has identified several domains that constitute the curriculum for citizenship. However, the most used domain is found in the summary provided by Hebert and Sears (n.d). The summary provides four major domains of citizenship: "civil, political, socio-economic and cultural or collective dimensions. The first three domains have their origins after the Second World War (WW11). The fourth has emerged since then" (p.1).

The civil domain of citizenship includes freedom of speech, expression, and equality before the law. The political domain involves the right to vote and to political 
participation (political citizens) and is referred to in terms of political rights, and duties with respect to the political system. The socio-economic domain refers to the relationship among individuals in any given society and the right to participate in a political space (Gilbert 2005). The cultural or collective domain of citizenship refers to how societies take into account the diversity due to global migration. This includes the quest for recognition by minority groups of their rights and certain conceptions of human dignity and the affirmation of legal equality against all forms of discrimination (Hebert and Sears, n.d, pp.2).

\subsubsection{Citizenship Curriculum models}

Hebert and Sears, (n.d) in their study of curriculum models of citizenship have pointed out four components. They are: "national identity; social, cultural and supranational belonging; an effective system of rights; and political and civic participation" (p.2). Those models, although attributed to the Canadian context, are also recognised among other developed countries. In England, the models that are debated for Citizenship Education encompass the following: "the nature of the community, the roles and relationships in the pluralistic society; duties, responsibilities and rights of being a citizen; the context of a family and the political system..." (Gilbert, 2005 p.143).

\subsubsection{Citizenship curriculum Approaches}

There are arguments that certain subject areas are more suitable for the teaching of Citizenship Education than others. This section highlight some of the approaches commonly use for Citizenship Education.

\subsubsection{Segregated curricula approach}

Some commentators argue in favour of teaching citizenship as a segregated subject. In one argument, Turnbull cited in Kerr and Cleaver (2002), advocates segregation of the subject as opposed to taking a cross-curricula approach to teaching Citizenship Education. Wilkinson (citied in Kerr and cleaver 2006), argues that timetabling Citizenship Education as a discrete subject in the school curriculum will ease the burden for others in other subject areas; it is easier for those who are responsible to teach the subject to handle it rather than to expect every teacher to teach it. It becomes 
"someone else's problem", that is, those who specifically trained to teach the subject. Developing Citizenship Education as a segregated subject is perceived as a prerequisite for the effective implementation of the subject in school, (ibid).

\subsubsection{Cross-curricula approach}

The cross-curricular approach on the other hand, has its strengths as well. However, some Citizenship Education advocators see the development of the whole-school approach as a difficult process. Despite that, some knowledge of the CE can only be delivered through certain subjects in the formal school curriculum. Therefore, it is important that such issues needs to be taken into consideration when trying to develop Citizenship Education. Jerome (citied in Kerr and Cleaver 2006) asserts that, opposite views should be seen as part of a continuum, rather than as a mutually exclusive position. Such an assertion is based on the argument that "one size of citizenship cannot fit all". Thus, the success of the Citizenship Education initiative rests on its very flexibility. In some related arguments, citizenship will be most successful where it becomes a unifying element within the curriculum and where schools use it to further their existing aims as well as appreciating how it can empower young people.

\subsubsection{Extra curricula approach}

Another approach which has been advocated in promoting CE is the extra curricula approach. In this approach, CE is promoted through activities such as flag raising, singing of national anthems, arranged sport activities among schools and others. Those activities are assumed to promote national consciousness and to unify people of different backgrounds. Some commentators view this as a very appealing and effective means to promoting CE because of how it is practised. This approach is situated outside of the school academic timetable. The most used approach in the teaching of CE is through the teaching of Social Studies.

\section{12 Social Studies curriculum approach}

This section presents literature reviews on the origin of Social Studies, why it is an integrated discipline and the importance of teaching Social Studies to create a stable society. 


\subsubsection{Origin}

Social Studies has emerged as a subject in the formal education system from around 1897 (Heater, 1999). Earlier than that, much of the school time was devoted to separate topics of history, geography, and civics. However, prior to the $20^{\text {th }}$ century, what was expected was for students to memorise information in their text books and then recite this in class. From the late $19^{\text {th }}$ century to the early $20^{\text {th }}$ century, there were great changes to the Social Studies curriculum and methods of instruction. This period was viewed as the "progression period", a period that reformed American life through social and political movements influenced by education philosophers such as John Dewer (1900 -1902) and the innovation of Parker (1883; 1894). Social Studies was born during this period" (Heater 1999 p.8)

However, Social Studies with its focus on human behaviour is subject to more pressure for change than other subjects in the curriculum. This can be "attributed, at least in part, to the subject's relatedness to the rapid rate of social and technological change evident in many societies around the world" (Heater 1999 p.5). "Since its inception as a school subject in the early twentieth century, it is a subject that has been rocked by battles over its purpose, content, and pedagogies" (Ross, 1994, p.266). "Even the historical account of its origin as a school subject is in dispute" (Ross, 1994 p.17).

According to Cater (cited in Marsh, 1991), Social Studies is a subject born from the parent disciplines of social science, the humanities, and the natural sciences. It closely links with the democratic ideals and is considered to be part of the general and liberal education that particularly specialises in the education for an effective democratic citizen. Engle and Ochoa (1988) see such an explanation as quite narrow. That is because, although the disciplines mentioned have important goals, the contents do not expose children to meaningful contexts. It is just an exposition of facts and generalisations about which social scientists at a given point in time are in reasonable agreement. Such claim was supported by the work of Wesley (1937) cited in Engle and Ochoa (1988), who referred to Social Studies as social science adopted and simplified for a pedagogical purpose. It means a "mere exposition of a relatively small 
number of facts and generalisations selected from social science and presented to students as truth to be committed to memory" (p.92).

\subsubsection{Social Studies as integrated Discipline}

Social Studies is the combination of varying disciplines into one teaching subject. This has shown clearly the integrated nature of Social Studies. The fact is, this is the only field which attempts to draw different disciplines together. The combined teaching disciplines include social science, the insights of the humanities, sociology, geography, history, and Citizenship Education. Such a combination is seen as value laden and problematic (Hill, 1994). Despite such arguments, the subject matter of citizenship in the teaching of Social Studies is believed to help students construct the knowledge base and aptitude to live as good and active citizens. However, some writers points out that citizenship lacks clearly defined and generally acceptable boundaries, in varying degrees (Cater, cited in Marsh 1991). This is because people interpret the combined discipline's concepts, knowledge, values, and skills of social studies according to their context and situation.

What is considered to be a broad definition for Ochoa and Engle (1988) is to approach Social Studies as a critical study of the social science and history to engage directly in the intellectual process of students whereby the social science and history become instruments in the learning process rather than the ends of education. Such a definition is similar to an explanation provided by Shermis, forwarded by Wesley (1978) who asserts that "Social Studies is an integrated study of social science and humanities to promote civic competence. It integrates concepts of social science and humanities for the purpose of practising problem solving and decision making for developing citizenship skills on critical social issues" ( p.4).

The explanations provided above are related to two of the three Social Studies traditions provided by Wesley (1978). One is "Social Studies taught as social science". This tradition, at least in its most recent form, stems from a variety of events which took place in the 1960's. For example, in the 1960s there was a shift from the post-war patriotic rhetoric to one with a focus on social justice and a more global view (Mutch, 2005). The aim of Social Studies in such a circumstance was to help 
children understand the world they were living in and to take their own place in it; in particular, to help children to think clearly about social issues (Mutch, 2005). It means that teachers acquainted students with the methods of research modes of inquiry and ways of looking at the world adopted by the social scientist.

The second tradition is "Reflective inquiry...a tradition which focuses on preparing students for citizenship and is regarded as the most important component of citizenship because it concerns personal choice. Students will need to identify problems and issues and make decisions on matters of policy and belief" (NFEA, p.19).

The third tradition in teaching Social Studies is "Citizenship tradition." This tradition is viewed as the oldest tradition. The essence of the tradition is the deliberate inculcation of what is considered the most desirable knowledge values and skills assumes necessary for survival of the culture.

What kind of citizens does society want? What knowledge does society recognise as worthwhile? What needs are fundamental to society and how can society meet these needs? In what ways can society select content areas that can best transmit to the next generation? These questions beg scrutiny and are the focus of studies such as this one

\subsubsection{The importance of Social Studies}

The Social Studies curriculum is taught in many if not all formal education systems globally. It has been widely considered as an essential and appropriate approach to deliver and promote the concept and values of Citizenship Education (Marsh 1991; Engle and Ochoa 1988; Allen and Stevens, 1998; Zarrillo, 2004; Hill, 1994; Massialas, and Allen, 1996; Kerr, 2000). According to the literature (Heater, 1999) it is appropriate because it has the prerogative to transmit knowledge and understanding about people, environment, moral values, political structures, government, and how to deal with issues and conflicts of the contemporary period. It is a subject that teaches about people to help them acquire knowledge and master the process of learning to become active citizens (Ross, 2006). In other related literature, Mutch (2005) noted that, "Social Studies is a discipline that teaches about people, women, men, and 
children. It teaches about how and why in diverse culture, and in different times, and places they think, feel, and act, and organise their way of life" (p.192). Furthermore, "Social Studies teaches about how people interact with others and their environments, initiate their responses to changes and meet their political, social, economic, legal, and spiritual needs" (Ministry of Education, 1994. 7 cited by Mutch, 2005).

Reley and Wofford citied in Adeyemi, Boikhuto and Moffat,(2003), in discussing the relationship between education for citizenship and Social Studies, have asserted that students should be challenged to apply civic knowledge, skills, and values as they solve real problems either in school, their community, nation, or the world. The Citizenship Education concept seems to be the driving force in education that will promote the values considered important for good and active citizenship (Zarrillo, 2000).

Social Studies is a subject that is believed to teach children to value themselves by nurturing positive self conception and learning (Mutch, 2005). It should help students adopt healthy values toward school and learning, the social and physical environment, and the political and legal propositions of the state (Zarrillo, 2000). The values that need development and promotion should constitute the standard or criteria against which individual behaviour and group behaviour are judged; beliefs represent commitments to those values (Honesty for example is a value) (ibid.). A set of values that Social Studies emphasis is civic and citizenship values and beliefs that lead to good and active citizenship.

\subsection{The purpose of Education in Solomon Islands}

The purpose of schooling is very much similar in any environment. The education system of Solomon Islands has been developing the citizens of the country through a variety of ways particularly through the teaching of various academic subjects at school. This, as in any country, is to help in creating an enabling atmosphere for the citizens to achieve the broad educational aims of the state. The overall aims of education in the Solomon Islands are, similar to many of the countries in the Pacific Islands. Education is defined particularly by the academic subjects taught in the 
formal education system. Such conceptualisation of education by people of Pacific Island nations is very narrow compared to the definition provided by Lawton cited earlier in the chapter. As stated by Thaman (citied by Manu, 2009), "current school curricula in most Pacific Islands countries are too academic and geared towards university study, and therefore most school leavers will have learnt little that is of practical value to them in the context of their own societies" (p.50).

Taking a similar view, Ben and Openshaw (2005) points out that the aim of the curriculum concerns the values to be upheld, the characteristics to be fostered, and the content to be covered in subjects taught in the formal school curriculum. This may mean that formal curriculum should base its content on the values relevant to the society.

However, the concepts of Education and curriculum as observed are far from achieving its broad educational aims. The fact is that, in its current form, education in the Solomon Islands is very limited in its capacity to give students the understanding about values that will affect their behaviours in order to make a positive change to the social, political, and physical environment. It has been found that the curriculum does not enable students to gain understanding of the diversity of community and society and an awareness of equal opportunities, national identity, and cultural difference (Advisory group on citizenship, 1998, p.19 citied in Demaine 2004, p.18).

\subsection{Social Studies Curriculum of Solomon Islands}

The Social Studies curriculum of Solomon Islands is developed in accordance to the Education Act 1978 of the Solomon Islands. Similar to many Pacific Island curricula, in the 1980s Solomon Islands Curriculum framework was driven by the global shift in aims, goals, and content to address challenges the societies experienced during that period of time. Particularly, on the changes of behaviours for certain global events. For instance, the changes made to the Social Studies curriculum of Solomon in the 1980s after gaining independence from Britain, are similar to the new Social Studies curriculum promoted in Australia, Canada, England, and the United States (Hebert, and Sears (n.d); Print, 1999). In Australia the study of society and environment 
encompasses themes such as culture, place and space, resources, time, continuity and change, natural and social systems (Sander \& Yulaelawati, 2008).

\subsubsection{Social Studies Themes}

In the Solomon Islands, Social Studies syllabus comprises the following themes: social relationships; people, place, and the environment; time, continuity, and change; conflict and cooperation in the modern world; people and their development; industrial and urban growth; and continuity and changes in the Solomon Islands (Secondary Social Studies Syllabus, Solomon Islands, 1988). These were aimed to expand students' knowledge and understanding about relationships within the family, respect for environment, events occurring in the past, what is happening in the present, and to anticipate what might happen in the future (Social Studies Syllabus of Solomon Islands, 1998). Such expectation is limited only to memorisation of events. The fact is the framing of the competencies are only on facts, concepts, and generalisations.

\subsubsection{Social Studies Goals}

The current Solomon Islands Social Studies curriculum has the following goals: first, for students to be well informed about other countries' social, economic, political, and belief systems both past and present; second, for students to be aware of and understand the changes that occurred in the past and are currently occurring; third, for students to develop an awareness of the society's human and physical resources; fourth, to develop an understanding of the diversity yet independent people; fifth, develop the skills and attitudes needed for them to be committed to play an active role in the life of their communities (Social Studies syllabus, 1998).

\subsection{Barriers to Social Studies teaching in Solomon Islands}

The content, themes, and teaching pedagogies in Social Studies appear not to address the current physical and social needs of the Solomon Islands. For instance, teaching about families, religions, denomination and churches, the history of wars, the antigovernment movements, and resolving conflicts seems dogmatic and non-influential to the children's mental, physical, spiritual, and social development. The knowledge received is purely for memorisation of facts in preparation for national examinations. 
In the current teaching of Social Studies, students receive teaching about families, colonialism, government structures, wars, revolutions, and political systems. However, it is not enough to teach about what happened in the past and acknowledge what the present values ought to be. In today's reality, it is important for students to have a broader and deeper knowledge of how culture and religion developed humans and the relationship of inter-connectedness of people, communities, and the states (Steward, 2007). This will not be achieved by giving students mere facts about the cultures, custom, families and historical events; students need to have critical thinking skills and to be taught key concepts that they can apply to situations.

Secondly, the current Solomon Islands Social Studies themes and topics have outdated their usefulness (Solomon Islands Curriculum Review committee, 2002). Many of topics were related to the broad goals of the 1960s, 70s and 80s. This can be found in the teaching of themes of government and political changes, early migrations, cold wars, and nationalist movements. Such themes are irrelevant to today's reality, providing only a large body of knowledge that does not lead itself to any critical analysis of the events and issues of concern. The teaching of Social Studies however, should give students an opportunity to compare and contrast the concepts rather than passively acquiring information as facts. Further, it is vital to relate relevant prior knowledge to present learning and recognise the social realities or what is occurring in societies (Levine, 2007).

In this case, Solomon Islands need a coherent and properly structured Social Studies curriculum - curriculum that prepares students for the future. The goals have to be rooted in reality (what is happening in the society) and based on students' own aptitude and experience. Such a claim has shown how important revising the Social Studies curriculum is for the Solomon Islands. How can Solomon Islands develop a curriculum that is relevant and contextual to citizens? This question is the subject matter of this research. 


\subsection{Summary}

In part two of this chapter, the literature review focuses specifically on Citizenship Education and the curriculum approaches and curriculum pedagogies used to transmit the knowledge. This literature indicates that citizenship is part of the Social Studies curriculum and that one can not go without the other. Both disciplines have similar curriculum content, pedagogies and strategies for teaching and learning. However, what constitutes effectiveness in citizenship curriculum development is a matter for each national system to determine and depends on what individual states perceive as relevant, contextual and sustainable for the people. 


\section{CHAPTER THREE \\ THE METHODOLOGICAL APPROACH}

\subsection{Introduction and overview}

Chapter two presents the literature review for the study. In this chapter, I examine the theoretical orientation and approaches adopted in this study. The chapter begins with definitions followed by brief explanations of research paradigms and methodological options, together with a brief account of what constitutes research and how it affects the paradigms that influence people's understanding and their worldviews. These are followed by an examination of the qualitative paradigm, coupled with the methodological approach of this study.

The chapter provides the reasons for the selection of the methodology. In this study the interpretative/constructivist paradigm was used. This qualitative approach starts with explanations and clarification of the methods used to collect data. It includes focus group discussions and one-on-one interviews. The chapter justifies the use of semi-structured questions as tools employed to generate data from participants. It includes brief descriptions of the procedures involved in the study, description and analysis of the data, discussion of the ethical considerations, and ends with a brief summary.

\subsection{Methodological orientation}

According to Everhard, (citied in Conrad and Serlin, 2006) methodology is the "philosophical underpinnings and assumptions embedded on how researchers constructed knowledge" (p.377). To set the context for this study's philosophical underpinnings, a definition of terms is offered so that "readers can understand the context in which the words are being used or their unusual or restricted meanings" (Castter \& Heisler, citied in Creswell, 1994, p.106). 


\subsubsection{The nature of research}

Research is a process (Bouma, 1996; Wiersma, 1995) comprising a series of linked activities moving from a beginning to an end (Bouma, 1997). It is "a systematic process of collecting and analysing information (data) for some purpose" (McMillan and Schumacher, citied in Weirsma, 1995, p.3). According to Kerlinger, citied in Weirsma, 1995) scientific research is a "systematic, controlled, empirical and critical investigation of natural phenomena guided by theory and hypotheses about the presumed relations among such phenomena" (p.30). For Bouma, (1996), scientific research involves the attempt to gather evidence in such a way that others can see what was done, and why it was done that way, so that people can draw their own conclusions on the evidence.

According to Burn, (2000) research is a systematic investigation to find answers to problems. It is also a means by which people appreciate their surroundings. Research has connections with the objective scientific endeavour to enhance knowledge and wisdom. Ary, Jocobs Razavieh, and Sorensen, (2006) explain scientific research as the "application of the scientific approach to studying a problem" (p.18). The purpose of the approach is to find answers that provide meanings to questions when scientific approach procedures are applied. It is a universal, systemic, and objective search for reliable and valid knowledge (Ary et. al., (2006).

In terms of educational research, the imperative is the application of the scientific approach to the study of educational problems (Ary, et. al., 2006). This is a way in which dependable and useful information is acquired about educational processes to find solutions that give insights to issues that need clarification (ibid). The general goal of education research, which Ary, et. al., (2006) pointed out is to "discover general principles or interpretation of behaviours that people can explain, predict, and control events in educational situations" (p.19).

\subsubsection{Theoretical orientation}

A theory is an explanation about the way things are (Bouma, 1997). It is a "set of inter-related constructs (variables), definition and propositions that present a systematic view of phenomena by specifying relations among variables, with the 
purpose of explaining natural phenomena" (Kilinger, cited in Creswell, 1994, p.82). The systematic view according to this interpretation can be an argument or discussion that can help to explain phenomena (Creswell, 1994).

The purpose of theory in research, according to Weirsma, (1995), is to help the researched to establish a framework where the researcher can start from and then proceed with the study. The theory identifies important factors that need consideration, provides guidance to different parts of the research and identifies gaps, weak points, and inconsistencies that may require further research (ibid).

In qualitative research, a theory is developed in the process of research. However, if no theory is generated the study may change focus, or be dropped or be refined as the study progresses (Weirsma, 1995). If the theory is based on data, it will form a grounded theory. "A theory grounded in data rather than one based on some apriori constructed ideas, notions or systems" (Weirsma, 1995, p.13). If no theory emerges, the research is atheoretical. (ibid). Quantitative research is deductive and tends to be more theory-based from the outset. Likewise, "if theory-based testing is done, it is quantitative research" (Weirsma, 1995. p.13).

This study explores the extent to which the Solomon Islands Social Studies curriculum is adequately preparing students for citizenship. To gain information, to form a theory and provide validity to this research topic, the study uses a qualitative paradigm. However, to justify my paradigm choice, I first engaged in comparing qualitative and quantitative paradigms to verify and justify the reasons for my choice.

\subsubsection{Quantitative Research Paradigm}

The quantitative is "termed the traditional, positivist, the experimental or the empiricist paradigm" (Creswell, 1994, p.4). The thinkers that established the empiricist tradition are, for social theory, Comte (1975), Mill (1965), Durkherm (1938, cited in Clark, 1997,), Newton and Lock (cited in Creswell, 1994) while in philosophy, the logical positivists were Carnap, Feigl, and Neurath in the twentieth century, (Clark, 1997). Quantitative research can be classified as experimental and non-experimental enquiry which uses objective measurements and statistical analyses 
of numeric data to understand and explain a phenomenon (Ary, et. al., 2006). It is originated in positivism. The positivist emphasises measurement to gather data with objective techniques to answer questions. It is a research that is systematic and open to replication by other investigators (ibid).

According to Clark (1997), "positivism has its origin in the enlightenment ideal of the rejection of philosophical, religious or civil authority... The clearest expression of this ideal is found in the work of Hume's (1888) treatise in human nature" (p.12). Hume sought to ground knowledge in sensory experience, distinguishing knowledge from metaphysics (Clark 1997).

The nature of understanding about the assumptions of the quantitative paradigm is better understood when it is explained based on ontological, epistemological, axiological, rhetorical and methodological assumptions (Creswell, 1994). For the ontological issues in research, quantitative perspectives see reality as "objective" out there, independent from the researchers; something that can be measured objectively (Creswell 1994). Epistemologically, this paradigm views the researcher as being independent from that being researched. From an axiological standpoint, the values of the researcher are kept out of the study. Rhetorically, the language of the research must not only be impersonal or formal but it has to use accepted words for quantitative research. From a methodological perspective of quantitative research, the approaches used are in deductive forms of logic within theories and hypothesis based on testing in a cause-and-effect order (Creswell, 1994).

The results generated from quantitative research are portrayed as reliable. Reliability in quantitative research "concerns the consistency of the research and the extent to which studies can be replicated" (Weirsma, 1995, p.9). There are two forms of reliability; internal reliability and external reliability. For internal reliability, the data collection, analysis, and interpretation are consistent and given the same conditions. For external validity, concerns include issues of whether or not independent researchers can replicate studies in the same time or in similar settings (Weirsma, 1995, p.5). 
A quantitative paradigm has positive contributions to make to research. However, this study is using a qualitative paradigm. The reasons provided here justify my choice: firstly, it is not time-consuming, not complicated for analysis, not demanding for research resources and easier to complete (Creswell, 1994). Secondly, it involves conversations between the researcher and the researched, whereby rich data is believed to be forthcoming for the study.

\subsubsection{Qualitative Research Paradigm}

Denzin and Lincoln (2008), summarise the definition of qualitative research as "a situated activity that locates the observer in the world. It consists of a set of interpretive, material practises that make the world visible" (p.4). Furthermore "qualitative research is rooted in phenomenology" (Ary et.al., 2006, p.25). In this theoretical view, the substance, social reality is unique; the individual and the world are viewed as interconnected and cannot be separated or function without each other (ibid). Ary, et. al. (2006) further explain that the researcher can only understand human behaviour through the meanings of events that people are involved in. The constructivist researcher does not only consider people but considers how people think and feel and the experiences that have happened to them (ibid). These practices, as Denzin and Lincoln (2008) point out, have transformed the world from the positivist position. Constructivism has turned the positivist world into representations such as field notes, interviews, conversations, recordings and memos.

There are different merits to qualitative research, which are considered vital as compared to a quantitative approach. In qualitative research, the main focus is to examine a phenomenon in rich detail and not as a comparison of relationship as in quantitative approaches (Ary, et. al., 2006). Secondly, the design of qualitative research evolves during the study and not prior to the study. Third, the study is approached inductively, to generate the theory and not deductively whereby tests are done to generate a theory. Fourth, the tools used require face-to-face interaction without standardised instruments. Next, samples are small and manageable, and analyses are informed by narrative descriptions and interpretations. Importantly, qualitative research is "holistic..., interpretative and empathetic...It is holistic in its concern with the process and context rather than simply outcomes and experiments 
research" (Stake, citied in Conrad and Serlin, 2006, p. 407). This means that qualitative researchers "consider, studying things in their natural settings, attempting to make sense of, or interpret, phenomena in terms of the meaning people bring with them" (Denzin and Lincoln, 2008, p.4).

This research project required a qualitative approach to collect "information-rich data" (Patton, 2002). However, to avoid invalidity qualitative researchers have to be aware of their own biases, and, to maintain the integrity of research, try to meet challenges they encounter along the way (Gay and Arasian, 2000). What is validity then as opposed to invalidity? Validity in qualitative research in general, as Weirsma (1995) points out, is based on facts or evidence that are justified as being true. Validity involves two concepts, internal validity and external validity. For internal validity, results can be interpreted accurately. For external validity results can be generalised to population, situation, and condition (Weirsma, 1995).

Three considerations are of note within a qualitative research framework. The research is placed in a natural setting where the researcher is able to access sites and participants, using methods that are "interactive and humanistic in order to build rapport and credibility with the individuals in the study" (Creswell, 2003. p.8). The study focuses on observing a variety of perceptions to allow for multiple sources of evidence to be obtained from participants (Creswell, 1994). The researcher is also able to explore the phenomena in their natural settings (Anderson, 2002) and to make sense of, or interpret, the phenomena in terms of the meanings people bring with them (Denzin and Lincoln, 1994).

\subsection{Interpretative/ constructivist paradigm}

A paradigm can be referred to as an Interpretative framework. It is a basic set of beliefs that guide actions (Denzin and Lincoln, 2008). A paradigm encompasses four terms, "ethic (axiology or Values), epistemology (the nature of knowing), ontology (nature of reality), and methodology (nature of acquiring knowledge)" (ibid, p.245). The major paradigms and perspectives that structure and organise qualitative research are positivist, post-positivist, constructivist, and participatory action framework (Denzin and Lincoln, 2008). 
This qualitative research employs an interpretative-constructivist paradigm. According to Lincoln and Guba, cited in Denzin and Lincoln, (2008), interpretivism/constructivism is aimed to produce and reconstruct understandings of the social world. From an "ontological position interpretivism views social reality as consisting of the intrinsic meanings shared by members of a social group which are sustained by the action and interaction of the members" (Clark, 1997, p.37). Such a perspective holds that "meaning is constructed by human beings as they engage in the world they are interpreting and make sense of it based on their historical and social perspective" (Creswell, 2003, p.9). Importantly, in this approach, people's knowledge, views, interpretations, and interactions are meaningful properties for the researcher and are viewed by Mason (1996) as a "legitimate way to collect the data on ontological properties, to interact with people, to talk to them and to gain access to their accounts and articulations (p.39)." Moreover, it is richer and broader to have data from face-to-face discussions and listening to people's views and perceptions. More so, "interpretative research practice seeks to make knowledge available to the research participants by revealing to them the reasons why they are acting as they did or answering questions and enlightening them of the significant of the actions" (Clark, 1997, p. 38).

\subsection{The Ethnographic Approach}

This section describes ethnography as a strategic approach for this study. Ethnographies are based on observational work in particular settings. Initially ethnography was used in anthropological studies (Silverman 2005). The anthropologist implies that if one wishes to study a group of people one has to spend time with the people to understand routines and language, or participate with people in their daily activities (Silverman, 2005).

The purpose of ethnographic research is to describe the whole culture. What is sought is the key informants and their perspective. In this study, the culture is the education context and its stakeholders. These include Ministry of Education officers and two high schools in the Solomon Islands. People from these organisations and institutions were informants. This required their voices to be highlighted as data for the study. 
Ethnography involves the study of cultures for a long period of time (Grbich, 2007). The length of time the ethnographer uses is purposely to learn about the people, the setting, and the language in order to gather data that can assume "thick descriptions". However, for the purposes of this study, to gather data I as researcher do not need to spend a long period of time to understand the culture of the people, the setting, or the language. I, as ethnographic researcher, I am from the setting, I am part of the culture and I speak the language of the setting. The eighteen years of teaching in the cultural setting after growing up as a child in the setting is deemed enough to satisfy the required purposes of ethnographic research.

Grbich (2007) explained the role of the ethnographic researcher as:

that of a neutral distant reflective observer, meticulously documenting observational and visual images and asking question both formal and informal conversation and formal interviews, in order to confirm and cross check and understanding of a social structure, social linkages and the behaviours patterns, beliefs and understanding of people within the culture (p.40)

\subsection{The Case Study}

This research uses a case study approach as a strategic tool for obtaining data. In the case study approach Stake (citied in Silverman, 2005) identifies that there are three types: the intrinsic case study, the instrumental case study, and the collective or multiple case study. In the intrinsic case study, one limitation is that, "no attempt is made to generalise beyond the single case or even to build theories" (p. 27). In an instrumental case study, a case is examined in order to provide insight into an issue or to revise a generalisation. Although in depth studies are conducted the main focus is on something else. In multiple case studies, a number of cases are studied. This is to investigate some general phenomenon. Thus, for this study, the multiple case study approach is chosen to fit the phenomenon being studied and to gain the "informationrich data" claimed by Patton (2002) or the "thick description" of data portrayed by Geertz (citied in Rubin and Rubin 2005). 
The use of multiple case studies helps to select the sites and participants. Presentation of the findings after analyses are completed is straightforward as selection is not random and data is compared among several varieties (Silverman, 2005). In case studies, "detail of qualitative methods derives from a number of case studies, too small for confident generalization" (Patton, 1987, p. 18). However, it is a valuable approach if someone wants to have information to obtain information and data. Using case studies as suggested by Yin (2003), is useful to understand a complex social phenomenon such as Citizenship Education. Further, the strategy allows the investigation "to retain the holistic characteristics of the real life events" (p.46) and it can deal with a full variety of evidence.

Yin (2003) considers a multiple case studies strategy to be more compelling and more robust with the ability for "direct replications (p.47)." Yin (2003) further points out that conclusions can independently arise from two cases as two experiments are particularly powerful. In addition, the contexts of the three cases are likely to differ to some extent. This is significant as a case study is intended to obtain differing perspectives according to the geographical locations of the case sites and the varying opinions from different cultural views.

\subsection{Site and sample selection}

This study uses purposeful sampling to select the sites and the study participants. What is powerful in purposeful sampling lies in selecting information-rich cases to have an in depth study (Patton, 1987). The information-rich cases are those that provide issues of central importance to the study (Ibid). In addition, as Silverman (2005, p.129) claims:

purposive sampling allows us to choose a case because it illustrates some features or process in which we are interested...purposive sampling demands that we think critically about the parameters of the population we are studying and choose our sample case carefully.

In such a method, sites and participants are not randomly selected; rather, they are selected according to differing characteristics (Wierma, 1995). There are several strategies for selecting information-rich data in purposeful sampling. One of them is "maximum variation sampling" (Patton, 1987). The logic behind the strategy is to find 
common patterns from the amount of sample variations that are of particular interest and valuable to capture core experiences central to the programme.

\subsubsection{Rationale for Selection}

In this study, the researcher selected samples and sites from 140 secondary schools who are offering Social Studies curriculum in the Solomon Islands. The schools are spread among inhabited islands within the 900 islands which cover a wide geographical area that make it hard to access every school. In such difficult circumstances, one has to maximise variations in a small sample. By doing that, the researcher begins by selecting diverse characteristics to construct samples (Patton, 1987).

In the Solomon Islands, there are 140 secondary schools holding the status of national secondary schools, provincial secondary schools and community high schools. Several characteristics have attracted this study selection which notably helps the researcher to generate a specific concept within the theory (Creswell, 2008). The geographical variations of schools include urban schools and rural schools. Generally, secondary schools in the Solomon Islands are located in both the rural and the urban areas, and all schools are either day schools or boarding schools. Such institution as suggested by Bouma, (1997) is necessary to select the best site, people or group to study. For example, if a typical rural school is selected it will be generalised to represent the whole of rural schools in the country

In this study, two schools were selected. They were a rural boarding school on Malaita Island and an urban day school in Honiara, the capital city of Solomon Islands located on Guadalcanal. The schools are assumed to satisfy the criteria for obtaining "information-rich cases" (Patton, 1987, p.51) from which the researcher could collect data of central importance. The importance in this representation is the qualitative data obtain from the qualitative case studies as cases were studied in detail. It is assumed that rural and urban populations in boarding and day schools would greatly inform the study. The richness of such perspectives is based on the factor that, influences that students in boarding schools experienced vary from those of the day schools students. The values and experiences that the participants provided 
differed markedly. Thus, the identified characteristics are expected to inform this research.

\subsubsection{Procedure to participants sampling}

The 21 participants for the study were selected from the two case study schools and the Ministry of Education (MOE).Importantly, however, the researcher needs to better understand the students of the two schools in order to give the researcher an opportunity to create a sampling frame (Comrad and Serling 2006).

In this study, selection was restricted to the students of Form 3 only in both case study schools. Limiting student participants to Form 3 only was based on a number of considerations. Firstly, there are currently themes of Citizenship Education in the Form three syllabus. Secondly, under the country's new reform initiatives, basic education ends at Form three; therefore this is the upper limit for all school-going children of Solomon Islands. Thirdly, mass elimination of students occurs in Form three after students have sat for the national examination.

A sample frame was used to identify the participants out of the total Form 3 students and is generalised as being representative of Form 3 students in the Solomon Islands and the students who have learnt Social Studies in secondary schools. The respondents were organized into focus groups and one-on-one interview groups. The cases are summarized as follows:

\subsubsection{Case study 1 samples}

In case 1, a rural school, a total of 10 respondents participated. Of these, six were students (three males and three females), three were teachers (two male and one female) and one was the principal. The Form 3 students were selected according to chosen criteria, deemed to be representative of the total enrolment of the class. To provide balance of opinion, to represent the views of rural males and females, and to avoid "bias", students were selected to allow gender equity (three male and three female). The gender equity representation formed one focus group. Rural and urban students display different behaviours. As a boarding school with students from around the province, selection was also representative of the region the students came from. 
The students' daily contact with things at home, their families and church beliefs, peers, and their socialisation with the social and physical environment have influenced how students see and judge things. Not only that, but even the food they eat, the clothes they wear, their living environment and after-school activities reflect the behaviours they display at school and outside of school. Therefore, selection of students in rural areas varied to a certain extent. However, the selection criteria was based on the following characteristics: students who were entrusted with some leadership responsibilities, (form captain, prefect, sports team captain, and religious group leader), active participation in organised school activities, and good behaviour among students. "Good" refers to caring, respect for fellow students, teachers, and school property. Selection of students for this study was done by the principal and Social Studies teachers.

\subsubsection{Case study 2 samples}

In case 2, the urban school, similar numbers and categories of respondents participated. Three male and three female students were selected and organised into one focus group. The characteristics guiding the selection of samples from the urban school related to the school's mixture of students from different ethnicities and backgrounds. In the Solomon Islands, there are more than 80 different languages and cultural groupings, spread among the 900 islands divided into nine provinces. The selection of the groups was made according to provincial representation. This was to ensure that each province was represented. The urban experience and influences are different from that of the rural school population. Therefore, significant to this selection criterion is the behaviour demonstrated among students of differing ethnic backgrounds (respect, caring, individual relationship etc). The responsibilities that students performed at school (form captain, prefect, and perform leadership role in various school organisations) were also important.

The other group of informants for this study were the teachers. It is important to note that teachers of both rural and urban schools were selected on the basis of their Social Studies teaching qualifications. In the case of teachers, gender equity was not so much of a concern because gender representation in secondary teaching is uneven. For 
instance, some schools only have female Social Studies teachers while some only have male teachers. The two respondents in case study 2 were both female social studies teachers.

The richness of the data is facilitated through questions that are constructed based on values of citizenship and Citizenship Education that teachers have taught in the Social Studies curriculum and the impact it had on students - most importantly, their perspectives of the values of Citizenship Education in teaching of Social Studies and the relevance to the Solomon Islands context. Teachers from both schools were represented - two teachers from the urban school and three teachers from the rural school - and the teacher sample of 5 represents the whole cohort of Social Studies teachers nationally. Lastly, for the 2 case study schools, both principals were also chosen to provide data for the study.

\subsubsection{Case study 3 sample}

Another group of two respondents was selected from the Ministry of Education of Solomon Islands (MOE) officials to participate in the study. One is an officer responsible for formal education policy initiatives and implementation of policy programmes for the formal education sector of Solomon Islands, which includes all secondary schools; the other is a senior curriculum officer responsible for the Social Studies curriculum development.

\subsection{Research Method}

"Research methods" refers to the logic that the researcher uses in conducting a study. These include "how research questions are stated, sampling strategy, data collection procedures and ways of structuring, analysing and interpreting data" (Conrad and Serling, 2006, p.377). The methods in qualitative research include interviewing; group discussion; direct observation; the analyses of artefacts, documents and cultural records; the use of visual materials; and personal experience (Denzin and Lincoln, 2008). 


\subsubsection{Interview assumptions}

Interview as explained Wilkinson and Birmingham, (2003) is not an easy option, because it involves a conversation between two people. The vital aspect for the interview is the way it obtains information about a topic or subject. "It has been said that while other instruments focus on the surface of the elements of what is happening, interviews give the researcher more of an insight into the meaning and significance of what is happening" (Wilkinson and Birmingham, 2003).

Interview is however, a useful tool in qualitative research. It is both a science and art. According to Rubin \& Rubin (2005), "in science, there are general rules and normative standards that should be followed... in arts, techniques are modified to reflect the individual style of the artist" (p.15). It is a method of collecting data employed both by quantitative and qualitative methodologies. In qualitative interviews the importance is in the depth, detail, and richness expected to be gained from the conversations. What Geertz citied in Rubin \& Rubin (2005) called "thick description" (p.13). The process requires the researcher to pay attention to the important information that the study wants to gain from the interview (Gillham, 2000).

Again, in qualitative interview, according to Rubin and Rubin (2005), interviews are extensions from the ordinary conversation which builds from the conversational skills that already exist. Such a bridge is pivotal in research as pre-understanding and experience of conversational partners (interviewer $\&$ interviewee) would ignite the free flow and unthreatening space in the interview. Interviews can be explained as conversational exchanges that involve exchanges of information among individuals and groups. It has a social nature that makes it more attractive for qualitative researchers to select as a research option (Ruane, 2005).

Ordinary conversations and interviews are similar, but there are also distinct differences. In interviews the discussions are more focused, in-depth, and detailed than ordinary conversations. In contrast, it is less balanced as the interviewer does most of the questioning and the informant does most of the answering (Rubin and Rubin, 2005). In trying to balance the conversation, the researcher in this study 
adapted the responsive interview model which is known to be more flexible in conversation, but more insightful.

\subsubsection{Responsive interviewing model}

According to Rubin and Rubin (2005) the Responsive interviewing model relies on the interpretative/constructionist philosophy. The significant factor for the choice is that the model recognises the people involved in the interview as having feelings, personal interests, and experiences. Such interview techniques are not expected to be neutral. However, what this project expected was who the informants were in terms of the interview. This is significant for this research, particularly, the context and participants who were involved in the discussions. The culture of the social environment, in this case Solomon Islands (cultural and religious affiliation), has a strong influence on how informants respond to interview questions.

According to Rubin and Rubin (2005) the style of interviews varies from person to person. This does not matter in responsive interviews. It depends on what style the researcher is more comfortable using and, importantly, how well the style is able to obtain rich data to inform the study. As noted," none of those stylistic variations are inherently right or wrong. What works is a style that makes the conversational partners comfortable" (Rubin and Rubin, 2005).

This study used a more gradual approach. An interview would start with the building of relationships among conversational partners and informal talks on non-related matters before getting into the formal discussions. This style required more time in order to get to know one another.

\subsubsection{Models of interview}

There are three models for interviews: the unstructured interview, the semi-structured interview, and the structured interview. The unstructured interview is very flexible but needs control by the interviewer and interviewee while the structured interview is more highly controlled by the interviewer with predetermined questions and order of questioning (Wilkinson and Birmingham, 2003). This study used the semi-structured interview approach to collect data. 


\subsubsection{Semi-structured interviews}

Semi-structured interview questions have less flexibility than unstructured interviews. The interviewer directs the interview closely as questions are predetermined but there is flexibility to allow the interviewee an opportunity to shape the flow of the information (Wilkinson and Birmingham, 2003). The semi-structured interview questions that were developed for this study by the researcher were viewed by the supervisor and were deemed appropriate.

\subsubsection{The Focus group interview}

In case studies, a focus group discussion is a useful tool for the researcher for several reasons. It is naturalistic because it offers an opportunity for constructing meaning among the participants giving them power to participate (Krueger and Casey, 2000). Interactions among participants, as claimed by Cohen (2003), lead to useful data outcomes. Similarly, the method allows the researcher to use group synergy to maximise, recall, and highlight the diversity of perspectives thereby providing a richer qualitative perspective (Anderson, 2002). In addition, focus group discussion creates a context in which participants are free to express their opinions and make judgments for themselves on the questions posed by the researcher. It is crucial to note that in case studies, proposed questions for focus groups must be carefully worded so that they appear genuinely naive about the topic (Yin, 2003). The role of the researcher is generally to facilitate discussions through directives, to encourage participants to express their opinions, and to ask carefully worded follow-up questions (Cohen, 2003).

Focus group discussions were held with the twelve students and five teachers using semi-structured and open-ended questions.

\subsubsection{Focus group interview procedure}

Before I conducted the interviews I visited the school and held talks with the principals both of whom were supportive. I explained the purpose of the study, who would be involved, what was needed, and the procedures involved. Both principals of case study schools gave me assurance that they would prepare the site and those who were to be involved before the interview. 
The first important factor I considered was the physical setting to host the meeting. In both schools, teacher interviews were conducted in the staff room. Student interviews were conducted in classrooms after all the other students had left school. The arrangement of the site and organisation of the context was done by the principal and myself. I adopted a Wilkinson and Birmingham (2003) procedure, pointing out that very formal settings where the interviewer sits in front facing the interviewees, can be confrontational and may intimidate the interviewee. Taking this advice into account, to put the parties (interviewer and interviewee) at ease, I arranged for the site to become less formal. This allowed the interviewer and the interviewee to sit alongside each other. The audio tape used for the discussion was placed discreetly, where it did not distract the interviewees.

In each case the first interview was with the principal of the school, followed by the Social Studies teachers, with the student focus group interviews third in line.

As a matter of respect and with regard to the Christian values of Solomon Island children, as well as tradition and higher protocol, the discussion was opened with a prayer by the interviewer. Following the prayer, consent forms were signed by participants. I then proceeded to welcome the participants and acknowledge them for being part of the research. Before the actual interview I asked introductory questions to get the attention of interviewees while slowly placing the recording device in position. I introduced myself before outlining the purpose of the research. In focus group discussions I posed questions and then waited for the participants to respond. This allowed them to think over the question before responding. I posed questions which were needed to direct some discussions. It was obvious that some respondents were very vocal and active and often dominated the discussion, leaving those who were slow to respond left out of the discussion. In such circumstances, I called the interviewee by name to respond. Similar procedures and techniques dominated the discussion until the end the session. At the end of the interview I thanked the interviewees again for their contribution. 


\subsubsection{One- on- one Interview}

For this study, the one-on-one interview has the following advantages. As explained in Bell (2006), the researcher can "easily follow up ideas, probe responses, and investigate motives and feelings from the interviewee" (p.157). Anderson (2002) noted that value that is placed on the individual subject, allows for in-depth analysis and pursuit of details geared to each respondent. The one-on-one interview enables the interviewee to describe and interpret his/her experience.

The one-on-one interview was used for the MOE officer, the curriculum officer and each of the two school principals, using a semi-structured format and open-ended questions.

\subsubsection{Procedure}

Before I actually conducted the interviews, I made arrangement to meet with the Under-Secretary of the Ministry of Education who is responsible for all research conducted in the MOE, and formal and non-formal schools in the Solomon Islands. I met with him on the $9^{\text {th }}$ of July and we discussed the research fieldwork. As someone who had held the positron for quite a while and had previously worked with similar academic research, he provided a support letter to endorse my research. I submitted the letters seeking permission with the endorsement letter from the Undersecretary. I followed up the letters with a visit a day after to check on the selected officers in the Ministry of Education on their approval. The officers gladly accepted the offer to participate in the study so we agreed on a date for the actual interviews. During that first contact period, I gave the formal consent forms and approval forms to the interviewees to read and upon acceptance, signings took place before the start of the actual interviews.

The first interview was with one officer in the Ministry of Education. The interview was conducted on the 12th of July 2008 starting at 10:30am and ending at 11:15am. The second interview was held with a Curriculum officer who was responsible for the Social Studies curriculum. The interview was conducted on the $13^{\text {th }}$ of July 2008 starting at 4: $30 \mathrm{pm}$ and ending at 5:30pm. The interviews were held in the participants' offices. I started each interview with some informal discussions outside 
of the study's topic. While we were talking, I set up the recording device and placed it between us as we were facing each other. When I knew that the interviewee was in the right mode to respond to the questions, I started the interview by introducing the research and explaining the purpose of the study.

I asked questions and allowed the interviewees to talk as freely as possible to answer them. I put in probes when necessary to keep the discussion going. I ended the interviews with words of appreciation and with a small gift for the participants.

Similar procedures were used with the remainder of the one-on-one interviewees, including the school principals. Most of the them had their own offices so it was easier to adopt the same procedures. The interview conducted with the urban principal was held on the $16^{\text {th }}$ of July 2008 at 11:00am to $12: 15 \mathrm{pm}$. For the rural school the one-on-one-interview was conducted on the $24^{\text {th }}$ of July from 12:00 noon to 1:30pm at the school in the Principal's office.

\subsection{Document Analysis}

Document analysis is another method of gathering information for the study. Document analysis has the potential to inform and structure the decisions which are made by people on a daily basis (May, 1997). The documents constituted the readings of social events, goals, purposes, and aims. It informs readers about the aspirations, requirements and intentions of the period which were referred to, describing ideas, places and social relationships (May, 1997).

There are different sources of documents which are relevant for research. Primary sources include historical documents, laws, declarations, and statutes (May, 1997). Other sources which are secondary to the first stated documents are people's accounts of incidents or periods in which they were involved.

For this study, the source of documents include the Education Act of Solomon Islands, Education policy statements and educational strategic plans, secondary School Social Studies curriculum documents, which includes the syllabus for Forms 1 -5 . The secondary sources of documents used in this study included journals written by Solomon Islanders on education and citizenship. 
The purpose of using the Document Analysis method in this research is to gain a fair understanding of the aims, objectives, purposes, goals, mission and vision of Education in the Solomon Islands. It is also to collect information relating to the study for the purpose of consolidating data gained from the interview method. It is also to provide the basis for critical analysis of the documents, general arguments about the issue of citizenship and Citizenship Education from public opinion by comparing views of respondents of the study with the documents, purposely, to justify the validity of the questions and statement of this project.

\subsection{Data recording}

A tape recorder was used to record the focus group discussions and one-on-one interviews. Burns (1994) suggested tape recording to be the best method as "raw material will remain for later studies while not taking notes enables the researcher to take part in conversations in a natural way" (p.284).

In this study I transcribed the recording from Pijin (a borrowed national language or lingua franca made from a variety of languages including English) to English. The scripts were analysed using certain coding systems and stored on the computer according to coded files, for easy analysis and access. Coding, according to Charm (cited in Ezzy, 2002), is a process of defining what the data are all about. It is an attempt to fix meaning, constructing a particular vision of the world that includes other possible viewpoints (Barbour, 2008).

In this study the coded identities are set as "sign posts" (Barbour, 2008). The sign posts assumed here are "indexes that represented some of the data and not merely a final argument about the meaning" (Seal, 1999, cited in Barbour, 1998. p.196). The codes were placed under themes for further analyses with other data received from the document analysis source.

\section{10 Data analysis techniques}

According to Wiersma (1995), in qualitative research data analysis begins soon after transcribed scripts are systematically recorded. The initial stage for such analysis is 
known as the preliminary data analysis (Grbich, 2007). The next analysis stage is post data analysis.

\subsubsection{Preliminary data analysis}

Preliminary data analysis involves checking and tracking of the data from information collected. The purpose is to find themes that form the base of the analysis. It gives the researcher clear direction. As Grbich (2007), points out, it will provide "deeper understanding of the values and meaning which lie therein" (p.25). The importance of this preliminary analysis is to highlight and identify emerging issues important for the study.

In the study's preliminary analysis I went through the interview recordings soon after the interviews were completed. This was to confirm the validity of the information. If information gathered was not sufficient to provide useful data I could have to returned to the site for further data collection. Early data analysis also provides clear systematic placement of coding under relevant themes.

\subsubsection{Post data analysis}

The post data analysis occurs after the preliminary analysis is completed. At this stage the reduction of data is more involved. In this stage, the researcher is more likely to have a fair idea of what he/she is looking for and what the "database contains in terms of issues that are being evident" (Grbich 2007. p.31). The data is then processed in the analysis using a coding process. The process identifies themes and concepts in the data through certain comparisons, categorisations, interpretations, descriptions and synthesis (Ezzy, 2002). The process is intended to create meaning out of the text data, examine codes for overlaps, and redundancy and collapsing the codes into broad themes. This is an inductive process of narrowing data into few themes (Creswell, 2001 citied in Creswell 2008).

In line with the coding guidelines suggested by (Cresswell, 2003 citied in Creswell 2008) the following coding steps were used: To obtain a sense of the whole picture, I read all transcripts and noted ideas as they came to mind. I chose one document, 
considered its meaning and wrote it down in words drawing a line to highlight its distinction. I began the process of coding by identifying text segments, placing a bracket around it and assigning a code word for it. The codes were grouped together into patterns to provide an answer to the question that are use in the field work.

\subsubsection{Content Analysis}

The "content analysis traditionally referred to the examination of written text" (Leavy, 2006, p.286). It is often used to study difference. For this study the main content of analysis was the transcribed scripts from the interviews. All the information providing details of the response were the contents that this analysis focused on. Other important texts considered and used to support the interviews were the secondary Social Studies syllabus, media news letters, journals about Solomon Islands' state of affairs, and education policies.

The process involved themes which were identified through information from the scripts. These themes were derived during the preliminary and post analysis stages. These themes were inducted and highlighted as headings for the categories. The categories were specific ideas, concepts and phrases.

\subsection{Ethical consideration}

Ethics, according to the Ninth New Collegiate Dictionary (1988, p.426 citied in Morris 2008. p. 2), indicates "what is good and bad and with moral duty and obligation." Three meanings are usually associated with the term "ethics". According to Newman and Brown (cited in Morries, 2008, p.2):

the first focuses on fundamental principles of moral behaviour that should apply, at least in theory to everyone. The second refers to principles of conduct developed by, and for, members of a particular profession. The third involves the systematic study of the beliefs people hold, and the behaviours they exhibit relevant to morality.

For this study, all three meanings are relevant and relate to ethical challenges found in the process of this research. For example, careful ethical consideration is required in order to carry out research on human subjects. Ethical consideration includes "paying 
attention to the way in which the research is presented to potential participants, the likely impact of taking part in the research, the effects of sampling strategies, engaging with the researcher and dissemination sessions" (Barbour, R. 2008. pp.78 79).

This research was subjected to the requirement of the Victoria University of Wellington Research Ethics Committee and followed the ethical guidelines, ethical protocols and processes of the Victoria University of Wellington. Next, each society has certain unique values that need to be carefully observed. People are bound by ethical regulations, designed to govern within well defined principles that are embedded on people's values. This conceptualisation relates to the meaning provided by Newman and Brown earlier in this section, stating that ethics is associated with moral behaviour, the beliefs people hold and the behaviours they exhibit. Therefore, to complement those requirements, this research had adhered to the following ethical considerations.

I ensured that the study did not cause harm to respondent participants. Prior to the study, approval was sought from appropriate authorities and institutions who were involved in the study, as well as the local communities. I ensured that the aims, objectives and guidelines of the study were thoroughly explained to the participants. I gained access and entry to the sites through pre-contact sessions. This accomplished what Becker (cited in Silverman, 2005, p. 125) advised researchers to take note of "When studying an organisation we are dependent on the whims of gate keepers. Such people will usually seek to limit what we can study assuring us that if we need to know more they can tell us about". This approach of building relationships was important to ensure that the participants knew me. In societies like Solomon Islands where traditional values are dominant, building relationships is an important factor to gain people's trust and acceptance. Further, it was necessary for the researcher to be briefed on local ethical requirements so that the study can be conducted under the school and local community's ethical standards.

As the researcher, I ensured that, throughout the duration of the study, care was taken at all times. I ensured that I was ethical with my research on respondents in participating schools and communities. 


\subsection{Summary}

Reiterating what has been covered in this chapter, the interpretative/constructivist paradigm which is used to inform this study is pivotal. For instance, the ethnographic approach used in this study has provided rich data from respondents who were selected to provide information about Citizenship Education in the Social Studies curriculum. The local culture observed here was that of the schools and education stakeholders. Secondly, using interview methods, involving semi-structured questions applied to focus group and one-on-one interviews have generated valuable rich data for this study. Thirdly, the qualitative analysis and approaches that were used have generated useful themes that informed the study and have answered the main questions explored in this study. 


\section{CHAPTER FOUR}

\section{INTERVIEW - DESCRIPTIONS AND FINDINGS}

\subsection{Introduction and overview}

In the previous chapter, I explained the methodologies and methods utilised for this study. This chapter provides the results and findings of the study from the interviews, focus groups, and one-on-one interviews. The findings are organised under themes derived from the main questions used for the fieldwork and form the main sections for this chapter. These include the definitions of citizenship and Citizenship Education; the values of Citizenship Education relevant to a Solomon Islands context; citizenship and the Social Studies curriculum of Solomon Islands; and barriers and recommendation to teaching citizenship values in the Social Studies curriculum. The chapter ends with a brief summary to re-iterate the main findings.

The interview findings in this chapter are presented thematically; the data gathered using the various interview techniques employed is recorded under major themes to form the main sections of the chapter. The sections are then further reduced to subthemes derived from sub-questions. The information provided in this chapter is best described as raw data. This information is then further compiled to form the assumed rich data for this study which is located in chapter five, consisting of post analysis and discussion discourses. Since this is raw data, the presentation of information may not be entirely consistent with English grammatical rules, but this is deemed appropriate in order to maintain the exactness of respondents' views. Also, as interviews were transcribed in "Pijin" English, (Pijin is a lingua franca made from a variety of languages including English) the language used as a national language in the Solomon Islands, presenting written scripts in raw form will maintain the rich meaning provided by the respondents.

Individual respondents are represented by codes and the descriptions of data from their interviews has been internalised using the simple coding shown in Table 3. In order to protect their anonymity and confidentiality, interviewees' names have been replaced with the codes shown. 
Table 3. Codes representing respondents.

\begin{tabular}{|l|l|}
\hline Interviewee & Code \\
\hline Education Officer & MOEF \\
\hline Curriculum Officer & MOEC \\
\hline High School Principal (urban) & HSUP \\
\hline High School Principal (rural) & HSRP \\
\hline High School Teacher (urban) & HSUT 1 \& 2 \\
\hline High School Teacher (rural) & HSRT 1, 2 \& 3 \\
\hline High School Student (urban) & HSSU 1, 2, 3, 4, 5 \& 6 \\
\hline High School Student (rural) & HSSR 1, 2, 3, 4, 5 \& 6 \\
\hline
\end{tabular}

\section{2 Defining Citizenship and Citizenship Education Concepts and Challenges}

Solomon Islands is a diverse country with over 80 different languages and cultural groupings. It is therefore likely that the definitions of the concepts "citizenship" and "Citizenship Education" may vary from person to person, depending on their cultural, geographical, and social status. This variety of perspectives is significant for this study, as differing views are considered to add enrichment to the findings.

\subsubsection{Conceptualising Citizenship}

What does it mean to be a citizen? Or, What is citizenship? The technical definition of citizenship is the formal identification of a person within a nation state through such means as identity cards or passports that imbue certain rights and responsibilities. Further, similar descriptions conceptualise citizenship as the status, rights, duties and responsibilities of individuals in their community or nation. Some definitions, as outlined in the literature chapter, view the concept as a defining feature, implying how people should behave. 
According to respondents of this study, citizenship is defined as an individual's membership within a community or country. For example, according to several respondents citizenship is defined variously as, "membership of a group identified through birth and for naturalised citizens, identification is by law" (HSUP); "affiliation people have with a particular country by birth (HSRP)"; "one's original place of birth including parents and relatives who are also part of the original place of birth" (HSUT1) Similarly other respondents asserted, "if my parents are from the Solomon Islands then I am a citizen of Solomon Islands" (HSUT 2); "I am a citizen of Solomon Islands because I am entitled to land ownership handed down from generation to generation by my ancestors ... to live in the land, freely rear the land, based on the recognition I have by birth" (HSRT 3).

Respondent teachers defined citizenship in terms of entitlement. According to one, citizenship is "an entitlement conferred in recognition of land ownership" (HSRT1). Expressing a similar view, another teacher viewed citizenship as "having full entitlement and ownership of traditional and cultural property, including land, historical sites, and natural resources" (HSRT2).

Respondent students conveyed similar responses and views. According to (HSUS3), "Citizenship is related to the individual's place of birth, including land ownership and demonstrated values". Similarly, other students defined citizenship as "people who are born in the Solomon Islands.... Recognition of something assumed by birth" (HSUS 1); "People who are born in the country are citizens of that country" (HSUS 5). Another student defined citizenship as "recognition conferred on individuals through tribe and family affiliation" (HSRS3).

\subsubsection{The rationale for Citizenship}

According to the two Ministry of Education respondents, citizenship is defined using two distinct knowledge types; traditional knowledge and modern knowledge. Traditional knowledge is described by the first respondent as "an essence in which form a peaceful co-existence and mutual relationship among people. How people relate to each other and accept each other through cultural values" (MOEF). In similar fashion, good citizenship was seen as, "people's responsibility to their own community and society and what they demonstrate that reflects their consciousness of 
the traditional custom, modern law and respect to institution is good citizenship" (MOEC ).

It is still very common in the Solomon Islands for people to be acknowledged and given recognition for displaying good behaviour, in preference to those individuals with modern academic qualifications, wealth, and/or social status. Two teachers confirmed this; "People are recognised among the community not because of power but through demonstration of acceptable attitudes and behaviours. Behaviours that reflect the custom, culture, and religion of the immediate setting" (HSUT1); "My attitude and behaviour indicate my status and the value I have among people" (HSRT1). Another teacher offered, "Who I am as a citizen is determined by my cultural consciousness of important values and living in harmony with each other" (HSRT1).

The demonstration and practice of cultural and religious values also show an individual's identity as a citizen. Such identity relates to the beliefs and values people practise. One respondent principal explained good citizenship as, "A person of the locality with exotic values displayed and recognised within the society and outside of the immediate society" (HSRP). This perception implies that "any value displayed in the immediate setting, contradictory to the shared values of a society, is unacceptable among the people and should not be tolerated" (HSRP).

Respondent students perceived good citizenship as "having the freedom and rights to participate in activities organised and conducted by cultural and religious institutions" (HSRS4). This idea was expressed by one student as something gained from the individual's position among people, "Individuals who freely partake in restricted ceremonies have certain rights and values that justify their right to participate" (HSRS2).

\subsubsection{Citizenship perspectives by modern rule of law}

The modern contemporary understanding of citizenship, according to MOEF, is that of a group of people or communities of people living together but having different cultures and religion. The unifying factor is the modern rule of law. "People of 
different cultures, religion, and status come to live together under the recognition of the modern law" (MOEF). HSUP expressed similar views, "People from different islands or different countries who are recognised by their right and freedom to live in the country of their origin or not of their origin." Another MOE respondent said, "People under this category do not have one common belief and way of life" (MOEC). This, he said, is a cause for great concern to the country today because people do not recognise others who also share similar entitlement or right to live and occupy the same geographical location. The recognition and unifying theme in this category is the modern rule of law (MOEC).

However, the challenge is that the modern implications of citizenship are new to people in the Solomon Islands. According to MOE respondents "People might be living together but they are from different islands and ethnic groupings" (MOEC); "People never realised that although they are different culturally and linguistically, they are unified by the modern rule of law. People's ignorance of the modern unifying system causes people not to understand each other and that causes problems" (MOEF).

This modern system has come into force despite Solomon Islanders lacking the knowledge to fully understand it. Therefore when people fail to relate to each other well, they break the law and the law punishes them (MOEF).

\subsubsection{Definition of Citizenship Education}

According to MOE staff, Citizenship Education is defined as the "teaching of citizenship values that aim to unify people through developing new relationships among people with diverse cultures. This is significant for modern contemporary societies and institutions" (MOEF). As one MOE respondent explained, the reason for such a definition is because "society is drastically changing due to modern influences and people are having different perceptions when looking and interpreting their surrounding world" (MOEC). He further expressed, "Citizenship Education is the provision of knowledge that educates people of right and honourable behaviours with responsibility; developing informed citizens who have the capacity or knowledge to 
judge based on moral values. This includes the teaching of right values that prepare students for their future".

According to one school principal, Citizenship Education is defined as "knowledge taught in schools that develops students to be good and active citizens" (HSUP). Further, he asserted that in developing good citizens "what is significant is the teaching of values that are culturally and religiously relevant to people's way of life" (HSUP). Another principal explained that "the values that stabilise families and communities are practised by elders, "big men", and recognised by society as morally relevant and important for our society" (HSRP). He went on to say that "in today's societies, developing students to become good citizens is quite difficult. The reason is because of the changes in behaviour and lifestyle found commonly among youths". Therefore, using the formal school system as the resource to disseminate citizenship knowledge, values, and skills is fundamentally important.

Similarly, one teacher explained Citizenship Education as "formal learning of the concepts of citizenship" (HSUT2). Another defined citizenship as the "teaching of values to conserve the environment, building relationships with people of differing cultures, and formal teaching of moral values" (HSRT2). One of the daunting issues unfolding in the Solomon Islands is the deliberate destruction of the physical environment by large-scale logging activities. The environment as a whole has not been well cared for, resulting in infertile gardening areas, contamination of drinking water and pollution of waters which people use for gathering food. One MOE respondent pointed out, "It is imperative to educate people about the values that create a safe and conducive environment for people to live and enjoy" (MOEF).

\subsubsection{The rationale for Citizenship Education}

Citizenship Education comprises the teaching of values in both the formal and nonformal settings. The underlying significance, as one teacher posited, is to "educate students to become good citizens" (HSUT1). This is due to concern over behaviour that undermines the modern rule of law, cultural values, and religious values. In Solomon Islands social environment, the changing nature of behaviour among youths 
can be seen after the recent social unrest. A teacher expressed this sad truth as," the respect which was commonly practised in the country has declined to a devastating degree and has detrimentally affected the structures of all sectors of the society" (HSUT2).

The teaching of values in citizenship is seen as an important way forward for social stability. As one teacher said, "The teaching of values in education is important as they serve different purposes to human development" (HSRT 3). He strongly asserted, "If we need to solve our current problems we have to introduce citizenship values in our school systems. The values I prefer are the teaching of virtues" (HSRT 3). He assumes these would solve the issues of disrespect, immorality, dishonesty, hatred, and instability which currently disrupt the society.

In such a chaotic environment, the teaching of Citizenship Education based on moral values seems vital. However, there are mixed reactions from advocates and commentators on the teaching of moral values, with some ascertaining them to be contradictory to democratic values. On the other hand, as expressed by one teacher, the change of behaviour has cost the country significantly (HSUT1). As one student respondent expressed, "The need to teach moral values is essential for Solomon Islands society" (HSUS2). Other student responses also indicate support for the notion that values necessary for Solomon Islands be included in the teaching and learning about character traits (HSUS6). One student "recommended values are values that develop us to be good citizens" (HSUS1).

\subsection{The extent to which values are covered in the Social Studies curriculum}

This section presents the interviewees' perceptions on the extent to which the Social Studies curriculum has covered the values that reflect the characteristics of citizenship or how to be a good citizen. It is generally understood that citizenship is part of Social Studies. Therefore, values of citizenship concepts are believed to be, or should be, included in the current Social Studies curriculum. 


\subsubsection{Values of citizenship covered in the Social Studies curriculum}

It is evident that some citizenship concepts are taught in the current Social Studies curriculum of Solomon Islands. One urban high school teacher stated, "There are values covered in citizenship. However, the consistent teaching of concepts and practise of the values are lacking" (HSUT). This, he assumed, is a hindrance to teaching of important citizenship knowledge, values, and skills because what is stipulated in the syllabus is not covered. Another teacher points out that much of what is covered in the Social Studies curriculum is "on the content of historical events and not so much on values of critical judgement of current events" (HSRT). Similarly, another teacher noted that "values that are assumed important include decision making on conflicts, family units, communities, government, leadership, and the physical environment" (HSRT3). This is also supported by similar claims made by one MOE respondent who supported the claim that citizenship is adequately covered in the current themes in the Social Studies curriculum of Solomon Islands (MOEC), pointing out, "There is content concerning the teaching about the people, environment and how to keep the environment, including topics of over exploitation of natural resources and environment."

One rural teacher stated strongly, "We should have no excuse as the associated problems of human activities were evident. Young people have seen the reality of forest and land destruction by logging activities and other human exploitation of the environment because it affects them. However, if they fail to recognise the effects, they themselves have to be blamed" (HSRT1). Such responses indicate the perception that what represents important concepts of citizenship has not been fully utilised in the Social Studies curriculum.

\subsubsection{The preferred values for Citizenship Education}

Regarding the values that are preferred for Citizenship Education in the Solomon Islands, there was unanimous support to promote the value of virtues and moral values in schools. According to the MOE respondents, the values that once united people and created a safe and enabling society are disappearing. One said, "People 
have seen the rise of social problems, violence, disunity among different ethnic groups, and disrespect to leaders, family values, cultural values, church rules, and the rule of law" (MOEC). Consequently, MOE respondents view the promoting in schools system virtues and moral values as highly desirable. However, despite this, respondents still had some reservations on where the values may be derived from. Some insisted that virtues and moral values have to "derive from the common values of the local cultures and the religious values common to people in the Solomon Islands". These include, "respect for one another, culture and religion, the environment, and people's background" (MOEF).

Another MOE respondent argued that the values that engage students to be responsible citizens are vital. These include "moral values, which hold respect, honesty, and teaching of relationships ... (and would) unify people of different ethnicities as Solomon Islands is diverse geographically, culturally and religiously" (MOEC). MOEF argued in favour of moral citizenship values, because this is what he sees as missing, resulting in numerous problems the country has witnessed and experienced. This respondent stressed that the value of respect is drifting away.

Teacher respondents expressed similar views, stating that the teaching of values is important for citizenship teaching in the Solomon Islands. For example, "The teaching of values on virtues would solve the current behavioural problems and improve our current social chaos" (HSUT1). The preferred common values include respect, honesty, care, accountability, and ethical leadership. A teacher explained that, "the cultural values and religious values are important teaching components for Solomon Islands formal education system in order to control people's behaviours because the rules that govern people are no longer respected" (HSRT2).

The social environment of Solomon Islands is very complex, making unification attempts difficult, particularly, when numerous issues undermine the people's or state's capacity to satisfactorily solve everybody's needs. In such a complex environment, the only unifying instrument is the "inculcating of common values like respect, honesty, care, accountability, and ethical practice" (HSRT3). These values are part of the cultural values and religious teachings that are common to people. 
They are "important values that are relevant to Solomon Islands nowadays situation" (HSRT2).

Another teacher commented, "They are moral values that existed and continue to exist among people....despite the challenges the country has gone through" (HSUT1). The teaching of moral values is considered relevant to people's way of life. The reason, as one principal claimed, is that "people of the Solomon Islands value their cultural norms and religious principles immensely and with pride" (HSRP).

It could be argued that the reason that Solomon Islands experiences so many social problems is because people are becoming reluctant to uphold their cultural values. As one principal expressed it, "We think that sending students to schools will develop them to become good citizens. But this is not happening. If those traditional values can be promoted in the school systems it would help to address our current volatile situation" (HSUP).

It is important to teach moral values to young people to help them cope with the current volatile environment. For example, according to various literatures, teaching about honesty, respect, ethical and truthful practices, and acting with a clear conscience are important values that need to be taught in schools. In addition teaching about faithfulness, building relationship, showing moral behaviours and living according to the principal of justice are significant values as well.

However, increasingly young people consider only skills and knowledge of subjects that would give them formal careers as important. As expressed by one student, "Learning about moral values does not give me knowledge to have a formal employment in the future" (HSUS 4). Such a perspective is very worrying in the Solomon Islands. One MOE officer lamented, "It is a drastic setback to Solomon Islands to note that young people nowadays see the teaching of good values as something primitive or that of the village" (MOEC). Similarly, one respondent noted that "city schools are currently in a state where the control of student behaviour is becoming very difficult ...rules to govern students are not respected ... (there is a) drastic decline in moral behaviours and students are challenging the school authorities 
about their rights. Parents in urban areas are finding it difficult to control their children" (HSUP).

Teachers supported this view, stressing that, "moral values are central to Citizenship Education. Introducing moral values in schools will impact student's behaviours and change their perceptions regarding education"

(HSUT1). As expressed by another teacher, "Students equate education with formal employment and take for granted having moral behaviours, never considering moral values as respect, care, honesty as fundamental to unity which is the prerequisite for a safer living environment" (HSUT2), However, it is encouraging to see that some students retained the respect for the traditional values - in contrast to the students perspectives presented above.

According to students, the relationships people have with each other and the respect rendered towards people and elders are the marks of a good citizen. This includes "demonstration of respect and promotion of mutual relationship" (HSUS2). One student describes a good and active citizen as someone who "demonstrates leadership qualities among people, shows moral character to those they lead, shows good respect to others in the community" (HSUS6). In a similar vein, another student expressed that, "moral values such as respect to one another, public properties, and the rule of law is significant for Solomon Islands" (HSUS5).

\subsubsection{Values considered for Solomon Islands Citizenship Education}

The values considered are those that enhance the skills and knowledge of students to relate well with others among the diverse population. According to respondents, the following knowledge, values, and skills are considered appropriate for Solomon Islands.

\subsubsection{Rights}

According to respondents, selection of values has to be carefully considered. Some values, although important, contradict people's culture and customs. One such value is that of individual rights and freedom. 
One MOE respondent observed, "The teaching of rights may be conflicting to our cultural and religious values. In urban areas in our country it is becoming confusing for parents in that the conventions of rights of the child are based on individualism while the cultural understanding of rights is collective. Maybe people who support individualism do not know how to handle their child and think the law will correct their child. That is not true, therefore we should be careful when we try to preach the concept of rights" (MOEF).

One principal stated that city schools are currently in a state where control of student behaviour is becoming very difficult, claiming "The rules to govern students are not respected; drastic decline in moral behaviours and students are challenging the school authorities about their rights. Parents in urban areas are finding it very difficult to control their children" (HSUP). Another principal expressed, "The concept of rights is now becoming dominant among people and institutions. However, right is related to respect. It is not individual rights. The promotion of rights that do not go with respect should not be promoted in schools. If rights are to be included in schools it should be done with clear guidance. Rights should be considered, promoted and taught with responsibility" (HSRP).

Such confusion indicates that teaching of rights in the formal Social Studies curriculum of the Solomon Islands is important in order to clarify people's misconceptions. However, it must be guided carefully and not left to happen in an unconsidered fashion.

\subsubsection{Responsibility}

Responsibility implies being accountable for yourself and the community's actions, towards yourself, others, and the environment. According to one MOE respondent, teaching the value of responsibility is important to ensure that people display respect to others and the environment. The values that are considered important for our current society are the teaching of duties and responsibilities which include values of respect, honesty, and others disposition. One principal pointed out that "the teaching of duties and responsibilities is relevant for Solomon Islands because the cultures of the country are founded on the same responsibility" (MOEF). For example, each 
person is responsible for his own life and others' lives. The term used in the Solomon Islands for that understanding is the "wontok" system. The word in English literally means "speak one language." However, "wontok" represents not just the spoken language; it also means having concern for people of the immediate family, extended family, community, ethnic group, and even the immediate country when you are abroad. It contains an understanding of shared responsibility, obligation, and care.

Again, the values practiced are founded on duties that people render and the responsibility that one is entrusted to carry out in order that people may provide trust, confidence, and respect. In this regard "students need to be inculcated with values that develop them to become responsible beings" (MOEF). Supportive statements from principals have confirmed that "trust, confidence and respect for each other are lacking in the Solomon Islands societies" (HSRP). The problem, as pointed out by MOEF, is that "people do not demonstrate accountability to themselves, their neighbours, institutions, and the environment. No wonder...we have a behaviour problem, causing our towns to be dirty, damaging and destroying of property, and no good stewardship of the environment" (MOEF).

Furthermore, as expressed by another MOE respondent, “...people’s responsibility to their own community and abiding under the jurisdiction of the law is good citizenship" (MOEC). One principal expressed that "teaching of duties and responsibilities would certainly uphold the values of culture including reinforcing the communal framework" (HSUP). According to the other principal's view, "Each person is responsible for his life and others and such values are found on the works that people do and their accountability to the work they entrusted to perform" (RHSP).

\subsubsection{Respect}

The value of respect refers to treating others with consideration and regard. Respect is an important value in the Solomon Islands. According to the arguments provided by MOE respondents, respect is "part of all cultures in the Solomon Islands. Therefore, any consideration of values for teaching in our school system has to derive from the values that are common to people in the Solomon Islands" (MOEC., MOEF). 
The significance of respect underpins "valuing oneself and one another, their culture and religion, the environment and people's background. These Values will cause people to respect and understand each other, their neighbours and how the social environment lives together peacefully" (MOEF). Values of citizenship as stated already exist; "It is just a matter of putting it in the school system that is required, believing that it will work. Initially, how to put it in the curriculum and how to enforce it to teachers are what responsible authorities should try to resolve" MOEF). MOE staff advocated a moral values based approach to CE.

\subsubsection{Care}

The value of care concerns having a sense of caring for both yourself and others and acting with compassion. The direct opposite of the value of care is what is often practiced in the Solomon Islands today. According to teacher (HSRT2), Solomon Islands now has a major problem, "Young people do not have any regard for themselves and others, or the state institutions, including the rule of law, property, and their neighbours" (HSRT 2). In other words, as HSRP points out, "Having a caring attitude for people from national and local institutions is upholding good attitudes". Therefore, "educating students with values from our culture and religion is an enabling factor to developing students with understanding of care, unity, and practicing character that demonstrates care" (HSUT2).

\subsubsection{Tolerance and Understanding}

The values of tolerance and understanding concern the acceptance of people's differences and being aware of others. According to a MOE respondent, "Changes in our societies have caused people not to understand each other. Many things have come as a force whereby Solomon Islanders lack the knowledge to understand and fail to relate to each other, (then) they break the law and the law punishes them" (MOEF). On a similar note, MOEC observed that societies of our times are struggling to cope with the issues and find the means to create an environment where people can live together peacefully without any stress. He further expressed, "Since we are in the process of rebuilding Solomon Islands, it is timely to develop a curriculum that promotes values to maintain the unity of the nation". 


\subsubsection{Ethics and Honesty}

Honesty is having an ability to be truthful, to be sincere about finding and expression the truth, and requiring truth from others. According to MOE staff, the "teaching of the value honesty is very critical to today's Solomon Islands society" (MOEC). One principal noted, "The structure of local and national institutions are violated by dishonesty and then justifying the act as relevant to cultural values or "wontok system", when in fact it is a deliberate violation of modern structures" (HSUP). One teacher said, "People who are honest in their dealings with people should act as role models" (HSRT3). People must be role models in their own settings. One MOE staff member expressed, "In order for our societies to live up to the standard of honesty and ethical behaviour, it is very important to promote honesty and ethical values in formal systems as well as at home and in the communities as part of the Citizenship Education programme" (MOEC).

\subsubsection{Cooperation}

The value of cooperation is about working together to achieve a common goal, providing support to others, and engaging in peaceful resolution in conflicts. In a diverse country like Solomon Islands the need to emphasise unity and other values which create cooperation to build relationships is vital (HSRT3). "I think cultural values which create respect and unity should be included" (HSUT1). Teaching the value of cooperation develops mutual relationships "...the values offer peaceful coexistence. People relate to each other, accept each other through certain common values. People live together who have different cultures and religion but living together under the modern rule of law is not enough. People never realised that although they are different they are one people under the modern rule of law" (MOEF). It requires teaching the value of cooperation to unite people of different cultures and ethnicity.

\subsection{The extent to which the Social Studies curriculum is successful in teaching Citizenship Education}

Citizenship tradition is part of Social Studies. It is considered a component of the Social Studies curriculum. In essence, what is taught as citizenship fits well with the 
values of Social Studies as both disciplines teach values focusing on the physical and social environment. However, the question of how successfully it is executed and learnt is what matters here. There are issues that limit the effective delivery of the concepts. This theme provides data, based on interviewees' responses, indicating why the teaching of citizenship is successful or unsuccessful. It includes understanding the social environment, the values, and the current new-found behaviours.

\subsubsection{The teaching of Citizenship Education in the Social Studies curriculum}

According to respondents, for the following reasons the teaching of citizenship and Citizenship Education concepts are not entirely successful in the Social Studies curriculum.

Firstly, citizenship values are taught but not successfully acquired and practiced because students use the knowledge for different purposes. One rural teacher stated emphatically: the problems we see are too obvious, thus, it is important that we do something about it. If nothing is done we will face a bigger problem than what is experienced today.

Secondly, the important concepts of citizenship have not been taught in the curriculum. One teacher admitted that she has never taught citizenship values in her eight years of teaching Social Studies, saying "I haven't taught values that develop students' behaviours. I know that contents that I teach relate to the topics of developing citizens to having understood the important of social and physical environment, but I never felt an urging to go further than teaching the content for examination only" (HUST1).

Another teacher stated, "The teaching of values of citizenship does not seem important to me to spend much time on.... to teach values that do not help students in their quest to gain academic knowledge for formal employment makes no sense" (HSRT1).

At the receiving end most students claimed that what they have received in the classroom is important knowledge. As one urban student stated, "I think teachers have 
taught what we need to receive during lessons. What else do we need? We learn about families, community, environment, and government in form three" (HSRS2).

When students were asked about whether they have applied the knowledge or values, most students said "no", with one saying, "We learn about Social Studies topic but have not applied the knowledge outside of the classroom" (HSRS 2). Another said, "In form one I learn about the topic 'My family, our community, our nation"” (HSRS1). Another student said "I learned about the environment, the effects of logging on the environment in from two" (HSUS2). Still another claimed, "I learned about the government but for me to apply the concept in real situations is what is lacking" (HSUS5). One blamed teachers for not teaching them the values stating, "Maybe the teachers have failed to teach about the good values" (HSRS6). Most students claimed that the good values they had acquired were received from home.

The urban principal's remarks indicated that he felt that the current curriculum content of Social Studies is not sufficient to provide students with knowledge that develops them to become good and active citizens. He preferred a change to the current content of teaching citizenship in Social Studies to include values of morality, virtue, respect, and identity and relational unity for a healthy living environment (HSUP).

\subsubsection{Challenges to teaching citizenship concepts in the Social Studies curriculum}

The unsuccessful teaching of values in the Social Studies curriculum is also because the citizenship knowledge and concepts taught are not reflective of what happens in the current society. According to respondent principals, "teaching about social realities is an important technique. Particularly, relating the problems encountered in the society to those that are taught in the curriculum" (HUSP). That approach might develop values that shape students to become good citizens. Considering the examination system this principal asserted, "It is the one distorting factor that hinders the teaching of good values from the syllabus." The other principal stated, "Teaching about moral values doesn't seem important for teachers and students. However, there is need for teaching on moral values in order to have quality leaders and good leadership (HSRP). 
There are several challenges to teaching the values of citizenship. The first, according to MOEF, is the challenge to review the curriculum. The current Social Studies curriculum which contains the teaching of citizenship is already overloaded. The second challenge concerns teacher training. If review is undertaken in the curriculum the teacher training curriculum must also be reviewed. Third, is the challenge associated with the national examination system. Many of the respondents regard the examination system as an obstacle to the effective teaching of values.

MOEC argued that "values are not covered because the emphasis is on examinationrelated content only. What is considered important is the examination". For example, "Students learn about family, communities, environmental conservation, leadership, and politics as knowledge for examination and not as provision to indulge understanding of care, unity and character traits that develop students' behaviour" (MOEF). According to MOEF, "The covering in detail of what is stated in the syllabus is lacking, although teaching strategies are provided in the syllabus".

HSUP argues that the provisions to teach values that develop students to become good citizens are included in the school curriculum, but teachers do not fully utilise the teaching methods provided in the syllabus to teach the concepts. HSUP suggests

If we have problems with teaching good values in schools why do we not have awareness programmes for students in the media, public campaigns, and education for people in our communities? There is no difficulty in teaching the relevant values. If we can provide useful advice to our children daily in our families or communities, why do we not do the same with values that develop students to become good citizens?

Teachers pointed out that the discipline of students in schools has declined because of human rights philosophies. As one teacher expressed, "The rights are contradicting the values of discipline for children. When we adopted modern strategies of discipline, problems emerged. Comparative reflections show that Solomon Islands in the past was a very safe environment. The reason is because people practiced the values of culture which include respect for one another" (HSUT1).

\subsubsection{Teaching on moral values}

There was unanimous support from all respondents to promote virtues and moral values in the communities, schools, and country on the whole. Interviewees felt that 
the values that once united people, and produced a safe society are disappearing. People have seen the increase of social problems, violence, disunity among different ethnic groups, and disrespect to leaders, family values, cultural values, church rules, and the rule of law. This caused interviewees to view the promoting of virtue and moral values as highly desirable. However, interviewees wondered where among the diverse cultures, the values will derive from. One MOE respondent expressed that values of virtue and morality have to "derive from the common values of the local cultures and the religious values common to people in the Solomon Islands" (MOEF) which include, "respect for one another, their culture and religion, the environment and people's backgrounds" (MOEF). Alternatively, one principal preferred developing citizenship on values based on the social problems (HSRP).

The values that respondents considered most important are the ones that encourage students to be responsible citizens. This includes "moral values which hold respect, honesty, and teaching of relationships" (MOEF \& MOEC). This, he assumes, may unify people of different ethnicities as in the Solomon Islands which are geographically, culturally, and religiously diverse. This respondent favours Citizenship Education based on moral values, arguing that it is because this is missing that the country has experienced many problems. He noted, "The value of respect is drifting away. There is no feeling of care and respect .... It is very important for students to have the opportunity to learn about good values when they are still young despite the perception that young people nowadays see the teaching of good values as something primitive or that of the village" (MOEC).

Responding to questions on values covered in the Social Studies curriculum, one teacher stated, "Never at any time do I teach values that develop students to be good citizens. The approach used as stated is ...teaching from the content on what I expect to come in the exam. The content includes ...teaching on events such of wars, or conflicts, their timeline and major historical events" (HSUT1).

There are "teaching methods provided to teach the themes relevant to capture expected value outcomes but rarely do we use the themes in teaching Social Studies as stipulated in the syllabus" (HRST2).

According to another teacher, 
I teach about families and community relationship in form one, environment in form two, role of leaders and government in form three. However, those are just knowledge to learn in preparation for examination. They are not there to shape students for their future. It is also evident that the national examinations often determine the topics that will be covered from the Social Studies syllabus (HSUT1)

With regards to the significance of teaching citizenship, this respondent pointed out that it is fundamental for social stability and continues to stress Citizenship Education as the foundation of a stable society. It is not a new concept for Solomon Islands. It has been practised as a source of social and political stability to communities. As another teacher expressed, "Our traditional societies have been teaching and educating our younger folks about community structures, leadership roles, relationships, and moral values from custom for respect for one another ever since. Such knowledge-based value in education is referred to as Citizenship Education (HSRT3).

Another teacher pointed out that Solomon Islands does not need "'quick fix" alternatives to address its current problems" (HSRT1). "There needs to be proper policies put in place to direct the initiative for Citizenship Education. However, promoting the concept in the formal education system should be the priority. It is not too late to engage in constructing a curriculum that considers the teaching of values from our culture and religion" (HSRT3). This is important knowledge to Solomon Islands compared to others such as rights and freedom which are also part of Citizenship Education, but requires careful consideration before it can be incorporated.

What is viewed as important values according to teacher respondents are moral values, cultural and religious virtues, valuing others, and relationships. Other values are also recognised as important; however, they have to be carefully considered before being approved for teaching. For example, regarding teaching the values of rights, one teacher claimed, "We have to be very conscious about how we teach about the international conventions of human rights and freedom. Our country has been plagued with violence in the name of right of ownership to land and properties, freedom to exercising individual's power to challenge authorities. That has turn into violence" (HSRT2). In a similar argument HSRT1 favoured teaching of values that are accepted by the society, "The rights coming from outside must be selected. Otherwise it will distort the social structures of society" (HSRT2). 


\subsubsection{Current social realities}

Current behaviour commonly found in the Solomon Islands shows that there is no holistic development of students. Children are educated without instilling the important values needed to sustain their moral growth. Furthermore, current social behaviours have contradicted what is taught in the Social Studies curriculum. As one teacher pointed out, "We claim that we are people embedded with good values but we are not. The behaviour we see around does not reflect what we learned in schools, at home, or in our Christian upbringing" (HSUT1). Supporting statements for the above argument were also provided by a MOE staff member who believes that "there is corruption everywhere, conflicts everywhere, and so people see themselves as different from each other" (MOEF).

Student respondents themselves identified reasons why the values of citizenship need to be added to the formal school curriculum. For example, "Just look around. We have seen and experienced a lot of problems in our school. Students burn down school buildings, vandalise and destroy school property. We learn about the environment but we don't apply the knowledge in real situations" (HSRS1). Another claimed, "We learned about people from different places but there are ethnic differences among students. We students see ourselves as different although we are from one school" (HSRS2). In similar fashion, another student claimed "the knowledge I receive from Social Studies does not inculcate any value, for me to value others. The values I apply in my every day socialisation were received from home. Thus, for me, the teaching of Social Studies is not so successful” (HSRS4).

In terms of including values of Citizenship Education in the school curriculum students expressed the following: "The behaviours found around our communities contradict what is taught and learned at school. Therefore, it is a good idea to promote good values in schools" (HSUS5). According to another student, "Teaching about good values helps stabilise the society" (HSUS2). Another acknowledged that "promotion of good values in the school system strengthens good relations among people of the society" (HSUS4). Similar views were expressed by another student who stated that "it is important to add values that promote unity and respect for one another in the Social Studies curriculum" (HSUS1). Another student asserted, "Values that teach us to obey school rules, to unify ourselves and to promote the value of 
respect are needed in our schools" (HSRS1). A teacher recommended values that give knowledge about living together with other people. He argued, "We need to see us as one people. I think teaching about moral values is necessary at this stage, because the respect once practised in our societies has now vanished (HSRS5).

\subsection{Barriers and recommendations for Citizenship Education in the Social Studies curriculum}

This theme provides a description of the findings in relation to the challenges or problems considered to be an obstacle to the effective teaching of citizenship knowledge, values, and skills. The focus is on what causes the challenges as well as the importance of adequately covering citizenship values in the Solomon Islands. Included in the findings are arguments portraying Social Studies as outlasting its usefulness, the practising teachers' attitudes toward work, the domination of the examination system in education, the overloaded nature of the Social Studies curriculum, the limited teaching resources available, and the curriculum pedagogies currently used and future recommendations

\subsubsection{Out of date curriculum}

The first barrier to teaching citizenship in the Social Studies curriculum is that it is out of date in nature when compared to the social, political, economic, and environmental changes that are occurring in Solomon Islands society today. According to the MOE staff respondents, the citizenship topics, themes, and the content in the curriculum are all out of date. This is evidenced by when it had been developed - the late 1980s for Forms One to Three, and the mid 1990s for Forms Four and Five (MOEC). A review of the Social Studies curriculum found that the knowledge and values taught were influenced by the situations and challenges of much earlier period (Solomon Islands Social Studies Syllabus form 1-5, 1988).

According to the respondents, those challenges have little relevance to today's situations. For instance, a Principal made this statement, "I think if we consider our 
social environment nowadays, the currently used Social Studies curriculum has outlived its usefulness. Considering what is happening in society, some of the topics and teaching content no longer relate to nowadays social realities. Worst still, there is no proper teaching of relevant values that are needed" (HSUP).

In education what is transferred as knowledge, values, and skills is fundamental to learning. However, in the case of Solomon Islands "effective teaching and learning does not occur much because teachers have failed to teach the values that are provided from the syllabus" (HSUP). From what has been seen and experienced, "Education stakeholders are blaming each other for not doing enough to solve behavioural problems commonly found in schools. Some say it should be the addressed by the government through dictating rights policies. Nowadays, the government is throwing it back to schools and assuming that the schools will solve the problems" (MOEF).

Stakeholders are blaming each other without considering the effects of Social Studies which of course has some impact on the problems seen all around. One student claimed, "Teaching is dominated by things from outside" (HSUS4). One teacher suggested that what is important is "teachers need to be aware of the issues in the topic and how students can solve the issues" (HSRT2). "We are so engrossed with the pedagogy and engrossed in the content in the syllabus, without looking at the effects of the current issues and devising strategies to solve the problems" (MOEF).

\subsubsection{Teachers}

In order for values to be covered in Social Studies, MOEF claimed "teachers should do their part in teaching and performing the role of parents. School students are no longer in a village setting whereby grandparents and parents are responsible for child rearing. The environment has changed, and parents rely very much on schools and in particular the teachers to teach, care for, and nurture the students". In today's environment teachers take the place of parents: "In the everyday life of students, for the 280 days they are in school, they are outside of their parents' control" (MOEDF). One teacher noted, "Our role as teachers is to ensure that topics are adequately covered. However, we often fail to move beyond normal teaching strategies whereby we can further advance our teaching to cover values that change students' behaviours" (HSRT3).

One teacher respondent acknowledged, "The good values that are displayed by students have been developed and acquired from home" (HSUT1). In response to 
what teachers said, an MOE respondent noted, "The responsibility of the school is more than just teaching for the memorising of facts, but rather an obligation for ensuring that students are embedded with values that can support them when they exit into the world beyond" (MOEF).

Learning is not a one-dimensional process. It involves the transfer of knowledge through many different mediums of instruction. One is through observation. "Students learn from actions seen in the classroom and school environment, what their teachers and others do. The teachers or school leaders' attitudes can be very influential to school students" (HSUP). "The behaviours and attitudes displayed by teachers have significant bearing on students' behaviours - for good or for bad. Teachers often believe in this saying 'do what I say but not what I do"' (HSRP).

In the Solomon Islands, as expressed by a principal, "You sometimes cannot distinguish a teacher from a "masta liu" (unemployed youth on the streets)" (HSUP). That is "devastating to the ideal of developing students to be role models. Teachers should be role models. They are not restricted only to teaching knowledge from the curriculum, but should set a standard that students can follow" (HSUP). Teachers on the other hand argued, "We have very limited time to teach all the topics in the curriculum" (HSUT1). In addition, "There is no time to teach important values beside those that have already been included in the Social Studies curriculum. If we assign extra time for additional themes or values in teaching, it will disrupt teachers' timetables" (HSRT2).

There are lots of complaints from the Solomon Islands public about student behaviour at schools these days and people have blamed teachers for not doing enough to develop and improve students' behaviours. According to one teacher, "I am sad to say that although we teachers have done our best, it is the system and the situation that has failed the students, with the implication being that many students in the Solomon Islands believe that academic subjects and knowledge are central to education" (HSRT3).

\subsubsection{Examination system}

The examination system involves a system of selective periodic advancement, involving both internal and external assessment of selected students. It is a dominant factor in "developing countries" where resources to provide access for all to modern education is scarce. In the Solomon Islands, the education system is based on the periodic examination system. 
One MOE respondent staff said, "It is a distorting factor that hinders the teaching of good values from the syllabus" (MOEF). A principal claimed that when it comes to the teaching of moral values, although they seem important, teachers deliberately choose the content required for examination (HSRP). This creates a huge problem, because the kind of misbehaviours commonly found in schools certainly indicate a need to "teach the quality of knowledge and values to improve life and behaviours of students" (HSUT1). In many ways, the examination system undermines the acquisition of useful knowledge.

As one High School principal puts it, the examination system is seen as a catalyst to the backdrop of teaching appropriate values. For example, the curriculum may seem attractive and appropriate, however, the examination system determines the knowledge and values that are transmitted to students (HSRP). As one teacher pointed out, it is no wonder "the outcome of what has been taught in classrooms was reaped. We have corruption everywhere, undemocratic elections and political instability in most government institutions" (HSRT 3). According to another principal, "Firstly, there is no proper teaching of good values, although some are included. Secondly, the teaching of historical wars and conflict only focuses on the content, and not inflicting a kind of knowledge that shows a devastating end. Teaching of topics on issues and events should show both sides" (HUSP). This was illustrated by a MOE staff member, "Teaching about retaliation as commonly found from historical wars can influence students to do likewise. If there is any change to the examination system, a new monitoring and assessment system has to be put in place. There needs to be a system put in place that would assess students' moral values and behaviour in schools and should take similar weight as academic assessment" (MOEF). "the assessment on students behaviours I hope will encourage teachers to adequately cover values that are important for good citizenship" (HSUT1). Students also need to know how different cultures and ethnicities came to live together; "How can we live together and how can we respect each others' culture and differences when we see ourselves differently" (HSRP).

From these responses then, it can be seen that respondents place significant blame for the failure of the education system to effectively teach values that influence behaviour positively on the constraints of the examination system. 


\subsubsection{Overloading of Social Studies Curriculum}

The current Social Studies curriculum is a combination of many disciplines, including history, sociology, geography, anthropology, social sciences, and citizenship. It seems the "subject is already overloaded" (MOEF). According to the teachers, "We cannot adequately cover themes and appropriate values of citizenship in the Social Studies curriculum because there are too many other teaching topics and themes" (HUST1). Another claimed, "The teaching of values in citizenship is covered but not so much on the expected outcome as stated in the syllabus" (HSRT2). The problem seems to be that "We teach about the environment, family relationships and community awareness but this knowledge is for different purposes. Not to develop students to become good citizens" (HUST2).

HSUT1 added, "I have taught the concepts but I cannot fully utilise the teaching methods to achieve the aims of the topic because it has very limited time and there are too many things to cover". Furthermore, "What I have in mind for given topics is stirred by different objectives. My deliberate goal is for students to understand the concepts for examination purposes and not so much on what will become of students in their future. ...we pick only topics that we consider appropriate from among the many topics givens" (HSRT3).

Another teacher further expressed; "I know that teaching useful knowledge can be done, but considering the time constraints, and the quantity of knowledge that has to be covered, it is unrealistic for students given their priority need of preparation for external assessments...Teaching about social realities is an important technique. Particularly, relating the problems encountered in the society by those to whom the curriculum is taught. But how can we teach about social realities when the government doesn't recognise its value?" (HSRT1).

According to the rural teachers' discussion group, "There has been no indication and reflection from students that Social Studies teaching and the knowledge underpinning citizenship have been covered. All I know is that good values demonstrated by students are learned from home" (HSRT1); "If some good values are demonstrated at 
school or outside the school, it is not from what they learn at school. It is from what is learned from home and the knowledge and values received from the teaching of culture and Christian religion" (HSRT2); "The values are covered but not as adequately as what the aims and goals of the syllabus expect. Much of the teaching is done on content only for what is expected to be assessed" (HSUT1).

\subsubsection{Teaching Resources}

Another daunting challenge is that of school resources as indicated by the following responses: "Here in rural schools we only have one copy of the student text book and one copy of a teacher's guide book. All of the time is spent writing notes on the blackboard for students to copy. In such situations, teachers cannot do much but focus on content required for internal assessment" (HSRT1); "Often teachers from different subject areas teach Social Studies because of lack of specialist teachers. That is one hindrance to teaching values in Social Studies" (HRST2); "In terms of ensuring that the values are adequately covered, a teacher from a different discipline or even an untrained Social Studies teacher cannot do very much for the students (HSRT2); As argued by one teacher, "The examination system which is the predominant driver for the assessment and evaluation of student's works needs consideration. There needs to be a system in place that assesses students' moral values and behaviour in schools and gives a similar weighting to academic assessment" (HSUT1). This would then encourage teachers to adequately cover values that are important for good citizenship.

\subsubsection{Curriculum pedagogy}

According to MOEC, "If proper coverage of citizenship values is required it has to be approached in a practical way. Firstly, teaching and learning has to be done concretely. It must be transferred concretely through dramatisation, guest speakers, student excursions and more emphasis on demonstration" $\mathrm{He}$ further argued, "teaching on real situations is fundamental to effective teaching and learning because what students see and experience is reality to them"

One teacher noted, "Teaching by demonstration is a useful method for Solomon Islands. This is because that is how we are trained in our cultural context. When we try to use conventional education approaches it affects our students' learning" 
(HSRT3). Another teacher asserted, "If we try to promote useful concepts as citizenship we have to involve concrete approaches. For the general public, it should be promoted through the media and public campaigns. In schools it should be transmitted in class through demonstration, dramatisation, fieldwork projects, excursions and guest speakers" (HSUT1). Another teacher claimed that "students taking note in class, which is the dominant approach in the Solomon Islands, is detrimental to students learning...that is the reason why students are passive in class" (HSUT2).

\subsection{Summary}

In reiterating the results and findings provided in this chapter, it is important to note that the data provided here represents the views collated from respondents of the three cases studies used to gather the data for this study. They were gathered at different times and in different geographical locations. The questions used were similar for every case and group of interviewees, providing the rich data for this study. The results and findings in this chapter are based only on the raw data gathered from the interviews. According to the respondents, the concept of citizenship is difficult when it is compared with more conventional concepts. In essence, it appears that one person's understanding of who they are in relation to their environment is different from that of another person living in another environment. Having this information is significant for this study. 


\section{CHAPTER FIVE \\ ANALYSES AND DISCUSSION \\ PART 1: CITIZENSHIP AND CITIZENSHIP EDUCATION}

\subsection{Introduction and Overview}

In the previous chapter, I have provided description of the findings of the study. This chapter will present the analysis of the data collected from the respondents and discusses the findings. The data was analysed under four themes and each is presented in this chapter. The first is the analysis relating to the theme of citizenship status. The second is moral and social virtues of citizenship, the third is active Citizenship Education model and the fourth are stakeholders' perceptions on curriculum policies and pedagogies recommended for Citizenship Education in the formal curriculum of Solomon Islands. This chapter ends with a brief conclusion, summarising the analysis and discussion.

In this analysis, the data is discussed under four broad themes. These themes are intended to create meanings that show evidence of what this study is exploring. Theme one, focuses specifically on stakeholders' perceptions of whether or not 
Citizenship Education is included or can be included in the formal Social Studies curriculum of high schools in the Solomon Islands. Further, the theme identifies the data on whether or not the concepts on rights, responsibility, national identity and sense of belonging are possible for inclusion in the Citizenship Education curriculum for Solomon Islands. The second theme involves the analysis and discussions based on stakeholders' perceptions of the value of teaching moral values and social virtues in Citizenship Education for Solomon Islands social environments. The third theme focuses on teaching approaches, strategies and teaching pedagogies relevant to teaching concepts of citizenship. The fourth theme discusses views regarding respondents' recommendations on the adequate knowledge, values, skills approach and strategies required to teach citizenship concepts in the formal education system of Solomon Islanders. This includes analysis of and discussions about models domains and methods considered to be contextual and relevant to Solomon Islands.

\subsection{Conceptualising Citizenship as status}

The literature regarding citizenship and Citizenship Education, according to Hebert and Sears (n.d); Khamsi, Torney-Purta, Schwille (2002); Kerr and Cleaver, (2006), have linked citizenship with status. Status is someone's legal standing with the state and community. As discussed in the literature review in Chapter Two, the concept of status includes the rights of individuals and groups, their responsibilities as well as their identity and sense of belonging. However, this understanding of citizenship varies from country to country and from culture to culture.

According to the findings described in this study, respondents have related citizenship status to land ownership, geographical and ethnic group affiliation and affiliation to a kin group and genealogy. Three important types of status have emerged. The first, is entitlement (right) through land ownership, the second is the demonstrated responsibility and leadership roles, which involve demonstrated behaviour and the disposition of character. The third is the citizen's recognition of personal identity implanted by birth, parents and next of kin or tribe. An obvious question to ask is, what relevance do these types of status have on the teaching of Citizenship Education in the Solomon Islands formal Social Studies curriculum? Do we have to formulate citizenship policies based on peoples' interpretation on rights? These themes sought to analyse data and discuss findings that answer these questions. 


\subsubsection{Citizenship Education on rights}

The concept of citizenship has been defined in the literature and by the respondents in this study. This leads us to now consider how this concept may be practically taught to future generations of Solomon Islanders through Citizenship Education and which aspect of the various definitions of citizenship should be incorporated into such Citizenship Education.

As stated, citizenship is closely related to the teaching of individual rights and the freedom of participation. This can be justified through the frameworks adopted for the building of democratic states. According to the literature, citizens are those who understand their rights and legal status in a state and amongst people. These rights include the right to association and participation in local and state institutions, freedom of election and free elections, and the right to peaceful protest (Gilbert, 2004). Those rights and other similar descriptions on rights has become the subject of much debates among citizens as societies have begin to fully engage in the development and practice of Citizenship Education in the formal education system.

\subsubsection{Solomon Islands Education stakeholders' opinion on incorporating teaching of rights in Citizenship Education.}

According to the findings of this study, rights are defined by Solomon Islanders as the entitlements that are held by individuals due to certain attachment to the culture or customs of a group of people, including land and resource ownership. Having such entitlements is not a deliberate choice as expressed by MOEC but a position one has acquired through birth. It is about who a person is among fellow tribesmen and others around them. That right requires a person to diligently carry out his/her duties and responsibilities as expected by society. These duties involve the obligations that serve the interest of everyone in the community, ensuring that others are not negatively affected.

People in such contexts have to be considerate and ethical in dealing with people they influence, in order to create respect among each other, unity and stability among people of different backgrounds. In this interpretation, people may have rights or entitlements but they also have a greater responsibility to perform for the collective good. It is an obligatory and participatory right which does not involve individualism but reflects sound communal underpinnings. According to teachers' views, it is not interpreted as a right conferred for legal recognition by the state, but a right conferred along hereditary lines which carry with it cultural obligations. Rightful status is handed down by ancestors from generation to generation through birth, for the 
purpose of establishing and maintaining good mutual relations between people. However, this specific cultural view of citizenship rights as accompanied by responsibilities does not always match the definition in the literature.

Based on this indigenous understanding of rights, the question remains as to whether rights should taught as part of the Citizenship Education curriculum. The respondents in the study expressed that rights should not be taught in the teaching of citizenship concepts. However, if it is to be incorporated as a teaching theme, it must not be done randomly. Rather, the values on rights have to be selected according to concepts that does not discriminate against other peoples' culture.

\subsubsection{Opposing views}

However, the specific cultural view of citizenship rights as being accompanied by responsibilities does not always match the definition in the literature. To compare the above definitions with that of the literature, one could see some obvious mismatch. For example, according to Herberts and Sears (n.d), Citizenship Education concerns the teaching of rights including freedom of speech and expression, to private interest groups and association, to freely seek political office, and the right to social security. Such interpretation contradicts Solomon Islanders' perspective on rights. The rights and freedom of individuals in the Solomon Islands is based on entitlements and the restricted association of people to cultural or ethnic groups. Such a narrow conception by Solomon Islanders on rights has caused serious unresolved consequences for the citizens of the country. These consequences include criminal and illegal activities such as illegal settlement in the form of the right or freedom to live and participate in economic activities, forced eviction of people from the lands and properties they acquired through legal means and ethnic conflicts because of strong ethnic affiliation.

According to one Principal respondent "teaching of rights need to be considered seriously, as there are several protest, in the form of rights that appears violent, resulting in mass distraction to the social, economic, physical and political environment" (HSUP). Similar thoughts were expressed by one MOE staff member who caution that:

If the teaching of rights are to be included in the formal curriculum, it should be selected or leave it for a later stage in children's learning, when they are mature enough to analyses the knowledge on rights to fit his/her context (MOEF).

Referring to indigenous interpretation on rights according Solomon Islanders, the individual's power and authority, to freely exert power is restricted. The practicing of individual rights can only occur through certain compromise between the individual 
and the family, tribe and culture on which norms and values are constructed to guide and harmonise people.

According to Western liberal thinkers the rights and freedom of participation in the affairs of the state include activities such as voting, the right and freedom of membership and association to institutions and individuals among the state (Heater 1999). In contrast, the concept of the rights of an individual in the Solomon Islands is founded on the idea of personal and group accountability to each other and their community. This concept extends to the areas of land ownership, cultural group membership, leadership and relationships.

Consequently, it is importance to reveal such contrast in perspective to firstly, to find areas in the teaching of rights that are adequate to Solomon Islands. Secondly, to give education stake holders a variety of opinion to develop Citizenship Education that reflects the social reality.

\subsubsection{The rationale for the teaching of rights}

The respondents of this study made imperative claims that serious critical consideration might be given to the conceptualisation of rights from the Western liberal ideological perspective. For instance, one Principal expressed that the drastic decline in moral behaviour from students in schools in the Solomon Islands was the resulting effect of the promotion of individual rights by civil society groups. The assumption was based on current student disrespect to school authorities. Students claimed that they have the rights to exert their will freely despite the school rules and regulations (HSUP). This is becoming problematic not only to schools but to the local community as the vertical and horizontal offering of respect once shared at all levels of society has diminished. Most student respondents and in particular in the rural area responded that they have limited knowledge of the concepts of rights. As claimed by two rural students,

I don't know what is right and freedom. All I know is the right I have over the land and properties own by my family and tribe (HSRS 3). I can only do what my parents tells me to do. I can not go beyond their advise (HSRS 1) 
Similar claims by respondent Principals have expressed that rights have differing meanings to different people. Therefore, the teaching of rights requires proper planning and guidance. This planning and guidance must reflect the contextual understanding of people. One Principal argued for rights to be taught but with guidance. He expressed that:

The teaching of rights without the teaching of respect should not be encouraged in schools. Both has to go together or if rights and freedom are to be included it should be done with clear guidance. Rights should be considered than promoted. Right have to be taught with responsibility. Every thing that are recommended and promoted on rights need to be selected (HSRP).

Claims expressed by one MOE staff member have pointed out why the teaching of rights is complicated and difficult. As he explained,

In human right based education, children have the right to education. If the government fail to put the child in school, should we take the government to court? In situations like the Solomon Islands whereby children are victimised by the government's inability to provide education for all children that question cannot be answered (MOEF).

Consequently, the teaching of rights to citizens has to be approached with cautions, especially with regards to the teaching of rights in the school system to young people.

Further, there are revelations that the teaching of rights needs to be carefully considered and should not be left to those outside the Solomon Islands to carry out. According to one teacher respondent, "in a country where more than 80 cultural groupings exist, initiating values on rights in the formal school system needs careful consideration as people might misinterpret the concept (HSRT 3) . For example, findings in this study have revealed that people narrowly interpret rights as the freedom to choose or decide, to act, to partake, to perform in activities and to own without interference from any person or authority. Such understandings contradicts cultural perspectives held by previous generations and directly challenges the understanding that children are supposed to respect their parents, teachers, or elderly people without question. Another teacher expressed her concern about teaching rights in the formal curriculum, stating that: 
We should be very careful about the teaching of rights because it will conflict with cultural and religious values. (HSRT2).

Respondents have shown obvious case scenarios where parents have challenged school authorities because the school sent their children home for failing to comply with children's school fee payments. Parents claimed the right of the child to education even if they fail to meet the school obligation. One teacher respondent further blamed responsible authorities for failing to pave the way in educating people about the values and principles of rights and freedom in a democracy (HSUT 1). The conflicting issues at the heart of this are, on one hand are "rights" and on the other hand are cultural values of parent relationship and reciprocity. The fact as noted was, conventions on rights have emphasised individualism whereas in the traditional Solomon Islands society individualism is not peoples way of life. Children are part of the family from birth until death and remain a member of the family from generation to generation. In similar arguments, MOEF pointed out in his opinion that Western parents did not know how to handle their children and they thought that the law will correct the child. He claimed that this is not true and it is the family's responsibility to correct and teach the child. He suggested that:

\footnotetext{
We are not ready for the teaching of Citizenship Education based on rights because there are a lot of misunderstanding on rights. Therefore we have to be very careful when we develop a curriculum for citizenship (MOEF).
}

Another attributing factor noted from respondents on teaching about rights in the formal high school curriculum of Solomon Islands is its invaluable knowledge necessary for children to learn in order to change children's perception and correct the currently held perceptions of rights. The truth as claimed by respondents is that $\mathrm{CE}$ and the idea of rights has not been introduced in the formal curriculum. People have only heard of the concepts of rights from civil society movements and other institutions who are involved in the promotion of individual rights. In this case, people lack the proper knowledge and understanding of the values of rights. According to respondents it is important to teach about democratic rights and the freedom of participation. However, it requires careful consideration and judgements, particularly, on concepts relevant to peoples understanding. As noted by one MOE staff member, for any attempt to promote rights based education, the knowledge, 
values and skills need to be carefully selected (MOEF). The assumption was based on the differences between the understanding of rights conventionally and the understanding of rights in the local culture.

Attempting to offer appropriate and contextual frameworks for the inculcation of values of rights and freedom in conservative traditional situations such as that of this study context will create unprecedented challenges. Hence, there is a need for careful effort to construct the Citizenship Education concept, knowledge, skills and values regarding rights for this curriculum. It must be relevant to the local and global context. Respondents acknowledged by that teaching about rights needs careful consideration and is important and worthwhile for the Solomon Islands.

Having Citizenship Education based on rights and freedom as advocated by the liberals may be conflicting to the local cultural understanding of rights. In order for the interpretation of rights to be meaningful among people of the Solomon Islands, it has to incorporated for teaching in the formal curriculum. Importantly, the content based on rights that is to be incorporated in the Citizenship Education for Solomon Islands has to be selected to match the peoples' understanding of rights.

\subsubsection{Citizenship Education on Duties and Responsibilities}

This theme now leads to an analysis of the data and discusses the findings on the teaching of citizenship based on the status underpinning people's duties and responsibilities.

In democratic states, citizenship is both a right and responsibility that cannot go unfulfilled. A person becomes a member of the state by birth or by being naturalised which carries a set of rights and responsibilities that is expected by the state on subjects (Gilbert, 2004). The fundamentals of duties and responsibilities focus on participating in the affairs of the state to protect and safe guard the national wealth which includes, human, economic and natural resources, to respect the law and constitution of the country, to respect the rights and freedom of others. It also includes mutual cooperation in the interest of solidarity and to support and raise children by giving them a true meaning of good citizenship. 


\subsubsection{Respondents' view on the concept of responsibility in the Solomon Islands}

The respondents in this study have stated that the citizen's responsibility is based on mutual relationships. This mutual obligation is a common bond shared among family (nuclear \& extended), community and the larger society groupings. Such relationships are based on a mutual understanding of common values and a respect based on cultural and religious rules. For example, individuals reciprocate their loyalty to local institutions because the same volume is reciprocated to them. One of the principal said:

Responsibility is a mutual relationship that is based on peaceful co-existence among community members. People relate well to each other and accept each other because of careful observation of common values. This include display of good character, respect for others and the environment, upholding the cultural and religious values (HSUP).

In such a status, what is required from individuals is to perform their responsibilities by demonstrating the value of care for one another, their neighbours and the environment. Fulfilling such obligations demonstrates a mark of good citizenship. The status of responsibility on the other hand according to western interpretations includes people's participation in local and national activities such as elections in the form of voting and participating in election campaigns. This also includes active participation in state and community activities and faithfully carrying out obligations that are expected by the state for its members.

For this study, Solomon Islanders interpreted responsibility in a more complex form. According to them, responsibility meant more than just participating in state or local community obligations. It implied an absolute form of engagement or commitment that each person has which should not be left unfulfilled. This included local communal works, responding promptly to family or tribe obligations, as equal distribution of wealth or resources and reciprocity, building mutual relationships and trust among people and demonstrating moral behaviours discreetly.

Consequently, such an interpretation not only contradicts the interpretation approached conventionally, but has created another new behaviour. The duty and 
responsibility that people have for each other or community now have to be compensated in cash money. This behaviour has influenced the informal and formal structures of the society causing people to offer labour only when cash payment is promised to be received at the end of the activity.

The challenge is that people see the state as their source of protection and have the assumption that the state will provide for all their needs in response to the full allegiance they offer to the state. This is obvious in the Solomon Islands where people are often seen and heard pressurising the government through their elected representative for school fees, church feasting, bride price, funeral obligations and other family and community obligation. However, when the Solomon Islands government support was not forthcoming, people became discouraged and resorted to violence to show their grievances to the government.

Some advocates of Citizenship Education have argued that the teaching of duties and responsibility that promote the giving of allegiance or showing respect to people and the state is minimal in teaching citizenship. (Abdullar, 2008). However, for this study, findings have shown that the teaching of duties and responsibilities is necessary for Solomon Islanders, particularly, to educate students about their responsibility to the family, school, local community and the nation. One teacher respondent claimed " it is the only way forward for stability in our nation" (HSRT 3).

\subsubsection{Rationale for teaching duties and responsibility}

According to the findings, people commonly relate themselves with their place of birth and ethnic group. Such a relationship determines social security, labour, power, wealth and stability and have emerge from peoples demonstration of responsibility. According to one teacher respondent "If someone is born in a particular geographical location one has a secured future for such reason that there is land to rear and cultivate for food, shelter and wealth (HSRT 3). When people have a mutual relationship based on trust they are secure, socially, economically and politically. The purpose of such assumptions is that peoples' live are built around each other. In such instances, people are for each other in all circumstance regardless of their status. One MOE staff member explained this as; 
People that share common beliefs and culture relate well with each other. The acceptance built around each other have cause people to live in harmony with each other (MOEF)

This study relates the teaching of citizenship for duties and responsibility with the maximal category because of its value and relevance to the Solomon Islands context. One MOE staff clarified that for students to be responsible citizens, they needed to be given education that would foster responsibility and care. Citizens that demonstrated values of care for themselves and their neighbours. Such important values were identified as missing. As pointed out by MOEC:

People did not show responsibility to each other the institution and the environment. That is why we have a behaviour problem, which causes our towns to be dirty, damaging and destroying of properties and no good stewardship to the environment.

Good and active citizens as expressed by MOEF is some one who carries out their duties and responsibilities diligently ensuring that their obligations are one to another, family, and community is fulfilled. This includes providing support for relatives or neighbours who are in need and help in community works. Building relationships with people around him/her, attending to family and community obligations and demonstrating active leadership responsibility are also necessary. This is aligned to the argument that the values of education for Citizenship have to consider the values that democratic communities adopted, emphasising "the practise of democratic decision making in which these values are given practical effects" (Gilbert, 2004, p.142)

According to the findings of this study, the duty and responsibility of a citizen is to serve the community through showing act of good behaviour towards others, ethical practice, ability to build relationship among people and showing leadership values (HUSP). It is an obligatory and participatory practice which does not involve individualism but reflects sound communal underpinnings (MOEF). According to the respondents the idea is to include the citizenship concept in the formal curriculum of Solomon Islands is a positive step forward for national stability. 


\subsubsection{Citizenship Education on National identity}

Identity in the Solomon Islands context means "ones existential foundation" (Gegeo, 2001 p. 2). This identity is conferred through individual's geographical and physical location. Such identification denotes the power of ownership of land, wealth and authority a citizen holds as recognised by people, among people and the society from where one is originated. It is an unquestioned position based on genealogy and marriage, from which one may speak on important issues without being challenged about identity (Gegeo, 2001)

\subsubsection{People's understanding of Identity}

According to this study, people consider land and their place of birth as their identity. Their conceptualisation of citizenship cannot be explained further than their personal relationship and attachment to land and family. However, such recognition is only attributed to people affiliating with a particular tribe or those who share the same dialect, or specific ethnicity. This means that people see themselves differently from each other and only attach themselves to their tribe not to the nation or to the state. This is in fact a critical challenge for stability in the country. For example, one Principal explained a citizen as "someone who is entitlement to live in the land through recognition by birth and by custom" (HSPU). A similar, judgment on identity is also expressed by a teacher, who pointed out that "a citizen is a person who is connected to local customs or culture including parents and relatives who also are part of that original setting (HSUT 1). One teacher expressed a citizen as a person who has full entitlement of ownership of traditional or cultural properties. That includes, land, historical sites and natural resources (HSRT2). Another teacher expressed it as,

The acceptance of a person to live among people in a given society, by law. Custom or culture is granted in recognition of an individual for land ownership and active participation in development activities (HSRT3)

This is problematic in modern democratic societies where people of different backgrounds and cultures come to live together and are recognised by the state to have share one common identity. In countries like the Solomon Islands where stability has been destroyed by ethnic conflicts, corruptions in the form of nepotism 
and discrimination among different ethnic grouping is overwhelming and the teaching of values to unite people is eminent.

According to one MOE staff member who claimed "People of the Solomon Islands have failed to recognise individual or group identity along national consciousness because people do not feel any effect of being part of a nation" (MOEC). People's wealth and survival, their attachment and affiliation to land, family, tribe and religion have sustained their livelihood. Therefore, the identity of citizens is based on the bonds of kinship with the tribe which relate to land ownership and wealth. In this case, shared language and ties to ancestral land, along with Christianity as argued by Dinnen, (2008) constitute the basis for individual identities and allegiance over abstract notions of citizenship or membership of the modern state.

\subsubsection{Issues of diversity}

The lack of national consciousness among people of different ethnicity has created division among people. Such an issue has caused problems to shared national identity which should set the base for national unity. There is no feeling of nationalism among people, although politically, people claim that they are Solomon Islanders. One principal have pointed out, "the feeling of oneness can only be seen during national events and regional sport events. When the flag is raised and the national anthem is played in a different country" (HSUP).

Sanga and Walker (2005) state the relationship amongst island groups, ethnic communities, and economic groups are clearly separated. National sovereignty as a united nation is at stake. It is obvious that "the animosities are likely to compound and may take another form including the formation of more autonomous political and economic entities, breakaway movements and further social unrest (Sanga and Walker, 2005. p. 18). If that happens it will be a problem. The Solomon Islands is heading towards an inevitable separation of people. This could be easily solved if there were better policies and educational programs to empower and enlighten people to recognize the existence of values among people locally, nationally, and internationally. 


\subsubsection{Why is teaching for National Identity important?}

Issues and challenges in national identity have caused respondents to give their support for themes concerning national identity to be include in Citizenship Education in the Solomon Islands curriculum. As one student stated, "I think teaching on values that develop us to honour our country is important" (HSRS 2). Another student expressed, “we don't respect any thing that belongs to the government because the government fails to support us (HSUS, 1). Similar claims are supported by teacher respondents who stated that the teaching of topics that develop students to be good citizens recognizing themselves as people of the Solomon Islands is important”.

\subsubsection{Citizenship Education on Sense of belonging or social cohesion}

The sense of belonging to a state is a unique challenge for Solomon Islands. The assessment reported by the United Nation on Solomon Islands have identified the scattered sense of national unity as one threatening factor to Solomon Islands social and physical environment (Pollard, 2005). Solidarity is the key to bringing social cohesion. It is found that "the wider the scope of solidarity (extent to different things) the more cohesion-forming it will be" (Matrai, 2002 p.89)

\subsubsection{The rational for Sense of Belonging}

Solidarity has been lacking in the Solomon Islands. Such weakness of relationships have cause major social problems. One obvious factor was expressed by one rural teacher who stated,

Young people today careless about who they are, properties of the state, communities and other people. Just look around, they burn school buildings, vandalised properties and distract school programs (HSRT 3). This was stem from the lack teaching students about relationship and solidarity as people of one nation (HSRT 3)

Such challenges have caused the people of the Solomon Islands to see building mutual relationship as an enabling factor for shared sense of national unity and identity, a factor which is missing among students nowadays (HSUP).

The Solomon Islands is divided politically, economically, culturally, religiously, and geographically. Therefore, "mechanisms that will provide some understanding that 
Solomon Islands as a nation that made up of thousands of islands, more than eighty cultural groupings and languages is critically important" HSUP.

\subsubsection{Values Calumniating sense of belonging}

According to respondents, both MOE staff support the teaching of moral values such as respect and tolerance in the formal education curriculum system. This could lead to having strong shared sense of belonging. As one MOE staff member have claimed,

\footnotetext{
Teaching about respect and care is an enabling factor that can influence younger people to love and respect their country and its people. Having a concern to the state and its institution does not necessarily mean singing the national anthem, raising flags only but more on having the moral values that unite people for national solidarity (MOEF).
}

\subsubsection{The importance of teaching sense of belonging}

The sense of belonging is a moral decision people in a society have chosen to have and to practice. It may be viewed as not a deliberate choice but what the society needs for its people. Young people are taught to respect and take pride in themselves, their community and their tribe. This strengthens, shapes and sustains the society. It is a tool that provides safety, prosperity, guidance, survival and empowerment. However, in today's reality, as Sanga and Walker, (2005) noted, such values are drifting away from the expectations of the society. People are continuously confronted with new conflicts over land, sea, business, women, status and with one another. In such circumstances, where conflict is dominant, countries have initiated strategies that they hoped would assimilate the focus of people to a sense of belonging to their society or nation. In the Solomon Islands, respondents suggested for schools to take a major role in the education of younger generations in the values of unity, tolerance and building relationships with one another and the state.

The underlying limitation as one teacher pointed out is that there is no effective means to develop a strong link with people and the state in order that people may have a sense of belonging to Solomon Islands (HSUP). The State and non Government Organisations have initiated programmes that aimed at drawing peoples attention to value where they belong but those initiatives seems meaningless to people. Overall, respondents expressed values of citizenship, based on sense of belonging as and enabling factor for stability and unity among people and their communities, particularly, among youths. Such challenges have caused people of the Solomon Islands to see building mutual relationship as an enabling factor for shared 
sense of national unity and identity, a factor which have been missing among students nowadays HSUP.

\section{3. Citizenship as moral imperatives}

Having analysed and discussed values of citizenship status, as perceived by respondents of this study, this section now analyses and discusses moral and social virtues. The focus is on why the teaching of moral and social virtues is important in Citizenship Education.

\section{3. 1. The rationale - moral values and social virtues}

Citizenship Education on moral values and social virtues is part of the whole concept of citizenship. The concepts are promoted in the education system to imbed certain kinds of knowledge and values that develop children to become good citizens. One central purpose is to develop student's awareness of the value of moral behaviour. This study's definition of moral values and social virtues is that moral value refers to the code of conduct put forward by society and is accepted by individuals. For social virtues, they are values deriving from local cultures and Christian religion. This includes the teaching of good manners, politeness, courtesy, good habits and behaviours. This section provides the discussions on respondents' perspective of the value of including both themes in the formal curriculum system.

One respondent Principal argued that, "moral behaviour is an imperative substance for a stable society" (HSRP). Similar view was expressed by another Principal who claimed that education could be meaningless if people who acquire the new knowledge in education lack moral behaviours to sustain good practice of knowledge. As he questioned,

\footnotetext{
How can one build relationship with one another and institution when the values demonstrated come in conflict with the values we trying to instil in student? Without moral values we cannot unite people. Through respect people can relate well with others (HSUP).
}

However, considering other advocators of Citizenship Education the concept on moral values by far has often being contested. In New Zealand as claimed by Barker, (2008) what might constitute the values such as morality is still argued. Such values maybe identified as, "honesty, reliability, respect for others, respect for the law, tolerance, fairness, caring or compassion non-sexism and non-racism (p.52)." Competing conceptions find these knowledge-based values in Citizenship Education to be inadequate to the challenges of educating a democratic citizen (Westheimer \& Kahne, 2004).

Conversely, what is adequate for Solomon islands according to respondents developing a framework on moral values and social virtues common to people is an imperative step forward. Considering, the social, political, economic upheavals in the country, a review of the formal curriculum to include moral values is a significant 
step that the Solomon Islands should seriously consider. For example, in the period of 1998 to 2003, Solomon Islands have gone through a period of turmoil. An outsider researcher expressed this turmoil as being:

...gripped by a progressively debilitating internal crises that manifest itself in series lawlessness... the breakdown of essential government services, closer of major commercial enterprises... due to armed conflicts between armed militia from two ethnic groupings and in its later stages, into a process of instrumentalisation of disorder whereby criminality become a key political instrument (Demnen, 2008).

Hence, it is through such circumstances, where social structures are affected that respondents see it necessary to reform the structures of the society. Therefore, respondents claimed that teaching of social virtues and moral values is assumed adequate if integrated in the social studies curriculum. The significance for such reform is purposely to solve shortcomings which distort the unity of people and the country.

\subsubsection{Citizenship Education on moral values}

Moral values are components of Citizenship Education. For Solomon Islands, developing a framework on moral values for Citizenship Education is essential. According to MOEF, in order for Solomon Islands to revitalize its chaotic situation, learning themes that target behaviours of young people is necessary; the teaching of moral values is believed to be an avenue for empowering and reforming youth's behaviours and attitudes. He argued that moral values should take a central position in the formal education of Solomon islands. This is aligned to what the former Director of the curriculum Centre stated in the media,

I believe teaching positive behaviours, attitudes and values can help to prevent these negative outcomes. As a country, we can only take one step forward to address some of the pressing problems, it is vital that we correct some of the mistakes. We must not let down our young people, particularly the school children who seem to be vulnerable. We must ensure that our children succeed, to have knowledge, the skills, the attitudes and the values to lead a happy and successful life. We certainly want our school children to get on well with others and have friends; to do well at school and achieve to their potential and to contribute positively to society both for their own benefit and for the good of society (Rodi, 2008). 
Similarly, assertive comparison made by MOEF, claim that no value is more significant non other than the values deriving from the common values of the local culture and religious values. A framework constituting respect for one another from differing cultures, understanding each other on the basis of difference and building relationship is vital for rebuilding Solomon Islands. MOEC see the teaching of such values as enabling paradigms to instil moral values that engage students to be responsible citizens. As he expressed:

Values that I considered important is that which develop respect among people those values have to derive from cultural and church values. Respected which I mean here is critical conscious about cultural values and church values (MOEC)

According to Abdullar (2008) moral values in Citizenship Education is about valuing others as person in fuller terms (p.32). In his framework on moral and Citizenship Education, he argued that moral and Citizenship Education is not about a good citizens but about a shared understanding of what constituted a person and the innate values of a person. Shared understanding among people of the Solomon Islands is lacking. People do not easily agree with people of other ethnic groups when it comes to decision making. This problem may have stemmed from individual's attachment and ethnic affiliation an influence for supremacy.

There is wide support from the Solomon Islands to teach moral values in Citizenship Education to attain share understanding. According to teachers focus group, "Moral values should be a central component for citizenship of Solomon Islands if people wants to relate well with each other" (HSUT 1). This would pave the way for unifying people. Moral values such as respect is fundamental to unity resulting in a safer living environment for people among the diverse population. "The teaching of moral values is lacking in our schools that is why we have a lot of problem" (HUSP2).

Again according to HSRP, moral values among school students are acquired from the family unit and not from the formal teaching in classroom or from the Social Studies which is expected to teach about moral values. This indicate a lack of concern to teaching moral values. A diverse country like the Solomon Islands requires teaching on moral values reflective on the framework of "shared interpretation". 
The provision of the formal education in the Solomon Islands is clear. It is aimed at providing knowledge, values and understanding that develop students to take up active responsibilities in the government sector for formal sector. This is obvious from how the education system of the country, put emphases more on academic subjects for higher expected academic qualification to sustain its functions on day to day basis. The principle objective of this process is to educate people to have jobs in order to solve the ills of the society.

It is obvious how students referred to education as the only way for success. Their worldview on education is limited only to having formal white-collar jobs, having college or university qualification. As stated by HSRP:

The mindset of students see teaching of moral values as something belonging to the home, traditional in nature and as primitive and not applicable to modern standards. What is viewed as significant in learning is the contents for examination. In this case I assume awareness is quite important to change people's mindset.

The present system of education in the Solomon Islands inculcates false hope to thousands of young people and parents. The operating system as observed by Dorovolomo, (2005) does not aptly address the needs of the society. Instead, it created violent youths and new found behavioral problem. As Sanga and Walker (2005), discovered,

\footnotetext{
Youths tend to disregard important values, protocols, rules that were regulated by the communities, churches and the national institutions. They choose to be arrogant and disrespectful in their approaches against the valuable and worthwhile norms of the society.
}

The choices that people make have threatened the environment, family, communities, and the nation. An appropriate example to explain this is found from why youth choose to consume alcohol and drugs rather than participating in sports, church and cultural activities. They choose to disregard the customary ways, clan protocols, church rules and values. In addition, in the case where teenagers have turned to drug and alcohol abuse, aggressive behaviours and attitudes, are of great concern. There are media reports of adolescents and the young involved in quite serious crimes. It is 
indeed puzzling to note the self-destructive path that some of our young Solomon Island people head down. It is obvious to that these youth lack hope (Rodi, 2008)

Such challenges, as noted by respondents and other Solomon Islands academics have occurred because of the irrelevant and uncontextual aims and objective of the education system. These has resulted in the current inadequate employment and income opportunities, restricted by dysfunction infrastructure (Pollard, 2005). More so, the fragmentation of traditional structures and democratic systems has failed to deliver good governance, which led to poor leadership in all levels of the society. Such challenges has become the subject of much debate by politicians, churches, academics, teachers and civil society agencies.

\subsubsection{Citizenship Education on Social Virtues}

Gilbert, (2004). argued that "any curriculum is a selection from our culture, and values of our culture are central to the understanding and participation in it" (p.93). Based on such arguments, the teaching of Citizenship Education on values such as character traits, respect for law abiding citizens are essential knowledge and values. Respondents have expressed that Solomon Islands need people with values of respect for people, for the environment, for local culture and to respect of other people's religious beliefs, and on values that unify people, consideration of building of relationship as one purpose of education in the country.

Therefore, education for respondents is important as people will have the ability to demonstrate competently the cultural norms and values, moral and ethical values, leadership and responsibilities. Despite the importance of education, in today's Solomon Islands education system, the aims and objective of teaching and learning does not demonstrate the expected outcomes. There are arguments from respondents that the current education system and in particular the curriculum have create violent youths whom does not consider societal values as important" MOEC What is missing from the current curriculum are the values that suppose to unite people, establish stability among people and instil values of respect, honour and care MOEC. One urban teacher respondent have stated that: 
cultural values makes people to live in harmony with each other with respect HSUT1 a person that display acceptable attitudes and behaviours and respect the cultural and religious values and the law of the land have received good and proper teaching. HSUT1,

There are certain consequences that are associated with violation of societal values. A person who violates or dishonours the norms of the culture or custom also dishonours the teaching and learning of cultural values. Such a person is assumed to have failed the cultural test standard, therefore, cannot be given responsible roles in the community. Teaching about good values is a living thing that becomes the social force that cuts a path on which one walks in life (Gegeo, 1998).

Essentially, teaching of good values are assumed to be significant for Solomon Islands for a number of reasons ,

First, the teaching social virtues will unite people of different cultures and dialects. Second, inculcating values of respect is related to cultural best practices that people have lived with ever since. Third, in comparison to academic knowledge dominant in our education systems it does not change people's behaviour? The country has gone from bad to worse in terms of stability to the social environment (HSRT3).

However, there are arguments that the teaching of such values does not address the situation of democratic societies. Despite that, Heater, cited in Gilbert, (2004), claimed, "Citizenship is more than a label... the exercise of citizenship is crucial for the development of the individuals maturity (p.140)".

Basing on the data collected, in alignment with the above note, one school principal stressed that,

Cultural values and church values are important. The principle of cultural values and church values are the teaching about honesty, respect ethical and truthful practices, acting with clearer conscience and faithfulness (HSUP).

This was supported by another principal who point out that "building relationship, showing moral behaviours and leaving according to the principles of church values and cultural values is crucial for Solomon Islands" (HSRP). 
In the Solomon Islands, the values of the society are shifting. As observed by one former Director of the Solomon Islands formal curriculum. Schools in the country were affected with unprecedented behaviours:

\footnotetext{
the media has been reporting bad images of our students in Honiara (but this could also be true in other parts of our nation) who have turned to marijuana, alcohol, betel nut chewing and premature sex. What concerns me most is the revelation of aggressive behaviours and attitudes of some school children by principals and head teachers. The general self-centeredness and lack of concern for others shown in some school children particularly after the social unrest is something that concerns me most (Rodi, 2008).
}

This was supported by the students claimed that they did not receive teaching of knowledge, values and skills that developed them to become good and active citizens. One student claimed that "the teaching of values in the Social Studies curriculum is not good enough to develop students behaviour" (HSUS2). Teachers concentrate on information that is expected in exams. Another student claimed that the dominant themes were about wars and events that occurred in the past (HSUS1). Similarly, as another student expressed, such teaching on content is for examinations only and does not help in developing students to be good citizens (HSRS4). In terms of application of the values learned, another student claimed, that values he applied in real situation were acquired from his family and home (HSUS 2).

\section{PART 2: CITIZENSHIP EDUCATION CURRICULUM APPROACH, MODEL AND PEDAGOGIES}

The second part of the chapter will analyse and discuss the findings of the models, approach and pedagogies useful for Citizenship Education curriculum for the Solomon Islands. The analysis and discussion will focus on citizenship as an active model of learning. This includes activities that form active engagement for people. In this case for students, the teaching of concepts of citizenship in a formal setting. It also includes the curriculum approach and pedagogy considered by respondents. This includes the cross-curriculum, extra curricula, segregated curricula approach, and the Social Studies curriculum approach. For curriculum pedagogy, the analyses and discussion involves comparative assessment on passive teaching and learning and active learning strategies.

\subsection{Citizenship model of active learning/community participation}


Citizenship is a model of active learning. It is a model of learning that occurs through active engagement in public affairs and obligations in societies. An explanation of the word "active" in this sense could be interpreted as for people to be "prepared to see beyond their own interest and commitments and take a wider, more impartial view" (Miller, cited in Pearce and Hallgarten, 1988, p.28). Active citizenship is described as active involvement in the affairs of the community, responding promptly to needs and requiring strategic actions to improve certain areas in the society. This statement means that for people to have knowledge of how the government functions and skills in organising activities and taking leadership roles in communities. In the literature, the term is known as active participatory citizens.

\subsubsection{Active Learning in citizenship}

In the Solomon Islands, active participation is found to be common amongst people. It is part of peoples' way of life and as members of a community. Considering what is active for Solomon Islands, a citizen or member of a group is accompanied by certain kin obligations and responsibilities that cannot go unfulfilled and is freed only from death. Such responsibility include contributing to bride price or bride wealth payments in marriage (Gegeo, 2001). The practice is especially obvious in traditional societies where the communal model is common. In the traditional setting, any person who does not actively participate in the affairs of the community is subjected to public condemnation. It is seen as a disgrace not to the person only but also to their entire family. Members of the family receive the blame for the actions that their subjects display, assuming that the child had not been properly taught and nurtured by the family of cultural norms and values.

What is described as active engagement or community participation as conceptualised by one teacher respondent is:

The values that unite families and communities together through helping each other when some one is in need. It is a difficult task to mould students to become good and active citizens if we try to do it nowadays because of the changes in behaviours and lifestyle. However, we can do it if we start teaching children about the values at school (HSUP). 
Secondly, in a community, a person who actively demonstrates values of care for oneself and others is belief to have practice the important values of society. The values of care are interrelated and aligned to obligations and responsibilities. In addition, to demonstrate obligatory and participatory values as one Principal claimed, is an obvious reflection of people's concern to culture. People sustain the continuity of the past, present, and future (HSUP). A supportive claim was made by one teacher who stated that:

Care and respect are values that the society need. They are the prerequisite for stability, cooperation and unity in a community of people HSRP.

Thirdly, the values of sheer obligation and responsibilities have to be demonstrated openly in order to show clearly that the results of the teachings are received from the family. People often showcase their activeness and distinct abilities in arranging ceremonies such as feasting, contributing to bride price, arranging and actively engaging with communal works and rendering support to help people with disabilities. Such active participation is displayed with great respect. In the modern contemporary interpretation, this is an active citizen. From the information that is analysed from the respondents, they favour the idea of using learning models that develop students to be active citizens . According to one MOE staff member, if we want to save our way of teaching children to be active, we have to promote the values at school (MOEC).

\subsubsection{Active citizenship - contemporary version}

In the modern context active citizenship is the ability to participate in the affairs of the community and the state. This includes participation in national institution programmes, national events such as elections, national sports, and taking an active role in organising activities for people locally and nationally. Acquiring values to actively participate in the affairs of the society is derived from the knowledge, values and skills obtained from the teaching of citizenship in the formal curriculum system.

In a contemporary Solomon Islands context, the understanding of rights and responsibilities which fosters active participation of people in the society is missing. People view the government as an institution with foreign ideologies and structures 
which is exclusive to people with modern education and knowledge to engage actively in the deliberation and participation on important affairs of the society. The reasons why such perception occurs is because of the gap between the educated and the uneducated. The educated people have acquired the knowledge of modern education, have white collar jobs and have the money power to manipulate people and system. These people constitute a very small proportion of the population but they are influential among the general population. The rest of the population view themselves as inferior, uneducated, uncivilised, low key figures. Such implications have caused people to remain passive and static, a dilemma which has become a challenge to the Solomon Islands.

In order for students to be responsible people, they need to be given the training that would develop them to become responsible beings. That is what I have found as lacking in our societies. People did not show responsibility to each other the institution and the environment. That is why we have a behaviour problem which cause our towns to be dirty, damaging and destroying of properties and no good stewardship to the environment (MOECCE)

What Solomon Islanders need is an education system that promotes active citizenship. The citizens who take up active roles in the affairs of the communities and the state. Education should include knowledge and values that benefit all people and not the selected few as found in the current education system. Any development of citizenship concepts have to be taken into account with how people live and work. It should include what people consider as active. The model of active learning rests entirely on common knowledge favoured by all people and teaching pedagogies that active in curriculum methods.

\subsection{Citizenship Education Curriculum Policy}

Globally, Citizenship Education has been approached in a number of ways in the formal school curriculum. According to the literature, the popular traditional approach is teaching citizenship in the subject of social studies. However, many academics, educationists and teachers have claimed that social studies is overloaded. Thus, teaching of citizenship may no longer be effective because of the limited time to teach values. Secondly, the content of Citizenship Education contains more themes and topics that can form a separate discipline of its own. Some commentators recommend 
approaching the discipline as cross-curricular or it as an informal subject which situated within the extra curricula approach.

\subsubsection{Citizenship Education Curriculum Models and Approaches.}

A policy statement on Citizenship Education has been initiated in the Solomon Islands. However, deliberation on the subject matter of policy and approach still exists. Despite that, according to information from the curriculum department of Solomon Island, teaching citizenship across the curriculum is considered for development. However, presented in the following section are respondents' views of the approaches.

\subsubsection{Cross- Curriculum Approach}

According to the data collected from respondents of the Ministry of Education level:

It is important for citizenship to be approach as cross-curricula. However, the challenges are, teachers need to be embedded with the curriculum under all discipline. That's the problem. It will take long period of time before it can materialised, as the capacity to finance the undertaking is a huge task for our government. There should be a change to the teacher-training curriculum, a change to the curriculum system as well as constructing a monitoring and examination system (MOEF).

There are several challenges that need to be considered if citizenship is to be constructed as a cross - curricula approach. First and foremost, is the challenge on the governments financial capacity and position to engage in the curriculum overhaul. According to Pollard, (2005) many school in the country are in a poor state. How can the government engage in overhauling the curriculum to assimilate citizenship values when the current curriculum resources have not been replaced ever since they were brought into the Solomon Islands? As Pollard noted the governments funding is simply for recurrent teaching cost complemented by school fees. Therefore, it is impossible to engage in the retraining of all teachers to qualify them to teach citizenship in all school subjects.

One teacher from the rural area suggested that Citizenship Education should be approached and included according to different levels in the school system. He states: 
In primary it should be taught as a cross curricula. In secondary it should be included in the Social Studies curriculum. Senior secondary forms, it should be included with history subject (HSRT 3)

The reason for the suggestion is that in the primary level, teachers are trained to teach all given subjects in a particular class. In reality, it would ease the challenges for teacher training. He further expressed "teaching children in an early age would be more effective than teaching students when they are mature" (HSRT 3).

Secondly, integrating citizenship values in the social studies curriculum would be easy as teachers of social studies have majored in the teaching of the values. This may solve the challenge of finances which authorities often base their blame on. Thirdly, integrating Citizenship Education in history for the senior secondary classes is possible as related topics of citizenship are already included.

\subsubsection{Segregate Curricula Approach}

Some educationists and academics support the teaching of Citizenship Education as a segregated subject. Wilkinson (2003) indicates that timetabling citizenship discretely can lead to it becoming someone else's problems within the school. In comparison, one urban teacher sees developing Citizenship Education as cross curricula or whole school approach as a difficult task to achieve. He preferred teaching it as a separated subject because it is a very important subject for students nowadays (HSUT)

Respondents have expressed that, if Citizenship Education is included in the formal school system as a subject of its own will be taught effectively as teachers are trained specifically to teach the subject. Moreover, as expressed by respondents it is essential to having proper training to disseminate the concepts in a more effective and convincing way. If it is taught as a separate subject then those who teach the subject can concentrate on delivering the knowledge and values without confusing other themes or subjects.

\subsubsection{Extra Curricula Approach}

Another approach is concerned with the extra - curricular. In the extra curriculum approach the knowledge, values and concept of citizenship is delivered outside of formal subjects that are timed tabled in the school. In a survey conducted in 2002 of 
the need to promoted national identity in the Solomon Islands, surveyors recommended from their findings that activities such as flag raising, singing of the national anthem, interschool or national sport activities should be promoted by schools and facilitated by the government to be made compulsory (Community High School Survey Team, 2002).

According to interviews from the school principals from the two case studies, HSRP, argued, that in order to promote unity and national identity, the government had to facilitate activities in schools that promote relationships and unity. For instance, flag raising and singing of national anthem daily. Engaging in such activities instils a sense of pride to student of their own country and have national consciousness.

In the Solomon Islands as claimed by HSUP, children do not recognise the value of flag raising and the singing of the national anthem. They do not even know meanings of symbols on the flag and/or meanings of the words in the national anthem. This may have led to problems in the country. According to the teachers view, HSRT1 claimed that emphasising good values can unite people and needs to be done as extra curricula activity, such as activities of flag raising, singing of the national anthem and other activities to promoted national identity and social cohesion. "Maybe involving in such activities should be time tabled as the first thing to do every mornings at school before the start of academic activities" (HSUP).

However, in interviews with MOE officers, MOEF argued that promoting activities as such would not make a differences in school and the lives of students in the future. He claimed:

The teaching about national identity is important but not just about raisings flags or singing the national anthem. It is more to do with having the right values. Values that respect and understand each other, ourselves, the how the social environment live together peacefully. Values of citizenship have already existed. It is just a matter of improving for use in the school system and believing that it will work. Initially, how to put it in the curriculum and how to enforce it to teachers are what responsible authorities should do (MOEDF). 


\subsubsection{The Social studies approach}

The most dominant approach is teaching citizenship in the social studies curriculum. Traditionally, citizenship is part of social studies. It is generally regarded as a subject that is related to the promotion of Citizenship Education in schools. It is part of social studies education, an approach use in the school curriculum to facilitate the goals of citizenship.

According to the school principals' level of perception, for HSUP, in terms of curriculum: "Citizenship for now should be included in the Social Studies curriculum as much of the concept of Citizenship Education have already been included. However, as he further reiterated, the values recommended for social studies are ones that instil unity amongst people, the respect of cultural values, national consciousness and church values.

From the MOE staff members' point of view, MOED claimed that the subject is already overloaded. It has teaching themes from history, geography, sociology, politics and citizenship. He claimed that current themes in the social studies are hardly completed by the end of the each academic year. Therefore, to included citizenship concepts in social studies, MOEF recommended that a revision to the social studies curriculum has to be made to reconsidered some of the topics that are out of date or irrelevant to Solomon Islands current society.

According to students' view, the themes and topics relating to citizenship knowledge and values has a place in the current teaching of social studies. However, it makes no change to the students as the knowledge learn is for examination purposes only. As claimed by one student respondent:

The teaching of Social Studies that I know of does not change my behaviour. The behaviours I display at school are received from home. Teaching of Social Studies is not successful, because it doesn't reflected from what people demonstrated out side (HSRS 2).

The current topics in social studies are: teaching about family, community, the environment, government and changes. According to the findings respondents stated that knowledge and values learnt from Social Studies do not help to develop students to recognise the importance of relationship unity and respect for the social and physical environment. That can be justified from the values displayed in the country by youths. One teacher asserted, "If we look around nothing is respected. There is 
corruptions, everywhere, conflicts, every where and people are not in good term as seen" (HSUT 1)

\subsection{Citizenship Education Curriculum Pedagogies}

Pedagogy in the curriculum refers to the methods of teaching and learning in formal and informal contexts. In the curriculum it is fundamental for the effective dissemination of knowledge skills and values. The technique in which one applies in curriculum teaching to achieve the goals and objectives is fundamental for effective learning. There are two related dimensions as noted by Print, (2008) on conceptualisation and the classification pedagogical activities. These are the passive learning and the active learning strategy.

\subsubsection{The passive learning strategy}

The passive learning strategy is referred to as teacher-centred strategy where students are perceived as passive learners. Students in this regard, Print, (2008) argues are "sponge-like" where they are "fed" with the information provided by the teacher. This is common to the teaching of social studies in the Solomon Islands where some topics of Citizenship Education are included. According to the data, the every day teaching of social studies in the Solomon Islands is predominantly teacher-centred. The teachers talk while the students listen and take notes. As one respondent principal stated "we are engrossed with the method of teaching where the teacher talks and explain and it become part of our every day teaching technique" (HSUP).

Any change to the strategy as noted from teachers seems unnecessary as it would not help students in their examinations. As noted by (HSUT 1) There are reasons why the pedagogical teaching technique is adopted. First, it is not time consuming; secondly, it helps students in national examination through having large amount of facts to study in preparation for examination

As teachers are aware of the limitations students face with the teacher - centred strategy, they said they cannot do much about it because it is a commonly used strategy. Therefore, varying arguments from teachers have indicated a need for change. As confirmed by another teacher, 
The current traditional teacher talk and students note take should be change. There needs to be a lot of concrete examples and practices. For instance, demonstration, dramatisation, excursion and guess speakers (HSUT2).

According to the students' view about the social studies curriculum pedagogy:

The teaching and learning where the teacher teach and we student write notes is boring and in effective. We need to have teaching that shows as examples and concrete application (HSUS 2).

However, teachers argued that the reason why they dominate the classroom teaching and learning is because of the time allocated for teaching each topic.

If we use practical techniques in teaching the topics it will take all of our teaching times.

As such it hindered our schedule to teach all topics before the national examination (HSRT)

\subsubsection{Examinations}

The dominant exam oriented education system has created the teaching and learning of contents to be passive for students. According to students' interviews some of the concepts of citizenship is taught in the social studies curriculum, but is learnt as theory. When ask about why they responded with:

we have to learn about the events and dates by memorising from reading the notes in preparation for national examination (HSRS3).

Examinations influence the teaching component and also determines teachers status from the publics' view point. For example in the Solomon Islands teachers who are ranked higher amongst other colleges are those who produce higher pass rates in national examinations.

\subsubsection{Active models and strategies in teaching and learning.}

In teaching citizenship teachers use techniques that help students to acquire the knowledge skills and values effectively. According to what has been gathered, from the MOE level, staff member respondents suggested that all mediums of dissemination of knowledge, values and skills should involve more concrete application (MOEF). Concrete presentations have to involve student's projects, demonstrations, dramatising, guess speakers, teachers as examples. MOEC suggested teaching on "real situations" is vital for active and effective learning. "real situations" are methods that are concrete in nature as opposed to abstract teaching. Not only do teachers and school leaders have to be role models who display and demonstrate qualities of leadership. Discussed below are assertive strategies recommended by respondents. 


\title{
5.6.2.1 Teachers as role models
}

The most influential people in school communities in the Solomon Islands are teachers and school leaders. Their actions and behaviour that are demonstrated in front of students speak louder than what they would teach in the classroom even in the policies they legislate for the school.

\begin{abstract}
Teachers should first demonstrate character traits before any transfer of knowledge can be effectively acquired. They should display good character. That should be the start of their teaching on Citizenship Education values (HSRT3)
\end{abstract}

According to urban teachers, the attitudes of some teachers have affected the way students act in schools. The respect that students should show to teachers and leaders of the school is missing because teachers influence the students attitudes that distract their behaviours (HSUT2). According to one teacher respondent some high school teachers even take students for drinking alcohol, training students to take drugs and even, lead them to sexual activities (HSUT2).

\subsubsection{Demonstration strategy}

With regard to teaching, demonstration in the traditional context of Solomon Islanders is part of their cultures. Learning is transmitted through listening, watching, imitating, and doing things. Learning without imitating and practice is not learning at all. In this sense, abstract learning found in the Solomon Islands classroom is not effective learning. Therefore, the respondents suggested for a change to the passive approach in teaching and learning to include demonstration of activities in the classroom.

Teaching and learning usually involves acting out the concepts or topics in Citizenship Education in the classroom with students. For example teaching the "topic voting in national election" what would happen here is for the teacher to organise the class room as a poling station where pilot boxes are place. Students are to take their pilot papers and drop them in the box they prefer. Such pedagogy is aligned to how students were taught at home or in their communities.

\subsubsection{Dramatisation strategy}

In Dramatisation in the traditional context involves dancing out the concepts or situations that are of important to people. If important messages are to be transmitted across generations, the knowledge skills, and values have to be formed into a dance or drama. 
For example the teacher organises students to involve in the role play. If the teacher wants teach on the relationships amongst different ethnic groups they organised students into groups and those groups come together and live as one group of people.

\subsubsection{Class projects strategy}

In traditional context of Solomon Islands, personal discovery is a significant value of maturity. If someone wants to be recognition for their leadership in the community, they have to seek advice from the elderly people. The research of Gegeo (2001), referred to this as secret knowledge and is the important knowledge and values.

The modern contemporary context, in class projects, students are expected to follow the same process as well. In such teaching strategy the students are given a topic to research, for example, what are the characteristic of a good leader in the traditional and modern societies? The students are required to interview the elderly and discover for themselves the characteristics of a good leader. This is active learning and is also regarded as effective learning. In citizenship, learning from active methods is the appropriate technique to develop active citizens.

\subsubsection{Guest speakers' strategy}

In the traditional settings knowledge is built and acquired around the family, tribe and the whole community. Teaching and learning is not a single persons responsibility. It is the obligation of the whole community. Younger people are expected to be taught by people of specialised skills and knowledge and values, aside from their immediate family.

The respondents recommend the need to change teaching strategies for effective and active learning for Solomon Islands. The teachers' talk and students listen without application as noted from students is considered boring.

We see the teaching of Social Studies as one of the most boring subject in school because teachers do all the talking while we listen a take note (HSUS 1)

Respondents state that the teachers do all the talking and they listened. When they were asked about the teaching strategies and learning they recommended that dramatization, demonstration, and inviting expert guest speakers.

\subsubsection{Excursions strategy}

Excursions in teaching according to respondent teachers are part of people's traditional learning. In the Solomon Islands traditional setting, skills, knowledge and values that are considered worthwhile, to develop younger people to be come good and active citizens are transferred through excursions. These excursions involve hunting trips, fishing trips and for girls' mothers to take their daughters to the garden or to collect shells from the beach or take them to where they can find ropes to make 
baskets or mats. Younger people learn through observation and practice. This is effective teaching and learning for developing a person for leadership and self sufficiency.

In modern learning, the absence of active teaching and learning has resulted in negative implications. Students leave school as passive students and consequently have failed to apply what they have learnt in schools. This is has been devastating to the social and physical environment of Solomon Islands.

\subsection{Summary}

In summary, the analysis and discussions of this chapter, indicated that Citizenship Education has a variety of perspectives. This is due to the fact that issues affecting specific nations states are varied and with one framework, would result differently. However, the aims, goals and objectives are similar to some extent. For the purpose of education students become informed citizens and have the ability to make a difference in their own society. Citizenship Education which introduced in the school system has the potential to provide knowledge and values that are relevant to democratic societies. It is clear that the themes relevant to Solomon Islands include the teaching of rights, responsibility, national unity and identity. The data also shows that teaching of moral values and social virtues are important components to Citizenship Education for Solomon Islands. Finally, the citizenship model of active learning has been favoured by respondents as an important step to effective teaching citizenship values. 


\section{CHAPTER SIX \\ RESEARCH CONCLUSION, IMPLICATIONS, CONTRIBUTIONS AND FUTURE DIRECTIONS}

\section{1. Introduction and overview}

Chapter five of this study analysed and discussed findings obtained from the data gathered. This chapter provides the main conclusions of the research study. First, it reports on the findings. Second, it presents contributions significant to the project. Third, it provides research implications and recommendation for the study. This chapter ends with a brief description of limitations encountered during the field work period, recommendations for future studies and ends with a final thought to conclude the chapter and the whole of the project.

This summary of findings has been directed by the four main research questions. The main questions are constructed to explore the meanings and understandings of the terms "citizenship" and "Citizenship Education" by Solomon Islanders, the extent to which the existing Social Studies curriculum teaches the values of citizenship, how successful that teaching is in achieving its goals, and recommendations for how to address dilemma of improving the Social Studies curriculum to accommodate the teaching of citizenship values in order to enhance good and active citizens.

\subsection{Summary of Findings}

The first question has elicited respondents' views on their conceptualisation of the term "citizenship". The second question aimed at gathering data based on the teaching of corresponding values of citizenship in the Social Studies curriculum, its importance 
to Solomon Islands education and the challenges faced in transmitting the knowledge. The third question aimed at generating data on the teaching of the values of citizenship in the Social Studies curriculum - particularly in the area of teaching strategies and pedagogies used for teaching the values of citizenship. The fourth question focuses on recommendations about how to change or improve the Social Studies curriculum in order to include values that enhance good and active citizenship. This has been examined by focusing on the policy, pedagogy and defining of a citizenship curriculum which will be integrated into the Social Studies curriculum in the Solomon Islands.

\subsubsection{How Solomon Islanders conceptualise citizenship and Citizenship Education}

Citizenship is a "catch-all" term. The common assertion in literature is that the term has no definite definition. People conceptualise citizenship based on their own interpretation influenced by their social, political, and economic environment. According to this study's findings, citizenship is defined by Education stakeholders' respondents of the Solomon Islands in terms of entitlement and obligation.

The entitlements of citizenship as depicted by the respondents, referred to the rightful ownership of land, resources, culture, and custom. Such recognition is attained through birth. According to the findings, citizens of the country are people who have certain connections or affiliation with the land, indigenous cultures, and customs. That connection provides acceptance for people to live and participate freely among people in the affairs of culture and custom which have blended with modern law. As such, the conceptualisation of citizenship would mean the following:

First, according to peoples' belief systems, having status as citizens of the country is not conferred by the state. Their recognition is transferred from their ancestors and not from the legislative construction of the state. The findings discovered that people have narrowed their recognition only to their own social and cultural setting. They only recognise themselves along with their ethnic group and have no sense of belonging to a nation state. Their nation is their ethnic group. Such indications shows that people are recognised only when they are identified with a tribe or kin group

Second, the entitlements as denoted imply having rights over land, culture, and custom and are not about democratic rights which is promoted by liberal Western theories concerning human right and philosophies. When Solomon Islanders talk about entitlements, they particularly refer to having rights over properties that have been transferred from generation to generation. People self-identified along ethnic or tribe affiliation lines and not with a national identity under national symbols like the modern constitution. This traditional kinship system is ultimately related to the property rights system. As pointed out by Fukuyama (2008) kinship systems are constructed as mechanisms for passing on properties to descendants; thus, people would view land ownership as their birthright and national entitlement. 
Third, the rights in connection to birth are recognised only through affiliations with land, indigenous culture, and custom and not so much on rights by birth itself. For instance, although there are migrants in the country who are citizens of Solomon Islands, people still see them as different because they have no indigenous land rights. Such a perspective not only affects migrants but indigenous people of the country who settle on different islands not of their origin within the Solomon Islands. The freedom to mobilise, manoeuvre and participate in and among society is limited to only where one is ethnically situated. Recognition through formal holding of passports does not make any sense to people.

Such conceptualisation reflects the complexities and the diversity of people and the fragmentation of the state which has caused by far the most challenges to the building of the Solomon Islands as a nation state. The main obstacle or weakness of such segmented societies is the inability to achieve collective action at a larger scale for extended periods of time (Fukuyama, 2008). The challenge is to change the people's perceptions and their ways of thinking. The useful steps to take are to teach Citizenship Education in the formal education system so that younger generation who determine their own future will play a leading role in society.

Another important recognition is regarding citizens' responsibility and obligations that are entrusted to them by society. A person is recognised by their moral behaviour and values and the contribution made to the community. This includes participation in cultural ceremonies and family or tribal obligations. People may be stereotyped as "different" if they fail to uphold the moral values of the culture and religion. This includes demonstrating and practicing the values of respect responsibility, care, honesty, and other character traits recognised by the culture of the people. That difference is articulated in the following judgment:

People may be from a different land, culture, or custom but if they demonstrate acceptable behaviours they will be accepted and highly regarded among local

people. The significant factor is for people to respect and uphold the values of the culture and customs of the people they live amongst. That is the solution for mutual relationship and unity. In contrast, a person may be a member of the ethnic group, but if he/she fails to live up to the standards of culture and custom, that person will be dealt with accordingly or reprimanded. Often in the traditional Melanesian cultures, people who are reprimanded for violation of cultural values only reconcile with the community when they change their behaviour and attitudes towards other and the environment. As such, good values and other character traits are significant characteristics for people's way of life and they are part of the responsibilities and obligations of a citizen.

These values, according to the data, are missing from the modern education system which is why the country has experienced upheaval and unrest. These traditional citizenship values are no longer included in the modern contemporary and formal teaching of younger people. 


\subsubsection{The extent to which Solomon Islands Social Studies curriculum teaches the values that promote appropriate qualities to enhance good and active citizenship}

In the current, Social Studies curriculum of the Solomon Islands there are values taught that reflect the values, knowledge, and content of citizenship which is promoted in other countries. The teaching of values includes the teaching about families and communities, the environment, and the history of Solomon Islands and its political system. However, according to the data, those values do not provide appropriate qualities to enhance good and active citizens. Based on interviewees' responses, the current teaching content is now inadequate to meet the challenges and social changes found in the Solomon Islands society today. To compare the values of good citizenship with the current behaviours it is apparent that actions demonstrated by people have no relevance to the knowledge taught in the current Social Studies curriculum. According to this study's findings, the teaching of family and community has in fact resulted in the opposite occurring. Respondents reported that there are family, community, tribal and ethnic divisions among people, a lack of cooperation and tolerance to one another, and a lack of respect to people, the environment, and to state institutions.

It has been found that the important values and knowledge that should influence students to be good and active citizens in Citizenship Education has not been included in the Social Studies curriculum. Much of what is learnt in the Social Studies curriculum are pure theories relating to history and learning is only for the memorising of facts for examination purposes. Even if citizenship values, knowledge, and skills are included, the effective learning and understanding of concepts to change children's behaviour would never be achieved because of the irrelevance and noncontextual goals and purpose of the current Social Studies curriculum. The respondents have expressed their concern over the weakening content, goals, and purpose of the curriculum in conjunction with the current changes of within society.

\subsubsection{The extent to which the Social Studies curriculum is successful in teaching values for good and active citizenship}

According to findings of this study, the teaching of the values of citizenship in the Social Studies curriculum has not been successful. Firstly, the values and knowledge of Citizenship Education which should develop students to be good and active citizens is not included. Secondly, although some values of citizenship are included in the syllabus, how these are disseminated by teachers and received by students is the barrier. It seems that citizenship had never been taught according to the teaching methods provided in the syllabus. The fact is, strategies, approaches, and curriculum pedagogies used in the teaching of the values, concepts, and content were inadequate for the purpose of teaching knowledge, values, and skills necessary to be a good 
citizen. That has failed to produce concrete results as portrayed by students. This is particularly clear when the teaching of contents on the knowledge and values are compared with the current behaviours and actions displayed by students. In order for the citizenship concept to be successfully promoted, the following has to be considered:

Firstly, the examination system must be reviewed. The Solomon Islands has adopted a system which is based on periodic assessment. The fact is progressive advancement of students is determined by national and regional examinations. Such a system would always be confronted with an environment of discrimination among students. Labelling students with the word "pass" is often associated with academic success while those who were identified as dropouts are labelled as "failures". In such an environment teachers have very limited choice to decide on what to teach. Their choice is to teach content that they predict will be later examined. What is provided in the syllabus is not so important because teachers are judged and credited not on the teaching of what is prescribed in the syllabus, but on the number of students who pass the examination. Again, any teaching on knowledge, values, and skills that may help students when they leave school is secondary to the content taught for examination.

The second barrier to the successful teaching of citizenship values is the inadequate, irrelevant, and out of date knowledge and values that dominate the teaching themes from the Social Studies curriculum. The dominant content is of wars and conflicts occurring outside of Solomon Islands, which people may see as irrelevant to their student's needs. Much of the knowledge is already out of date and has no relevance to today's societies.

Thirdly, teachers themselves do not feel comfortable to teach values concerning moral and social virtues because they themselves could not live up to such moral standards. In other words, teachers themselves fail to demonstrate those moral values in front of students and teachers and also they are not competent enough to teach what they have not been trained to teach.

Fourthly, there is the barrier of a lack of teaching resources. Teaching resources are not sufficient for efficient teaching and learning. This means teachers spend much 
time writing work on the board for students to copy. This is time consuming and thus, teachers have no choice but to select what they assume is necessary for students' immediate needs.

Thus, because of these and many other barriers to the teaching of values, the extent to which the Social Studies curriculum can be successful in teaching the values for good citizenship is very limited.

\subsubsection{How might changes or improvements to the Social Studies curriculum be made to include values that better enhance good and active citizenship?}

According to the findings, the improvement of the Social Studies curriculum would occur only if the following are addressed:

Firstly, a review to the examination system is necessary. There are strong arguments for a change or review to the examination system; particularly to cater for a system that would also consider and accommodate the monitoring of behaviours at school. What is needed is a system that not only monitors students' academic progress but is also concerned with the behaviours of students. Importantly, both teachers and parents would have the opportunity to monitor the child's progress. That would certainly keep track of students' progress academically and behaviourally.

Secondly, changes should also involve curriculum models that offer active learning. That may involve changes to curriculum pedagogies. Currently in the Solomon Islands the most commonly used curriculum teaching pedagogies are teacher-centred; primarily the teacher talks and writes notes on the blackboard while students listen and copy the notes in their exercise books. The barrier to learning in this regard is students' passive involvement in the learning activities. However, if active learning pedagogies were employed by students the values taught may have real positive implications in students' lives.

The third preferred change involves policy changes concerning the Social Studies curriculum to accommodate teaching and learning content, themes, and topics that are relevant and contextual to the Solomon Islands - in other words, the knowledge and 
values that reflect the social, political, cultural, and religious ethos of the society. This includes moral values and societal virtues such as respect, relationship and unity, care and responsibility, and honesty and integrity. The inclusion of these contextual and cultural values in the Social Studies curriculum would develop students to be more respectful and have greater unity; they will acquire the moral values to be good citizens and the desire to be active citizens too.

\subsection{Research Contribution}

This section will highlight the significant contribution of this study to the integration of Citizenship Education into the formal curriculum system and the wider field of research in education in the Solomon Islands. This includes the general perceptions of school stakeholder respondents on suitable and relevant curriculum themes, content, models and pedagogies, and the epistemological and ontological continuum in Citizenship Education curriculum research. As noted from academic research, such studies undertaken have to find solutions to the gap identified. This study has identified the following important contributions made by the research project.

Firstly, since this study is a new undertaking on Citizenship Education in the Solomon Islands, stakeholders' perceptions provide valuable insights for the development of policy frameworks for the new concept and curriculum. The policy frameworks would, in turn, provide guidance to education authorities on how to develop a new Citizenship Education curriculum based on curriculum content, themes, models, and pedagogies contextually and culturally relevant to Solomon Islands; to replace the uncontextual and irrelevant content of the currently used Social Studies curriculum. To be fully effective, such a new framework must include teaching and learning insights derived from the local culture and religions.

This paradigm shift in Social Studies teaching of citizenship concepts would replace the current academically-oriented teaching themes, knowledge, and values that fail to provide the most relevant knowledge, values, and skills for life after school in the Solomon Islands. The themes and topics have features, knowledge, and values on the rights and freedoms, duties and responsibilities of Solomon Islands citizenship with moral values and societal virtues also taught. These concepts are new to the education 
curriculum in the Solomon Islands. It is evident that all levels of respondents very strongly support embarking on such changes to the Social Studies curriculum.

Second, the study also provides new direction for curriculum development in the Solomon Islands, particularly, in the area of curriculum pedagogies. It has been found that Solomon Islands formal education, since its inception, has continued to use the dominant passive-learning, teacher-centred method of teaching. Respondents who were quite reluctant to discuss the limitations of this model of teaching have supported the idea of changing the methods of disseminating useful knowledge. This would improve the current passive behaviours found commonly in schools and local communities. As citizenship concepts are widely supported by an active curriculum pedagogy, they have to take over the traditional passive teaching. Respondents in this study have suggested a variety of teaching methods to select from. These include curriculum pedagogies that are active in nature and provide a concrete learning environment for students. It is predicted that such stimulating learning environments would provide for more effective and worthwhile learning for students.

Thirdly, the study also highlighted the worth of the teaching of citizenship values based on moral values and social virtues. From what has been found in this study, worthwhile learning is related to the teaching of values that unite people of differing ethnicities, languages, and geographical locations. However, this is missing from the values currently taught in the formal education of Solomon Islands. The literature states that students learn better in an environment where there is no hatred, discrimination, or bullying. Having moral values and social virtues in the Social Studies curriculum would be conducive to a better learning environment.

In this case, the important factor to consider is the socio-moral environment where learning is conducted. It is significant for values of morality and virtues to be integrated with the teaching of rights and responsibilities, national identity, and social cohesion. This study has provided an opportunity for education authorities and the curriculum development centre of the Solomon Islands to look beyond teaching merely for academic achievement to that which develops the behaviours of students to become good and active citizens of the country. 


\subsection{Research Implications and recommendations}

Having identified the gaps based on the studies, the literature and with the findings of my own study, I now present the general implications of and recommendations from this study.

First, most respondents stressed the urgent need for citizenship programmes both formally and informally. The reason this is of particular interest is to find ways to permanently solve events such as the recent ethnic conflict. It is evident from the findings of this study that the absence of Citizenship Education may result in a repeat of what was experienced in the country from 1998 to 2003. The fear is that Solomon Islands could once again erupt into violence. Therefore there is an urgent need for education authorities to initiate policy statements that support the inclusion of Citizenship Education concepts in the formal curriculum. The process I would recommend is to review the curriculum to identify parts which may need amendments to cater for any approved formulated policy statement that includes Citizenship Education. Without such a process, Citizenship Education may never be developed. If a policy statement is formulated by the government to include citizenship values and concepts, the question arises about which approach is most suitable for effective teaching and learning.

Several approaches that respondents believe to be favourable for selection by the government or concerned authorities are highlighted in this study. Of these, according to the data, two approaches are most favoured. These are the Social Studies approach which is traditionally used to teach citizenship concepts and the cross-curricular approach which requires citizenship to be taught in every subject. Most respondents recommended that citizenship be promoted in the Social Studies curriculum in the Solomon Islands.

There needs to be a review of the Social Studies curriculum to eliminate content that is irrelevant and un-contextual to the current Solomon Islands situation. This would provide room for the teaching of Citizenship Education. With regard to approaching 
citizenship as a cross-curriculum topic, although extremely important, establishing this approach would involve very large financial obligations and is therefore best left until the education development of Solomon Islands is healthy enough financially to sustain its development. Considering the teaching resources, changes to curriculum in the Teachers Colleges and a review of the general curriculum content and pedagogies would also be necessary.

Another approach which is also important is the extra-curricula approach. The need here is to promote national identity and sense of belonging through ex-curricula programmes such as flag raising, singing of the national anthem, and national sports activities. This could also include such events as young parliamentarians and national quiz programmes.

Secondly, in terms of useful themes that include the knowledge, values, and skills that are relevant to Solomon Islands society, or those that have been portrayed by respondents as valuable, the following have been identified; any program of citizenship has to include knowledge, values, and skills on rights and freedom. These concepts in the Solomon Islands have often been misinterpreted. This indicates the limited knowledge that Solomon Islanders have concerning understanding the values of rights and freedom as promoted by democratic societies.

According to the respondents in this study the promotion of rights was implied to have contradicted the cultural and religious values of the society. Moreover, misconception of rights which created conflicts needs to be addressed formally in order that students may correctly understand its value when they are still young. Such action would change societies in the future. Equally important are concepts relating to duties and responsibilities, national identity, social cohesion, and the themes of moral values and social virtues. As a country with diverse cultures, language, and ethnicities teaching on themes that comprise such knowledge, values, and skills is significant for the stability of the nation as a whole.

Thirdly, the findings imply a need to change the examination system, to avoid the overtly, abstract transmitting of important knowledge, values and skills. This will provide an avenue for teachers to teach not content only but also to systematically 
cover important knowledge, values, and skills necessary for life after school. There is also a need to formulate new assessment and monitoring systems to improve not only students' academic performance but also to monitor students' behaviours. Lastly, it is recommended that new policies on curriculum pedagogies be initiated for teaching and learning. What the teaching of citizenship concepts needs is methods that are active. These include teaching methods and strategies such as, dramatisation, student projects, demonstration and other concrete examples.

Overall, the Social Studies curriculum may include citizenship concepts and be effective only if themes/topics and goals of citizenship include values that are relevant and contextual to Solomon Islands. This includes, moral and social values, rights taught with responsibility, national identity, and social cohesion. Moreover, Social Studies curriculum pedagogies need to be active and not passive as currently practiced.

\subsection{Research Limitation}

The research limitations are factors that may or will affect the study, but are not under the control of the researcher (Mauch \& Birch, 1998). For this study, there are several limitations that hampered the progress of the research.

The first of these factors, which hindered progress, involved the personal loss of my own home (house) and its entire contents. This happened immediately prior to my arrival in Solomon Islands for the field work for this project. While such a limitation is clearly beyond my control as a researcher, I used my professional and ethical judgement to make decisions to ensure the study proceeded and was successfully completed. The ethical decisions prompted me to put the issue behind me and focussed on my research fieldwork despite the psychological impacts of the loss and time limitation resulting from dealing with the event.

The second limitation relates to the initial negotiation for entry into the study site. Generally, some schools are very reluctant to provide assistance to research that does not benefit the school directly. Schools' perspectives on research tend to be related to financial assistance that the school will benefit from after the project. This perception 
arises from experience of previous research projects undertaken by (external) donor aid assistance to schools. With this knowledge, I, as an "insider," used the reciprocity tactic: the give-and-take approach. That approach is aligned with the traditional culture of the people in the Solomon Islands. In addition, I managed to gain respondents' favour through thorough explanations of the wider value of the research.

The third limitation stems from the area of the selection of samples. Two awkward situations were encountered in the sample selections. In urban schools, the question of who to choose from among the diverse student population for fair representation was complex. I managed to select students not by their ethnicity but by their provinces of origin. There is a similar diversity of students in the rural school as it is a boarding school and enrols students from around the province. However, I managed to select samples based on regions in the particular province.

The fourth limitation involves the time required for the interviews. Many respondents held the view that interviews were unimportant compared with their own teaching and learning obligations or administrative schedules. I was aware that the time of the year (July \& August) were the busiest months for teachers and students as this period was the preparation time before National examinations which fell in the months of September and October. To overcome this limitation I used the patience tactic, waiting until respondents were free to participate in the interview process.

\subsection{Future Studies}

Citizenship Education is a new teaching discipline or subject in the formal education system of the Solomon Islands. Therefore, this study is regarded as a new initiative for the country. Consequently, in order to enhance this area of study to reach potential benefit, the following issues are recommended for future studies:

Firstly, as reform of the national curriculum is occurring, it is vitally important to explore the relationship of Citizenship Education curriculum with the OutcomesBased Education (OBE) currently initiated in the Solomon Islands. In fact OBE Curriculum Approach is currently being developed in the formal education curriculum system of Solomon Islands to replace the content and objectives-based curriculum 
approach. The question which needs to be explored is whether Citizenship Education models of teaching domains and curriculum approach blend well with OBE. The importance of such future study is to provide sufficient findings that would guide the successful integration of Citizenship Education curriculum into the OBE curriculum approach.

Secondly, future studies on Citizenship Education should focus on its integration into the cross-curricula approach which is currently initiated for Solomon Islands curriculum. The main factors to consider are how to gain consensus on how such an approach can be effectively implemented and how it can be successfully sustained in the dominant examination system. Those are leading questions that would direct future studies in this area.

Thirdly, future studies on citizenship should focus on adequate monitoring and assessment systems for Citizenship Education. The questions to explore are: how can students' progress be monitored in terms of knowledge, values, and skills? How can assessments be undertaken in teaching moral values? What impact will Citizenship Education have on students' education and their social environments? Those are important questions that need to be explored for future studies in Citizenship Education in the Solomon Islands.

\subsection{Final Thoughts}

The country of study for this research, Solomon Islands, is faced with numerous complexities and challenges. The purpose of this study was to find ways in which education may contribute to solving these challenges. From what has been found from respondents, Solomon Islanders have a simple conceptualisation of citizenship and they do not demand much for a good life. All they assume is a simple basic lifestyle that is safe and fair. Thus, Citizenship Education is presumed to be a better alternative for this perspective in order to provide substance for the assumption. In this argument, what Solomon Islands needs is a society that bases its development on values that are significant to peoples' ways of life. These include moral values, custom values and religious values. These values are important for the effective development of the country. In order for the desired safety and fairness, Citizenship 
Education which teaches those values has to be promoted and practiced in the school system. However, the key to the overall effectiveness of any Citizenship Education initiatives will be the extent to which what is taught in class translates to how students live their daily lives.

Citizenship Education has always been equated with the knowledge, values, and skills that families, communities and nation states use to promote the standard of behaviour that is acceptable in democratic societies and also to merge people with differing backgrounds. The knowledge, values, and skills are promoted in the formal education system in response to the social and political challenges that distort the effective practice of democratic systems. The principal focus of the Citizenship Education concept is to eliminate the injustice commonly found among people because of differences in ethnicity, status, and ownership of resources. In addition, it links to the knowledge, values, and skills that empower people to play a part actively and ethically in the process of nation-building, development and harmonious living.

Finally, it is important to understand that the knowledge, values and skills implied by "citizenship" vary from state to state, community to community and family to family. The fact is that each state, according to its development goals, has its own priorities about which aspects its citizenship programs have targeted. Therefore, it is imperative to note that much of what is promoted in Citizenship Education across nation-states varies according to time and space. The most significant aim of such Citizenship Education is the promotion of solidarity amongst people within the state, in the local community and in their own family. 


\section{REFERENCES}

Abdullar, M. S. N. (2008). Reframing the notion of others in moral citizenship education curriculum. In L. C. Hoon., N. M. Salleh., W. H. Wan Mamat. \& V. Balakrishnan (Eds.), Asia - Pacific moral, civic and citizenship education (pp. 31-39). Kuala Lumpur: University of Malaysia.

Allen, G. M., \& Steven, L. R. (1998). Teaching and learning for active and responsible citizenship. Needham Height: Allyn and Bacon.

Adeyemi, B.M., Boikhutso, K., \& Moffat, P. (2003). Teaching and learning of citizenship education at the junior secondary level in Botswana. Social Science Education Journal, 1 - 35. (Retrieved 28 April 2008).

Anderson, G. (1998). Fundamental of educational research. London: Routledge Farmer.

Anderson, G. (2002). Fundamental of educational research. London: Routledge Farmer.

Ary, D., Jacob, C. L., Razavieh, A., \& Sorensen, C. (2006). Introduction to research in education. Belmont: Thomson Higher Education.

Barbour, R. (2008). Introducing qualitative research. London: SAGE Publications Ltd.

Barker, M. (2008). Promoting values for citizenship: Revising a national education curriculum. In L. H. Hoon, N. M. Salleh, W. H. W. Mamat \& V. Balakrishman (Eds.), Asia-Pacific moral, civic and citizenship education (pp. 49 - 62). Kuala Lumpur: University of Malaya.

Bell, J. (2006). Doing your research project. Berkshire: Open University Press.

Benson, P., \& Openshaw, R. (2005). Towards effective social studies. Palmerston North: Kanuka Grove Press.

Bouma, D. G. (1996). The research process. Australia: Oxford University Press.

Burns, R. B. (1994). Introduction to research methods. Melbourne: Longman Cheshire Oty Limited.

Cater, D. (1991). Social studies, purpose, pattern and possibility. In C. Marsh (Ed.), Teaching social studies. Brunswick: Impact Printing Pty Ltd. 
Clark, J. (1997). Educational research: Philosophy, politics, ethics. Palmerston North: ERDC Press.

Community High School Survey Report, (2002). Children's behaviours from the post conflict period. Honiara: Independent consultant team

Conrad, F. C., \& Serlin, C. R. (2006). The SAGE handbook for research in education. California: Sage Publication

Copper, H. (1998). synthesizing research. California: SAGE Publication

Corhen, L. (2003). Research method in education. London: Routledge Farmer.

Coxon, E., \& Tolley, H. (1999). Aid to Pacific Education: An overview. In K. Sanga, C. Chu, C. Hall \& L. Crowl (Eds.), Re-thinking aid relationship in the Pacific Education (pp. 28 - 82). Wellington: He Parekereke, Institute for Research and Development in Maori and Pacific Education,.

Cresswell, W. J. (1994). Research design, qualitative and quantitative approaches. California: SAGE Publications.

Creswell, W. J. (2008). Educational research: Planning and evaluating quantitative and qualitative research. New Jersey: Pearson Education.

Crick, B. (2000). Essays on citizenship. London: Wellington House.

De Vaus, D. (2006). Research design in social research. London: Sage Publications Ltd.

DeLeon, P. (1997). Democracy and the policy science. Albany, New York: State University of New York Press.

Demaine, J. (2004). Citizenship and political education today. New York: Palgrave Macmillan.

Denzin, K. N., \& Lincoln, S. Y. (1994). Qualitative research method in education. California: Sage Publication.

Denzin, K. N., \& Lincoln, S. Y. (2008). The landscape of qualitative research. California: Sage Publication.

Deuchar, R. (2007). Citizenship enterprise and learning. Staffordshire: Trentham Books Ltd

Dinnen, S. (2008). Dilemmas of intervention and the building of state and nation. In S. Dinnen \& S. Firth (Eds.), Politics and State Building in the Solomon Islands. Canberra: ANU E and Asia Press.

Dorovolomo, J. (2005). strengthening vocationalism in Solomon Islands. In K. Sanga, Chu, C., Hall, C., Crowl, L (Ed.), Re-thinking aid relationship in the Pacific 
Education. Wellington: He Parekereke, Institute for Research and Development in Maori and Pacific Education.

Engle, H. S., \& Ochoa, S. A. (1988). Education for democratic citizenship. New York: Teachers College Press

Ezzy, D. (2002). Qualitative analysis. New South Wales: Allen \& Unwin.

Futuyama, F. (2008). State-building in the Solomon Islands: John Hopkins School of Advanced International Studies.

Gay, L. R., \& Airasian, P. (2000). Educational research: Competencies for analysis and experience (6th ed.). New Jersey: Prentice-Hall

Gegeo, D. W. (2001). Cultural rupture and indigeneity: The Challenge of (Re) visioning "place" in the Pacific. The contemporary Pacific 1 - 15. (Retrieved $5^{\text {th }}$ October 2007) www.galegroup.com.helicon.vuw.ac.nz.

Gegeo, G. W. (1998). Indigenous knowledge and empowerment: rural development examined from within. The contemporary Pacific, $1-23$. (Retrieved $5^{\text {th }}$ October 2007) www.galegroup.com.helicon.vuw.ac.nz.

Geographix, M. (Cartographer). (1997). Solomon Island National and District Map. (Retrieved $18^{\text {th }}$ September 2007)

www.map.com

Gilbert, J. (2005). Catching the knowledge Wave? Wellington: NZCER Distribution Service.

Gilbert, R. (2004). Education for active and informed citizenship. In R. Gilbert (Ed.), Studying society and environment. South Melbourne: Thomson Social Science.

Gilbert, R., \& Hoepper, B. (2004). The place of values. In R. Gilbert (Ed.), Studying society and environment (pp. pp. 93 - 111). South Melbourne: Thomson Social Science.

Gilbert, R., \& Vick, M. (2004). The knowledge base for studying society and environment. In R. Gilbert (Ed.), Studying society and environment (pp.80 92). South Melbourne: Thomson Social Science.

Gilham, B. (2000). Case study research method. London: The Tower Building.

Gore, J. (1999). Civic education: A matter of values. (pp.71 - 76). In Print. M., Ellickson-Brown J., \& Balinda R. A. (Ed.). Civic education for civic society, London: ACADEMIC PRESS Ltd.

Grbich, C. ( 2007). Qualitative data analyses. London: SAGE, Publication Ltd 
Grossman, L. D., Lee, O. W., \& Kennedy, J. K. (2008). Citizenship curriculum in Asia and the Pacific. Hong Kong: Comparative Education Research Centre.

Heater, D. (1999). What is citizenship? Oxford: Blackwell Publishers Ltd.

Herbert, Y., \& Sears, A. (n.d). Citizenship education. Canada Education Association. (Retrieved $16^{\text {th }}$ March 2008) www.blackwell-synergy.com.helicom.vuw.ac.nz

Hill, V. B. (1994). Teaching social studies in a multicultural society. Melbourne: Cheshire Pty Ltd.

Hoffman, J. (2004). Citizenship beyond the state. London: SAGE Publications Ltd.

Holliday, A. (2002). Doing and writing qualitative research. London: SAGE Publications Ltd.

Hoon L. H., Salleh, N. M., Mamat, W. H. W., \& Balakrishman, V. (Eds.). (2008). Asia-Pacific moral, civic and citizenship education. Kuala Lumpa: University of Malaya.

Ireland, E., Kerr, D., Lopes, J., Nelson, J., Cleaver, E., \& (2008). Active citizenship and young people: Opportunities, experiences and challenges in and beyond school. National Foundation for Educational Research. (Retrieved $16^{\text {th }}$ March 2008)

www.blackwell-synergy.com.helicom.vuw.ac.nz

Jenning, R. N. (2003). Transforming civics and citizenship education in the middle years of schooling: An exploratory of critical issues informing teachers' theories of action, (Unpublished), James Cook University, Townville.

Kelly, C. (1989). Curriculum theory and practice. London: Paul Chapman Publishing Ltd.

Kerr, D. (2002). An International Review of Citizenship in the Curriculum: The IEA national case studies and INCA archive. In G. Kham-Steiner, J. Torney-Purta \& J. Schwille (Eds.), New paradigms and recurring paradoxes in education for citizenship: An international comparison (pp. 207- 237). Oxford ELSEVIER SCIENCE Ltd.

Kerr, D., \& Cleaver, E. (2006). Citizenship education longitudinal study, (No. Research report RR532,). London: National Foundational for Educational Research. (retrieved $16^{\text {th }}$ March 2008) www.blackwell-synergy.com.helicom.vuw.ac.nz

Kham-Steiner, G., Torney-Purta, J., \& Schwille, J. (Eds.). (2002). Introduction: issues and insights in cross-national analysis of cross-national analysis of qualitative studies. Oxford: ELSEVIER SCIENCE Ltd. 
Kiwan, D. (2005). Human rights and citizenship. Journal of philosophy of education, 39(1). (Retrieved $23^{\text {rd }}$ June 2008) www.blackwell-synergy.com.helicom.vuw.ac.nz

Krueder, R. A., \& Casey, A. M. (2000). Focus group discussion. California: Sage Publication Inc.

Kymlicka, W., \& Norman, W. (2000). Citizenship in diverse societies. Oxford New York: Oxford University Press.

Leavy, P. H. N. S. (2006). The practice of qualitative research. California: Sage Publications.

Lee, W. O. (2008). The development of citizenship education curriculum in Hong Kong after 1997: Tension between national Identity and global citizenship. In L. D. Grossman, O. W. Lee \& J. K. Kennedy (Eds.), Citizenship curriculum in Asia and the Pacific. Hong Kong: Comparative Education Research Centre.

Levine, M. (2007). The Essential Cognitive Backpack. Educational Leadership Journal, 64(7).

Lynch, J. (1999). Education for citizenship in multi-cultural society. London: Cassell Villiers House.

Mamat H. W \& Singh, K. M. (2008). Perception of students on citizenship education in school curriculum. In L.C.Hoon., N. M. Salleh., W. H. Wan Mamat. \& V. Balakrishnan (Eds.), Asia - Pacific moral, civic and citizenship education (pp. 87 - 93). Kuala Lumpur: University of Malaysia.

Manu, S. (2009). Developing curriculum for the basic education in the Pacific. In K. Sanga \& K. H. Thaman (Eds.), Re-Thinking education in the Pacific: Challenges and prospects. Wellington: He Parekereke, Institute for Research and Development in Maori and Pacific Education

Marsh, C. (1991). Teaching social study. Brunswick: Impact Printing Pty Ltd.

Mason, J. (1996). Qualitative research. London: SAGE Publications Ltd.

Massialas, G. B., \& Allen, F. R. (1996). Crucial issues in teaching social studies, $K$ 12. California: Wadsworth Publishing Company.

Matri, Z, (2002). National identity conflicts and civic education. A comparison of five countries. In G. S. Khamsi, J. T. Purta \& J. Schwille (Eds.), New paradigms and recurring paradoxes in education for citizenship: An international comparison. Oxford ELSEVIER SCIENCE Ltd.

Mauch, E. J., \& Birch, W. J. (1998). Guide to the successful thesis and dissertation. New York: Marcel Derker.

Maxwell, J. (1996). Qualitative research design. California: SAGE Publication. 
May, T. (1997). Social research. Buckingham: Open University Press.

May, T. (2002). Qualitative research in action. London: Sage Publications Ltd.

McGregor, S. (1999). Towards a rational for integrating consumer and citizenship education (Vol. 23): Blackwell Science Ltd. (Retrieved, $23^{\text {rd }}$ September 2008) www.blackwell-synergy.com.helicom.vuw.ac.nz

Ministry of Education Human Resource Development (1988). Secondary School social studies syllabus form 1 - 3. Honiara, Solomon Islands.

Ministry of Education Human Resource Development (1998). Secondary School social studies syllabus form $4-5$. Honiara, Solomon Islands

Ministry of Education and Human Resource Development, S. (2005). Solomon Islands education strategic plan, Honiara: Solomon Islands Government.

Ministry of Education and Human Resources Development, (2006). Solomon Islands education sector investment and reform programme, Key education policy Issues. Honiara. Solomon Islands Government

Ministry of Education Human Resource Development, (1978). Solomon Islands national education (Act, 1978). Honiara: Solomon Islands Government.

Ministry of Education Human Resource Development, (2002). Review of curriculum on the context of basic education. Honiara: A report to the Ministry of Education.

Ministry of Education Human Resource Development, S. (2007). Solomon Islands curriculum statement. Honiara: Solomon Islands Government.

Morris, M. (2008). Evaluation ethics for best practice. New York: The Guilford Publications Inc.

Mulalic, M. (2008). Making good citizens: Holistic education and civil society. In L. C.Hoon, N. M. Salleh, W. H. W. Mamat. \& V. Balakrishnan (Eds.), Asia Pacific moral, civic and citizenship education (pp. 19 - 29). Kuala Lumpur: University of Malaysia

Mutch, C. (2005). Developing Global Citizens: The Rhetoric and the Reality in the New Zealand Curriculum. In C. White and R. Openshaw (Ed.), Democracy at the Crossroad (pp. 187 - 211). Maryland: The Rowman \& Littlefield Publishing Group.

Mutch, C. (2008). Creative and innovative citizenry: Exploring the past, present and future of citizenship education in New Zealand. In L. D. Grossman, O. W. Lee \& J. K. Kennedy (Eds.), Citizenship curriculum in Asia and the Pacific (pp. 197 - 211). Hong Kong: Comparative Education Research Centre. 
Nabobo, U. B. (2008). Fijian epistemology: Examining aspects of Vugalei cultural pedagogies, processes and possibility. In K. Sanga \& H. K. Thaman (Eds.), Re-thinking education curricula in the Pacific: Challenges and prospects (pp. 137 - 158). Wellington: He,Parekereke, Institute for Research and Development in Maori and Pacific Education.

National Foundation for Educational Research, (NFER) (2006). Active citizenship and young people: The citizenship education longitudinal study, London: (Retrieved $16^{\text {th }}$ March 2008)

www.blackwell-synergy.com.helicom.vuw.ac.nz

Organisation for Economic Cooperation and Development, (1991). The curriculum. Paris: Centre for Educational Research and innovation.

Organisation for Economic Cooperation and Development, (1998). The Curriculum. Paris: Centre for Educational Research and innovation.

Osley, A. (2000). Citizenship and democracy in schools: Diversity, identity, equality. Staffordshire: Trentham Book Limited.

Patton, M. Q. (2002). Qualitative research \& evaluation methods (3rd ed.). London: Sage Publication

Patton, M. Q. (1987). How to use qualitative method in evaluation. California: SAGE Publication.

Pearce, N. a. H., J (1988). Tomorrow's citizens, London: Institute for Public Policy Research.

Pene, F., Taufe'ulungaki, M.A., Benson, C. (Ed.). (2002). Tree of opportunity: Rethinking pacific education. Suva: Institute of Education, University of the South Pacific.

Pollard, B. (2005). Solomon Islands education and donor assistance in the post conflict period. In A. Sanga K. and Taufe'ulungaki (Ed.), International aid impacts on Pacific education (pp. 155 - 198). Wellington: He Parekereke, Institute for Research and Development in Maori and Pacific Education.

Polydorides, K. G. (2002). Cultural appropriation of social and political education. In G. S. Khamsi, J. T. Purta \& J. Schwille (Eds.), New paradigms and recurring paradoxes in education for citizenship: An international comparison. Oxford ELSEVIER SCIENCE Ltd.

Purta, J. T., Schwille J., \& Amadeo J. A. (Eds.), Civic education across countries: Twenty-four national case studies from the IEA Civic Education project (pp. 137 - 159). Amsterdam: IEA Secretariat. 
Print, M. (1999). Strategies for teaching civics and civil society. In M. Print, J. Ellickson-Brown \& R. A. Baginda (Eds.), Civic education for civil society (pp. 81-98). London: ASEAN ACCEDIMIC PRESS LTD.

Print, M., \& Smith, A. (2002). Editorial. European Journal of Education, 37(2). (Retrieved $23^{\text {rd }}$ September 2008) www.blackwell-synergy.com.helicom.vuw.ac.nz

Print, M. (2008). Teaching, learning and teaching education. In L. H. Hoon, N.M. Salleh, W. H. W. Mamat \& V. Balakrishnan (Eds.), Asia-Pacific moral, civic and citizenship education. Kuala Lumpur: University of Malaysia

Rodi, F. (2008, 15 ${ }^{\text {th }}$ September). Value Education: A response to public opinions. Honiara: The Solomon Star.

Ross, W. E. (2006). The social studies curriculum. Albany New York: State University of New York Press.

Ruane, J. M. (2005). Essentials of research methods. Maiden: Blackwell Publishing.

Rubin, J. H., \& Rubin, S. I. (2005). Qualitative interviewing. California Sage Publications.

Rueda, A. R. (1999). Education for Democracy in Colombia. In T. J. Purta, J. Schwille \& A. J. Amadeo (Eds.), Civic education across countries: Twentyfour national case studies from the IEA Civic Education project (pp. 137 159). Amsterdam: IEA Secretariat.

Sander, F. M., \& Yulaelawati, E. (2008). Citizenship discourse in the context of decentralization. In L. D. Grossman, O. W. Lee \& J. K. Kennedy (Eds.), citizenship curriculum in Asia and the Pacific (pp. 111 - 126). Hong Kong: Comparative Education Research Centre.

Sanga, F. K., \& Walker, D. K. (2005). Apem moa Solomon Island leadership. Wellington: Hi Parekereke, Institutute of Research and Development in Maori and Pacific Education.

Sanga, K. (2002). Beyond access and participation: Challenges facing Pacific education. In F. Pene., A. M. Taufeulingaki \& C. Benson (Eds.), Tree of opportunity (pp. 52 - 58). Suva: Institute of Education, University of the South Pacific.

Sanga, K. (2004). Making philosophical sense of indigenous Pacific research. In T. Baba, O. Mahina, N. Williams \& U. Nabobo (Eds.), Researching the pacific and indigenous peoples (pp. 41 - 52). Auckland: Auckland University.

Sanga, K., \& A.Taufe'ulungaki (Eds.). (2005). International aid impacts on Pacific education. Wellington: He Parekereke, Institute for Research and Development in Maori and Pacific Education. 
Sanga, K., \& Pollard, B. (2006). Apem moa leadership long Solomon Islands (Unpublished). Honiara: Solomon Islands

Silverman, D. (2005). Doing qualitative research. London: SAGE OLIVERS YARD.

Solomon Islands Times Online Archives, (2008). The History of the Solomon Islands. (Retrieved 19 February 2008) www.solomontimesonline.com

Solomon Islands-country information paper-NZ Ministry of Foreign Affairs and Trade, (2008). The Solomon Islands history (pp. 1 - 12). Solomon Times Online, (Retrieved, $28^{\text {th }}$ June, 2008). www.solomontimesonline.com

Stevick, D. E., \& Levinson, A. U. B. (2007). Re-imagining civic education. Maryland: Row \& Littlefield Publishers.

Steward, V. (2007). Citizens of the world. Educational Leadership Journal, 64.( 1.).

Stoessinger, J. G. (1990). The might of nations. New York: McGraw-Hill Publishing Company.

Taufe'ulungaki, A. (2009). Tongan values in education: Some issues and question. In K. Sanga \& H. K. Thaman (Eds.), Re-thinking education in the Pacific: challenges and prospects (pp. 125 - 158). Wellington: He Parekereke, Institute for Research and Development in Maori and Pacific Education

Thaman, K. H. (2001). Towards culturally inclusive teacher education with specific reference to Oceania. International Education Journal 2( 5).

Wesley, E. (1978). The Future of the Social Studies. California: ETC Publications.

Westheimer, J., \& Kahne, J. (2004). What kind of citizen? The politics of education for democracy. American Educational Research Journal, 41(2.).

White, J. (2004). Rethinking the school curriculum. London: Routledge Falmer.

Wiersma, W. (1995). Research methods in education. Massachusetts Allyn and bacon, A. Simon and Schuster Company.

Wilkinson, D., \& Birmingham, P. (2003). Using research: a guide for researchers. London: Routledge Falmer.

Winch, C., \& Gingell, J. (1999). The curriculum: Key concepts in the philosophy of education. London: Routledge

White C., \& Openshaw R. (2005). (Ed.), Democracy at the Crossroad. Maryland: The Rowman \& Littlefield Publishing Group. 
Wylie, K. (2004). Citizenship, identity and social inclusion. European Journal of Education, 39(2). (Retrieved $23^{\text {rd }}$ September 2008) www.blackwell-synergy.com.helicom.vuw.ac.nz

Yin, R. K. (2003). Case study research: Design and methods. California: Sage Publications.

Zarrillo, J. J. (2004). Teaching elementary social study. Columbus: Pearson Education. 


\section{Appendices}

\begin{tabular}{|l|l|}
\hline Appendix & \multicolumn{1}{|c|}{ Description } \\
\hline A & Information Sheet and Request for Permission Letters . \\
\hline B & Consent Forms \\
\hline C & Agreement Forms \\
\hline D & Field Work Questions \\
\hline
\end{tabular}




\title{
Appendix A. Information Sheet and Request for Permission Letters.
}

\section{Information sheet (For the Ministry of Education and two case study schools)}

\author{
Citizenship Education and the Social Study curriculum of Solomon Islands
}

My name is Billy Fitoo and I am a Master of Education Student at Victoria University of Wellington, New Zealand. For this project, it is a student research study which tries to explore the perception of education stakeholders (MOE staffs, students, social study teachers, Principals of case study schools) on the values and knowledge of citizenship education in the social study curriculum of Solomon Islands.

Citizenship Education is new to Solomon Islands, despite the fact that, it is a widely explored global educational phenomenon. The knowledge and values of citizenship are widely practised and highly acknowledged by recipient countries. Particularly, countries that have included and trialled the concept in their formal education system. In the case of Solomon Islands, much is yet to be explored about the value and significance of citizenship education. Importantly, the relevant values and knowledge that might empower and transform the social environment through the formal education system. In essence, to gain understanding about the values, knowledge and skills of citizenship education, it is important to undertake research as such, to bring out varieties of perspectives that will help to construct citizenship education that is relevant and contextual for Solomon Islands.

This project is informed by the interpretative/constructivist paradigm and use qualitative procedures in research, whereby, focus group and one-on-one interviews are the methods for gathering data. The study will involve two case study schools and the Ministry of Education and resorts to purposeful sampling methods for participant sampling. Students and teacher participants will partake in the group discussions. The one-on-one interview will be used for the Principals and the Ministry of Education officers. The researcher will chair the proceedings in the discussions and interviews through systematically posing semi structured questions and respondents will be encouraged to response accordingly based on their personal conceptualization and interpretation. A tape recorder will be use to record the discussions and the interviews.

The discussion and interview processes will last between 45-90 minutes, depending on the nature of the interview and discussion. The information collected from the discussions and interviews will be collated and arranged according to themes, which will then be verified and analysed to generate data for the study.

This research project is done under the auspicious of the Victoria University of Wellington, New Zealand and an ethical approval has been obtained from the Human Ethics Committee, VUW to collect data. For this study, in order to meet ethical 
standards, first, transcribed materials will be destroyed in due course, but properly stored until completed. Second, data gathered will be kept locked and electronic copies wiped out as soon as analysis is completed. Third, the final report when appeared as thesis, the names of participants and the organizations will not be identified. This is to meet the required understanding of ethical issues that need to be properly and carefully handled.

Participants will not be forced to participate in the study. Therefore, those who are selected are free to withdraw from the study without question should he/she feel to do so. However, participants are encouraged to participate as all information collected and transcribed will be kept confidential. It can only be access by the researcher and the supervisor, Dr. Kabini Sanga as, it is an academic paper whereby, the supervisor under his role has the prerogative to check the documents.

This study is deemed worthwhile for a number of reasons. First, the documentation of its findings will be pivotal for further policy, curriculum, teaching and research development for Solomon Islands. Second, the thesis when completed will be shelved on the Victoria University of Wellington Library and a copy will shelved at the University of the South Pacific Solomon Islands Centre for students and for future references.

I will come in person to the Ministry of Education/schools before the commencement of the interviews and if you have any question regarding the project, please feel free to ask me.

My supervisor, Associate Professor Kabini Sanga, can be contacted for further information, if necessary. Kabini.sanga@vuw.ac.nz

Thank you

Billy Fitoo

Researcher 


\section{Citizenship Education and the Social Study Curriculum of Solomon Islands}

\section{Parents/guardians information sheet}

My name is Billy Fitoo, and I am conducting a study in partial fulfilment of Masters of Education Studies Programme. This process of data collection has been approved by the Victoria University of Wellington Human Ethics Committee. The study wishes to explore Education stake holder's perception on values of citizenship Education that is relevant and contextual to the Solomon Islands and how it can be effectively promoted in the formal secondary school curriculum, in particular the social study curriculum. In order to do so, this study wishes to involve students who apparently, are stake holders and are direct recipients of the knowledge and values of the curriculum. This research will involve students, through focus group discussions. In other words, a cohort group consisting of form three (3) students will be selected in consultation with the principal. The researcher's role is to facilitate the proceedings of the discussions, through systematically posing semi-structured questions and respondents will respond based on their own understanding and interpretation. A tape recorder will be use to record the discussion of which the recorded information will be transcribed for analysis to informed the research.

\section{How will your child be affected?}

- The researcher will chair all the proceedings of the focus group discussions. His role is to pose semi-structured questions and the students will respond to the questions.

- All responses will be regard as essential for the study. The researcher role is not to hinder the discussion but guide the progressive flow of the process.

- Your child's name will not be used in the write up, and confidentiality is assured.

- All the students' participants will be asked to sign an agreement form before the commencement of the discussion.

- At any one point if you child disagrees with how the research is chaired he/she can leave the venue without question.

The researcher is a student of Victoria University of Wellington and this research is a student academic research. 


\section{Request for Permission Letter}

To Ms. M. Kuve

Permanent Secretary

Ministry of Education Human Resource Development

P.O Box G 28

Honiara,

Solomon Islands

Dear Madam

\section{REQUEST FOR PERMISSION}

I am a Solomon Islander, studying at Victoria University of Wellington. I am conducting a research project on citizenship education in the Solomon Islands in partial fulfilment of the requirements of Master of Education Studies Programme. This research project is done under the auspicious of the Victoria University of Wellington, New Zealand and an ethical approval has been obtained from the Human Ethics Committee, VUW to collect data. The project procedure involves group discussions and one-on-one interviews. Some of your senior staffs will assist in this study through one-on-one interview with the researcher.

The attached Information sheet provides further details of the project. However, if for some reasons that this research should not proceed, do let me know or else, I will give you a call as a follow up to this request and if permission is granted, I will proceed in making arrangements to meet with the respondents so that other formalities (signing of consent forms) can be arranged before the start of the field work proceedings.

My supervisor, Associate Professor Kabini Sanga, can be contacted for further information, if necessary. Kabini.sanga@vuw.ac.nz

Thank you.

Yours faithfully, 


\section{Appendix B. Consent Forms}

\section{CONSENT TO PARTICIPATE IN THE RESEARCH}

\section{One-on-one interview}

\section{Citizenship Education in the Social Studies Curriculum of Solomon Islands.}

I have been given and do understand the explanation of this research project. I also understand from the explanation and to my satisfaction that any information I provide will be kept confidential to the researcher and the supervisor. I understood that I may withdraw myself from this project without having to give reasons or without being penalized of any sort.

I also understand that the tape recording of interviews will be destroyed or electronically wiped out after the transcribed scripts have been documented and submitted as a thesis for marking. I also understand that the data I provide will only be use for the project until such time when the project is completed that it can be use for other referencing purposes.

I agree to take part in this research.

Sign (participant)

Date:

Sign (Researcher)

Date 


\section{Citizenship Education and the Social Studies Curriculum of the Solomon Islands}

\section{Focus Group Consent Form}

\section{Consent to Participate in the research}

I have been given adequate information and have understood the nature and objectives of the research project and been given the opportunity to seek further clarifications and explanations.

I understand that I choose not to participate individually or as a group from this project before the $14^{\text {th }}$ of August, 2008. I understand that I may do so without providing reasons, and that any data already collected will be destroyed by the researcher.

I understand that any information or opinions I provide will be confidential. Only the researcher and the supervisor will have access to the information provided.

I give my permission for our discussion to be tape recorded.

I understand that the tape recording of discussions will be electronically wiped one (1) year after the research project completions. All data obtained will be destroyed by the researcher.

I agree to participate in this research project.

I agree and promise to keep the proceedings of the group discussion confidential

I would like to receive a copy of the findings

In duly agreeing to the terms above, I individually herewith place my signatures

Name

Sign

Date 


\section{CONSENT TO PARENTS/GUADIANS FOR STUDENT PATICIPANTS}

\section{Citizenship Education and the Social Studies Curriculum of Solomon Islands.}

I have been given and do understand the explanation of this research project. I also understand from the explanation and to my satisfaction that any information provided by my child will be kept confidential by the researcher and the supervisor. I understood that I may withdraw my child from this project without having to give reasons and without being penalized of any sort.

I also understand that the information provided by my child during the research will be destroyed or if electronically stored will be wiped out after the scripts have been documented for its intended purpose. I also understand that the data my child may provide will only be use for the project only.

I participate in the research. parent/guardian gives permission for my child to

Sign (parent/guardian)

Date:

Sign (Researcher)

Date 


\section{Appendix C. Agreement Forms}

\section{JOINT AGREEMENT BETWEEN THE CASE STUDY SCHOOL AND BILLY FITO'O}

\section{Citizenship Education and the Social Study Curriculum of Solomon Islands}

I _ Principal of ___ do

make the following statements

I have approved on behalf of the School Board for Billy Fitoo to conduct research in school from to July, 2008

That permission is given to Mr. Billy Fitoo to conduct research in the school through interviews with the principal and focus group discussion with students and teachers.

That I the Principal, Social Study teachers and students selected to participate in the study will fully co-operate with Mr. Fitoo

That having fully co-operated, I expect respondents to provide ranging views and opinions to the satisfaction of the research.

As an academic work the data may be viewed by Mr. Fitoo's Supervisor.

I Billy Fitoo, researcher and student of VUW make the following statements:

1. I agree to conduct research at Secondary School, Solomon Islands

2. These at all times, I will maintain a high standard of ethical behaviour during the course of my research.

3. That I will respect the right and privacy of all respondents.

4. That the Principal is my point of contact before contacting other respondents

5. That all soft and hard copies of the documents will be returned to the schools or electronically destroyed.

6. That copy of the thesis will be provided to interested parties.

We hereby agree

$\mathrm{Mr} / \mathrm{Mis}$

Principal

Date
Mr. Billy Fitoo

Researcher

Date- 


\section{JOINT AGREEMENT BETWEEN THE MINISTRY OF EDUCATION AND BILLY FITO'O}

\section{Citizenship Education and the Social Study Curriculum of Solomon Islands}

I do make the following statements.

the Permanent Secretary of the Ministry of Education

1. I have approved on behalf of the Ministry of Education for Billy Fitoo to conduct research with some staff on July, 2008

2. That permission is given to Mr. Billy Fitoo to conduct research in the Ministry of Education through a one-on-one interview

3. That the selected Minister of Education Officers to participate in the study will fully co-operate with Mr. Fitoo

4. That having fully co-operated, I expect respondents to provide ranging views and opinions to the satisfaction of the research.

5. As an academic work the data may be viewed by Mr. Fitoo's Supervisor

I Billy Fitoo, researcher and student of VUW make the following statements:

1. I agree to conduct research at the Ministry of Education, Solomon Islands

2. That at all time, I will maintain a high standard of ethical behaviour during the course of my research.

3. That I will respect the right and privacy of all respondents.

4. That the Permanent Secretary will be my point of contact before contacting other respondents

5. That all soft and hard copies of the documents will be returned to the Ministry of Education or electronically destroyed.

6. That copy of the thesis will be provided to the Government.

We hereby agreed

Mrs Kuve

Permanent Secretary

Date
Mr. Billy Fitoo

Researcher

Date 


\title{
Appendix D. Field Work Questions
}

\section{Citizenship Education in the Social study curriculum of Solomon Islands}

\author{
Interview Guide for students
}

\section{Warm-up questions; 5-10 minutes}

\section{Prompts}

* What do you like about your school?

* What subject is your favourite?

* What values do you receive from the subject learn at school?

\section{As young people of "place" how do you conceptualize citizenship?}

\section{Prompts}

* What is your understanding of the word citizenship?

* How do you relate it to the Solomon Islands context?

* What do you think citizenship education is about?

2. What does it mean to be a good and active citizen in your community context?

Prompts

* What are some of the values that indicate a good and active citizen?

* How do you know? Why are they important?

* How do you tell from good and active and not so good and active values?

\section{Is your conceptualization of citizenship reflected in the social study} curriculum?

Prompts

* In what ways is citizenship reflected in the social study curriculum?

* How do you identify the values of citizenship?

* If none is reflected in the social study curriculum, why?

*Can we add values of citizenship in the social study curriculum? how?

4. If in the social study curriculum, how well does the curriculum teaches the values?

Prompts

* What are the values taught in the social study curriculum?

*How do you apply the values?

* How do you know that these values affect others around you?

5. Why is the social study curriculum teaching citizenship well? Not so well? 
* How do you know that the social study teaches citizenship well? Can you identify examples?

* How do you know that the social study teaching of citizenship is not so well? Can you give some reason?

* What do you expect to learn from the teaching of citizenship? Why?

\section{What examples can you give as successful teaching? Not so successful} teaching?

Prompts

* Why do you think the teaching of citizenship is successful?

* What causes the teaching of citizenship not to be so successful?

* What values of citizenship can we include in the social study curriculum to make it more meaningful to Solomon Islanders? 


\title{
Citizenship Education in the Social study curriculum of Solomon Islands
}

\author{
Interview Guide for Social Study Teachers
}

\section{Warm-up questions; 5-10 minutes}

\section{Prompts}

* What do you like about your school?

* Do you enjoy teaching social study?

* What are the things that make you enjoy teaching social study?

1. As a Solomon Islander, how do you conceptualize the concept of citizenship? (In the Solomon Islands context)

Prompts

* What is your understanding of the word citizenship?

* How do you relate it to the Solomon Islands context?

* What do you think citizenship education is about?

2. What values are considered as important for your conceptualization? Why?

\section{Prompts}

* What values do you think are relevant to the Solomon Islands context?

* Can you give some of the most important ones? Why?

* How effective will the values influence the social environment?

* Whose values are these? How are they sustained?

3. To what extend are the values covered in the Solomon Islands social study curriculum?

Prompts

* How do you know that they are covered in the social study curriculum?

* Can you give some examples?

* If not covered, why?

*Are the teaching of citizenship Knowledge and values useful for Solomon Islands for context? Why? Why not?

4. What method and strategy does the curriculum advise you to teach the values for citizenship?

Prompts

* Are you satisfied with the methods and strategies used?

* If not, what method and strategies of teaching have you recommended?

*Why do you recommend that method and strategy?

* How effective will it help to teach the values for citizenship?

5. How adequate are the values covered in the social study curriculum? 
* Do you believe, the values of citizenship education are adequately covered?

* How can you tell that the values are adequately covered?

*What can you do to ensure that the values are adequately covered?

6. For the values covered, how successful is the teaching of these values in the social study curriculum?

Prompts

* How successful are the values taught in the social study curriculum? Why?

* What other values do you believe can be successfully taught in your social study lessons? How do you measure success?

* How do students apply the values?

\section{What improvement might you suggest?}

a. as values for inclusion in the social study curriculum?

b. for teaching of citizenship education in the Solomon Islands schools?

c. for policy, curriculum, pedagogy relating citizenship education?

d. for teacher and teaching?

e. for student learning? 


\title{
Citizenship Education in the Social study curriculum of Solomon
}

\author{
Islands \\ Interview Guide for Principals
}

\section{Warm-up questions; 5-10 minutes}

\section{Prompts}

* How do you like you job as the Principal of this school?

* What is you role as the principal of the school?

* What challenges do you encounter daily?

1. As a Solomon Islander, how do you conceptualize the concept of citizenship? (In the Solomon Islands context)

Prompts

* What is your understanding of the word citizenship?

* How do you relate it to the Solomon Islands context?

* What do you think citizenship education is about?

* Can it be promoted effectively for people in the Solomon Islands?

2. What values are considered as important for your conceptualization? Why?

Prompts

* What are some of the values that you consider as important for citizenship?

* Why are they important?

* What values do you think should be included and which should not be included?

* Were these important values shared by your elders, generation? Why? Why not?

3. To what extend are the values of citizenship covered in the Solomon Islands social study curriculum?

Prompts

* What are the values that are covered in social study curriculum?

* How well are the values covered reflective of the values you considered important??

*How well can we promote those values that you considered important?

\section{How adequate are the values covered in the social study curriculum?}

\section{Prompts}

* Do you believe the values of citizenship education are adequately covered?

* How can you tell that the values are adequately covered?

* What measure can be taken to ensure that the values are adequately covered?

5. For the values covered, how successful is the teaching of these values in the social study curriculum?

Prompts

* Who and how? And how well are the values taught?

* How well are students applying the values? 
* What are some of the values you witness from you students?

* Do you believe values are achieved from the teaching of social study?

* How do you monitor the teaching of values?

\section{What improvement might you suggest?}

a. as values for inclusion in the social study curriculum?

b. for teaching of citizenship education in the Solomon Islands schools?

c. for policy, curriculum, pedagogy relating to citizenship education?

d. for learning of values by students? 


\title{
Citizenship Education in the Social study curriculum of Solomon Islands
}

\author{
Interview Guide for Education/Curriculum Officers
}

\section{Warm-up questions; 5-10 minutes}

\section{Prompts}

* What is you role as an Education/Curriculum Officer?

*what do you enjoy in your role?

* What challenges do you encounter daily?

1. As a Solomon Islander, how do you conceptualised the concept of citizenship? (in the Solomon Islands context)

* What is your understanding of the word citizenship?

* How do you relate it to the Solomon Islands context?

* What do you think citizenship education is about?

* Why is it important to promote citizenship education in schools?

2. What values are considered as important for your conceptualization? Why?

Prompts

* What are some of the values that are important in citizenship?

* Why are they important?

* What values do you think should be included and which values should not be included?

* Can you list the values that should be included in the social study curriculum?

3. To what extend are the values covered in the Solomon Islands social study curriculum?

Prompts

* What values are actually covered in the Social Study curriculum?

* Who decide on what values to cover?

* When doe the values covered? Why doe the value cover?

4. How adequate are the values covered in the social study curriculum?

Prompts

* Do you believe, the values are adequately covered?

* What indicates that the values are adequately covered?

*How can you ensure that the values are adequately covered?

5. Who is responsible for ensuring that the curriculum adequately covers citizenship education?

Prompts 
* Whose role is to ensure that values are adequately covered?

* Who is responsible for ensuring that good values are taught well in school?

* What processes are in place to monitor adequate citizenship education?

\section{How well is citizenship education "taught" in your schools? Why? Why not?}

Prompt

* How do you ensure that citizenship education is taught well at Schools?

* Who monitors the teaching of values?

* What roles do parents play? Or should play?

7. What improvements might you suggest for improving citizenship education in schools?
a. as relating to policy?
b. as relating to curriculum?
c. as relating to pedagogy?
d. as related to teachers and teaching? 


\section{List of Tables}

Table 1. Number of secondary schools by type from 2003 to $2005 \ldots \ldots \ldots \ldots \ldots \ldots \ldots$

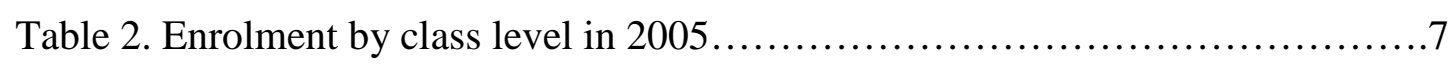

Table 3. Codes representing respondents................................... 76

\section{List of Figures}

Figure 1. A map of Solomon Islands by province..............................4 